\title{
Muscle strength and quality in old and oldest-old people
}

Citation for published version (APA):

Wearing, J. (2021). Muscle strength and quality in old and oldest-old people. [Doctoral Thesis, Maastricht University]. Maastricht University. https://doi.org/10.26481/dis.20210119jw

Document status and date:

Published: 01/01/2021

DOI:

10.26481/dis.20210119jw

Document Version:

Publisher's PDF, also known as Version of record

\section{Please check the document version of this publication:}

- A submitted manuscript is the version of the article upon submission and before peer-review. There can be important differences between the submitted version and the official published version of record.

People interested in the research are advised to contact the author for the final version of the publication, or visit the DOI to the publisher's website.

- The final author version and the galley proof are versions of the publication after peer review.

- The final published version features the final layout of the paper including the volume, issue and page numbers.

Link to publication

\footnotetext{
General rights rights.

- You may freely distribute the URL identifying the publication in the public portal. please follow below link for the End User Agreement:

www.umlib.nl/taverne-license

Take down policy

If you believe that this document breaches copyright please contact us at:

repository@maastrichtuniversity.nl

providing details and we will investigate your claim.
}

Copyright and moral rights for the publications made accessible in the public portal are retained by the authors and/or other copyright owners and it is a condition of accessing publications that users recognise and abide by the legal requirements associated with these

- Users may download and print one copy of any publication from the public portal for the purpose of private study or research.

- You may not further distribute the material or use it for any profit-making activity or commercial gain

If the publication is distributed under the terms of Article $25 \mathrm{fa}$ of the Dutch Copyright Act, indicated by the "Taverne" license above, 
Muscle strength and quality in old and oldest-old people

\author{
DISSERTATION
}

to obtain the degree of Doctor at Maastricht University,

on the authority of the Rector Magnificus Prof.dr. Rianne M. Letschert in accordance with the decision of the Board of Deans, to be defended in public on

Day, month, year at ..... hours

by

Julia Wearing 
Supervisor:

Prof. dr. Rob A. de Bie, Maastricht University, The Netherlands

Co-supervisors:

Prof. dr. Eling D. de Bruin, ETH Zurich, Switzerland

Prof. dr. Maria Stokes, University of Southampton, United Kingdom 


\section{Table of Contents}

\section{Chapter 1}

1. General introduction 6

1.1 Background $\quad 7$

1.1.1 Demographic trend and health consequences in the aging population $\quad 7$

1.1.2 Sarcopenia - skeletal muscle disorder in old age and physical consequences $\quad 7$

1.1.3 Importance of muscle strength detection 10

1.1.4 Significance of detection of muscle quality 12

1.1.5 Underlying neuromuscular changes in oldest-old people 13

1.2 Aims, objectives and outline of the research 14

$\begin{array}{ll}1.2 .1 \text { Overall research aim } & 14\end{array}$

1.2.2 Objectives and outline of the thesis 14

1.3 References 16

\section{Chapter 2}

2. Handgrip strength in old and oldest old Swiss adults - a cross-sectional study 22

$\begin{array}{ll}2.1 \text { Abstract } & 23\end{array}$

2.2 Background 24

2.3 Methods $\quad 26$

2.4 Results 28

2.5 Discussion 33

2.6 References 36

\section{Chapter 3}

3. Prevalence of probable sarcopenia in community-dwelling older Swiss people

- a cross-sectional study

3.1 Abstract

3.2 Background $\quad 42$

3.3 Methods $\quad 44$

3.4 Results $\quad 46$

3.5 Discussion $\quad 50$

3.6 References 53

\section{Chapter 4}

4. Feasibility and relevance of detection tests of probable sarcopenia in nursing-home residents

$\begin{array}{ll}4.1 \text { Abstract } & 57\end{array}$

4.2 Introduction $\quad 58$

4.3 Methods $\quad 59$

4.4 Results $\quad 62$

4.5 Discussion $\quad 66$

4.6 References $\quad 69$ 


\section{Chapter 5}

5. Quadriceps muscle strength is a discriminant predictor of dependence in daily activities in nursing home residents

5.1 Abstract

5.2 Introduction $\quad 74$

5.3 Methods $\quad 75$

$\begin{array}{ll}5.4 \text { Results } & 79\end{array}$

5.5 Discussion $\quad 84$

$\begin{array}{ll}5.6 \text { References } & 87\end{array}$

5.7 Supporting information 93

\section{Chapter 6}

6. Relationship between sonographic index of muscle quality and quadriceps muscle strength in nursing-home residents - a proof-of-concept study

$\begin{array}{ll}6.1 \text { Abstract } & 97\end{array}$

6.2 Introduction 98

6.3 Methods 100

6.4 Results 103

6.5 Discussion 107

6.6 References 110

\section{Chapter 7}

7. General Discussion 112

7.1 Main findings and clinical implications 113

$\begin{array}{ll}\text { 7.1.1 Handgrip strength in oldest-old adults } & 113\end{array}$

7.1.2. Prevalence of probable sarcopenia in community-living older people $\quad 114$

7.1.3. Feasibility and relevance of strength tests in nursing-home residents $\quad 115$

7.1.4 Relationship between quadriceps muscle strength and dependence in
daily activities in nursing home residents

7.1.5 Muscle quality in muscles of oldest-old, institutionalized people 118

$\begin{array}{ll}\text { 7.2 Methodological considerations and limitations } & 120\end{array}$

7.3 Future research questions 123

$\begin{array}{ll}7.4 \text { Conclusions } & 125\end{array}$

7.5 References 126

\section{Chapter 8}

8. Valorisation 131

8.1 Relevance of the topic 131

8.2 Main objectives and findings in brief 131

8.3 Implication, implementation and dissemination plans 132

8.4 Barriers for implementation of strength assessments and interventions in

nursing-homes 135

8.5 References 136 
Acknowledgement

About the author 


\section{Chapter 1}

\section{General introduction}

This chapter summarizes information about health-related consequences of the demographic trend and the importance of muscle strength for physical health in older people. The significance of detection of strength and muscle quality in oldest-old people (> 85 years), particularly in the specific group of nursing-home residents, and the subsequent need for better understanding of sarcopenia management in this age group is outlined. It is explained why further research related to strength and strength testing in community-dwelling and nursing-home residents was important to improve clinical practice and support further investigations of cohort studies. 


\subsection{Background}

1.1.1 Demographic trend and health consequences in the aging population

An increase in life expectancy is predicted to occur in industrial countries over the next 30 years [1] leading to a rapid rise in the number of individuals aged 65 years and over $[1,2]$. Accounting for just $18.5 \%$ in the Swiss population in 2018 [3], the number of those aged 65 years and over will have almost doubled by 2045 [4]. Although men and women are anticipated to live longer, the onset of age-related disease is expected to remain unchanged without intervention; leading to record levels of morbidity [5]. Therefore, older people in the near future will reportedly experience a high prevalence of morbidity, which will lead to limitations in daily activities [5]. In turn this will place a greater demand on institutionalization in long-term care facilities [6], which currently involves $13 \%$ in the Swiss population [7].

This demographic trend requires a modification to health care in old people, to delay the progression of chronic disease, prevent disability $[2,5]$ and increase life quality in nursing-home residents by minimizing life style-related risk factors [5]. Previous research in older people, which was primarily directed towards the so-called youngold (65-74 years), contributed to the improvement in health condition of this age group [8]. Health care needs specifically tailored to the older-old and oldest-old age group (75-84 years, and 85 years and over) have not been sufficiently explored to date, especially in those that are institutionalized in nursing-homes.

\subsubsection{Sarcopenia - skeletal muscle disorder in old age and physical consequences}

Sarcopenia is an important geriatric syndrome. In 2016, the International Classification of Disease recognized sarcopenia as an independent medical condition [9], which highlighted the importance of its relationship to health and adverse health outcomes [10]. The prevalence of sarcopenia will increase by as much as $73 \%$ as a consequence of the aging population, so that approximately $20 \%$ of older people will be affected by 2045 [11].

Sarcopenia is a generalized, progressive skeletal muscle disorder affecting strength, muscle mass and function of the whole body [12]. Possible consequences range from muscle-specific impairment in daily functioning to decreased capacity of whole organ systems with adverse outcomes for the independence in activities of daily life [13, 14], restrictions in participation in the environment [12] and mortality [15].

Moreover, low muscle condition is highly associated with impairments in the skeletal and the endocrine system [16] as it has negative impact on bone mineral density and insulin metabolism which are important for the origin of Osteoporosis [17] and Diabetes [16]. It is associated with the incidence of cardiovascular diseases [18], the most common non-communicable disease leading to premature death [19]. Figure 1 shows organ systems that can potentially be affected by sarcopenia. 


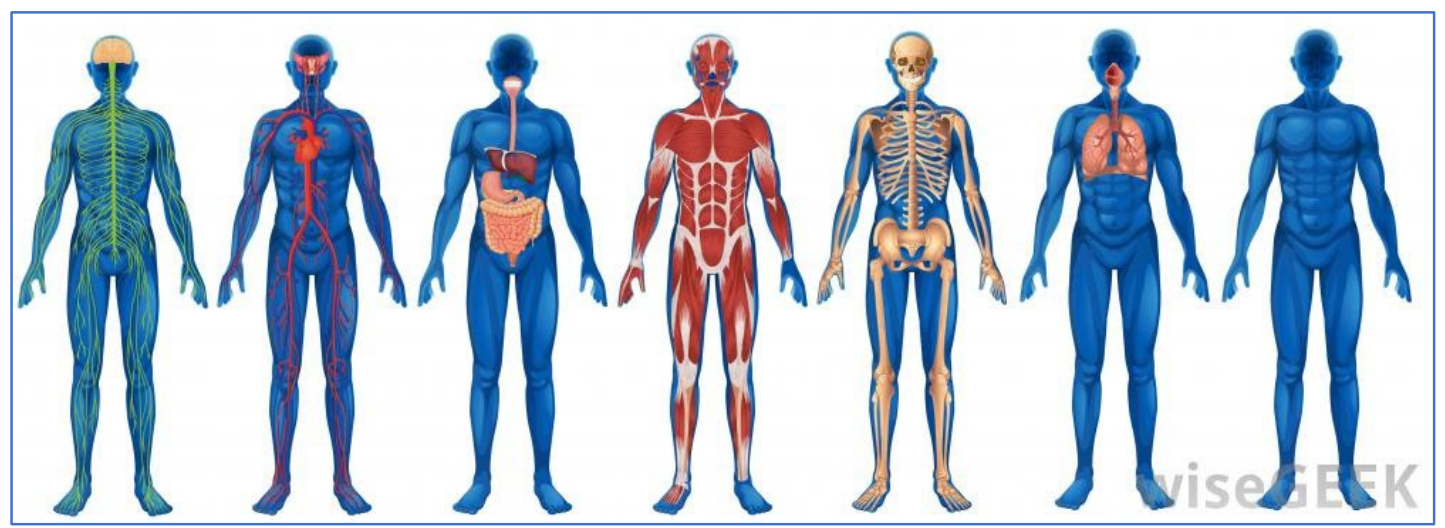

Figure 1: Organ systems potentially affected by age-related muscle wasting. Sarcopenia expresses in decreased neuro-muscular-metabolic function affecting the skeletal muscles and the neurological system involved in muscle contraction. Muscle dysfunction is associated with cardiovascular disease (cardiovascular system), insulin resistance (insulin-related organ system), bone mineral density (skeletal system) and breathing disorders (respiratory system).

Illustration from: https://www.tes.com/teaching-resource/revision-guide-to-anatomy-and-physiologyskeletal-muscular-respiratory-and-cardiovascular-system-12028493, download July $7^{\text {th }} 2020$, with permission.

Probable sarcopenia, a pre-stage of sarcopenia, is characterized by low muscle strength, which directly affects important functions of the legs, the upper body and the diaphragm [12]. Leg muscle dysfunction can result in e.g. walking instability and higher chance for falling and fall injuries [20], while weakness of the diaphragm can lead to impaired airway clearance with increased risk of respiratory infections [21]. Figure 2 shows consequences of sarcopenia on different health-related domains, using the example of knee extensor dysfunction.

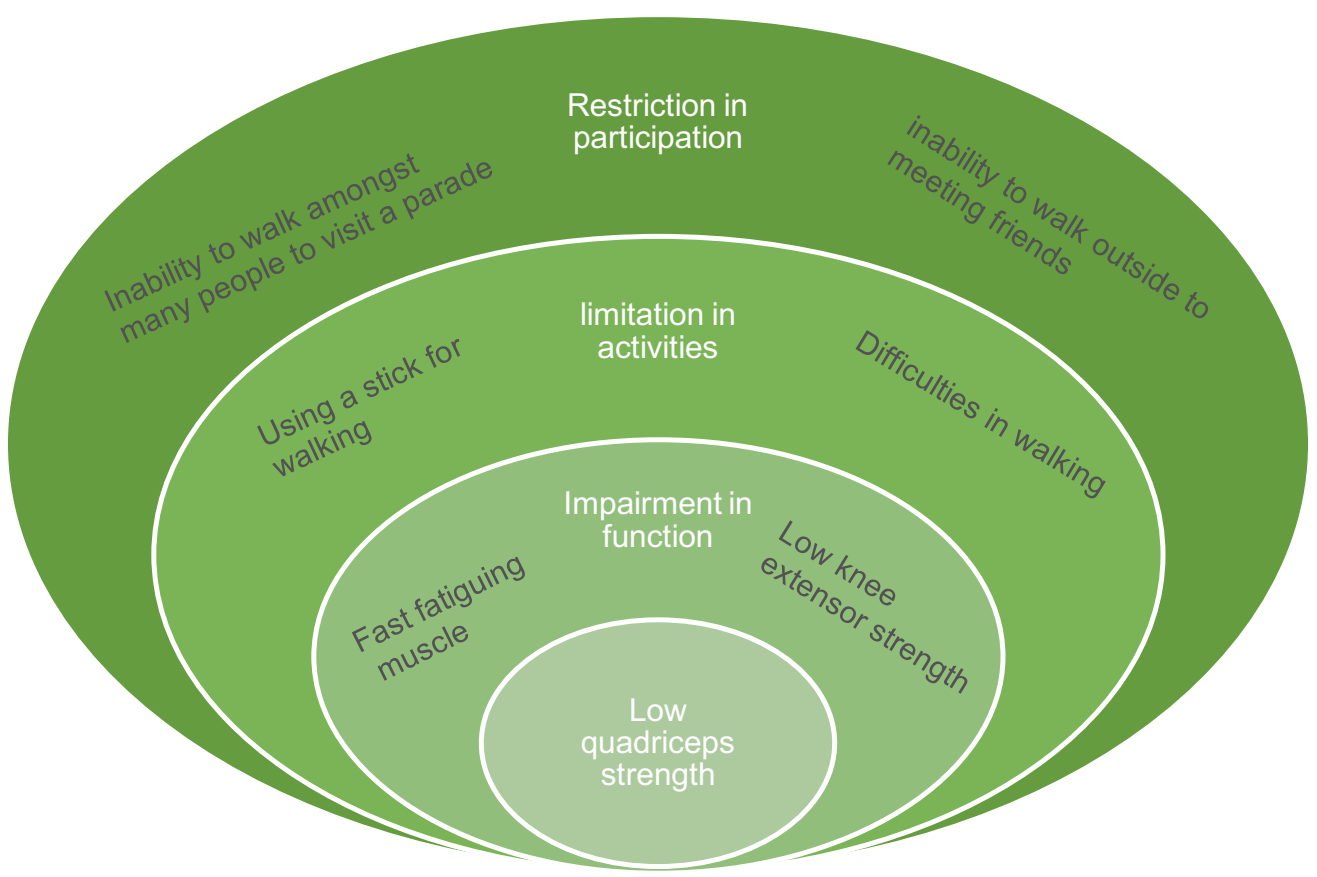

Figure 2: Probable sarcopenia and its consequences of knee extensor dysfunction on different healthrelated domains classified by the International classification of Functioning, Disability and Health. Restrictions in life, becoming more radical, the more health domains are affected. 
Furthermore, low muscle strength is closely related to frailty [22], a state of extreme vulnerability to stressors and decreased resilience with high impact on mobility [23, 24]. People with those dysfunctions are at increased risk of disabilities, however, high muscle strength prevents disabilities even in the presence of chronic diseases [25]. Therefore, it can be summed up that in community-living older people, good overall muscle strength and mass is essential for physical health, ADL independence even in case of chronic disease, and healthy life expectancy.

Community-living older people with comorbidities who cannot live at home independently or with support of care givers, get institutionalized in long-term care [6]. At that time, people are often in their last stage of life, highly affected by multi morbidity and poly medication [26], sarcopenia, physical limitations and frailty [27]. However, physical health is still a major resource, essential for the individual's overall reserve that helps to prevent lasting negative consequences [8] of acute diseases and further functional decline. Bed rest due to a flu, for example, is accompanied by muscle disuse which rapidly leads to degradation of muscle properties [26]. People who already have very low strength might not fully recover to their previous physical condition after overcoming the infection which further decreases independence in ADL, quality of life $[28,29]$ and mortality [30]. At admission to a nursing-home, older people have approximately 3.5 further life years ahead [31]. Remaining overall muscle strength is important to live with the best quality of life possible.

The definition of key disease characteristics and subsequent algorithms for the detection of sarcopenia rapidly change topics due to most recent research findings of changes associated with strength and their role in health and disease [22]. The recently published update of sarcopenia detection is based on recent research findings about muscular changes and their contribution to health outcomes [22]. The first stage of sarcopenia, according to the updated version of the European Working Group on Sarcopenia in Older People EWGSOP2, is called probable sarcopenia and is defined as low muscle strength [22] while diagnosis of sarcopenia requires both, low muscle mass and low strength. The recommended measures of strength include handgrip strength and a timed task of standing up from a chair. Low strength is defined by a handgrip strength $<16 \mathrm{~kg}$ for women and $<27 \mathrm{~kg}$ for men or a chair stand test $>$ 15 seconds. Probable sarcopenia requires optimal health care since the consequences of untreated weakness can not only be immense for the individual but also in terms of health care costs [32]. Figure 3 shows the chronological trend of strength and function decrease with age and its potential consequences for physical health. 


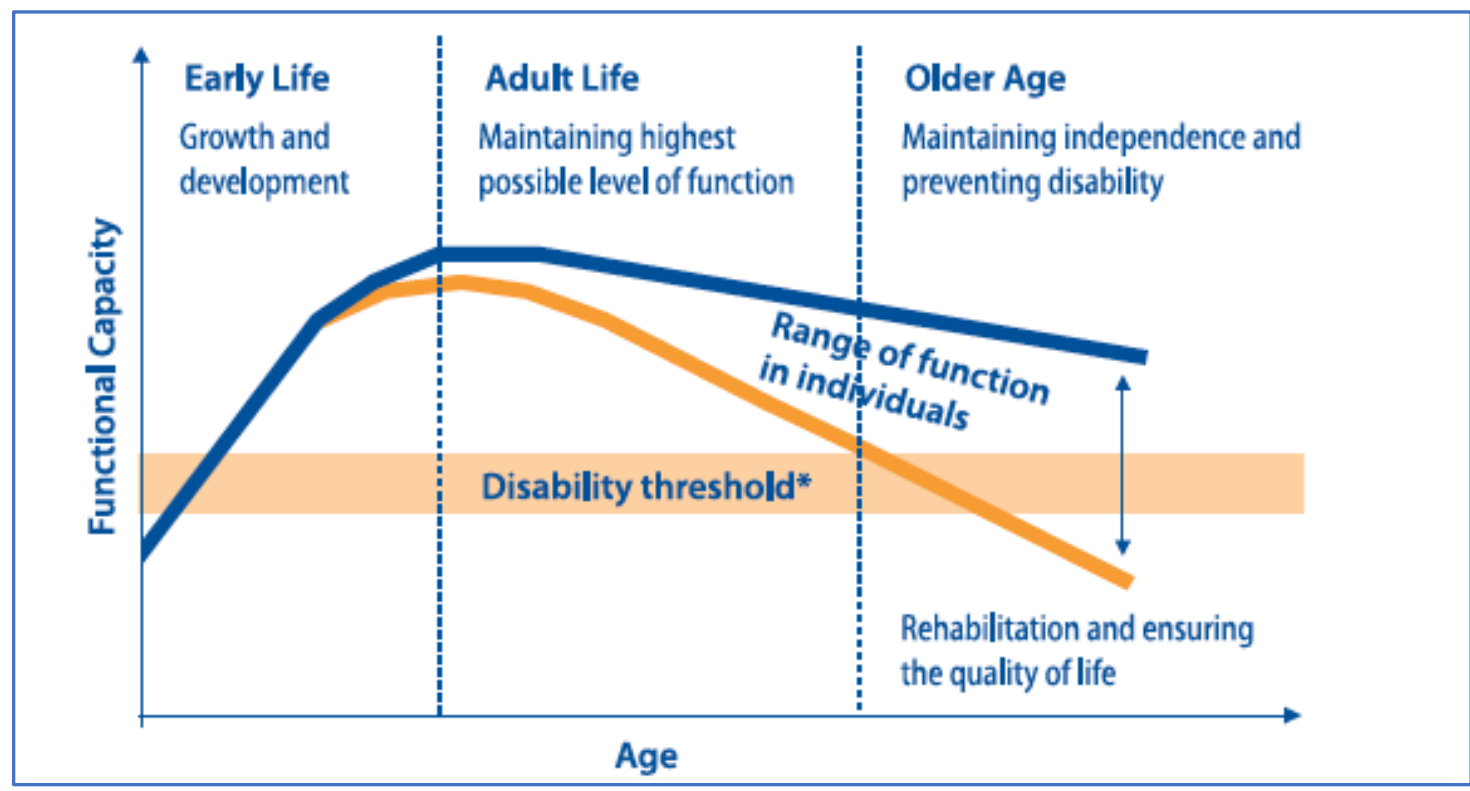

Fig.3 Maintaining functional capacity over the life course. Dependent on the strength and function peak in early life, the maintenance of strength during adult life and the loss of strength in older life, the range of strength in old and oldest age varies and might drop below the threshold for increased risk of limitations in daily activities or even disability.

Reprinted from Publication Active Ageing A policy framework, WHO/NMH/NPH/02.8, World Health Organization, Page No.14, Copyright (2002), with permission.

https://apps.who.int/iris/bitstream/handle/10665/67215/WHO_NMH_NPH_02.8.pdf? sequence=1, accessed July 8th 2020

\subsubsection{Importance of muscle strength detection}

Ongoing muscle wasting can lead into a downward spiral of health-related impairments [12] with an immense disease burden for the individual, as well as societal and economic implications [33]. Low muscle strength is an initial sign of muscle wasting and provides important information about muscle status and overall health condition [34].

As an estimate of whole body strength, handgrip strength has been shown to be a valid and reliable measure [35] reflecting overall neuromuscular capacity and integrity of organ systems [36]. Handgrip strength is referred to as a vital sign of health since it predicts health outcomes in many aspects, such as the incidence of functional limitation, diseases and mortality [37]. Early detection of low strength is essential to timely assess potential causes and underlying diseases of strength decline, and to initiate effective interventions to counteract further decline [38].

The presence of chronic diseases such as metabolic and neurological disorders, as well as malnutrition and inactivity, can immensely enhance strength decline that naturally occurs with ageing [38]. However, strength decline is still (partly) reversible through monitoring of disease-related medication, adequate diet and progressive resistance exercise [38, 39]. Even in nursing-home residents with very low strength, multi morbidities, frailty, undernourishment and functional impairments, multidisciplinary interventions have the potential to improve strength since neuromuscular plasticity, the ability of muscles and nerves to adapt to specific stimuli 
like exercise, is maintained in older people [40,41]. Older people with low strength, independent of their health status, benefit from strength increases; in young-old people, the intention of interventions is to maintain optimal physical health and prevent negative consequences of muscle wasting [38, 41]; in oldest-old nursing-home residents it is the prevention of disability with high importance for life quality [31, 41].

Large long-term benefits of early strength detection and improvement for the individual and the health care system can be derived from research evaluating individual disease burden of sarcopenia and health care costs likely to be related to adverse outcomes of sarcopenia [11]. The most effective intervention for improving strength in older adults is resistance training [38]. Studies determining health benefits of resistance training provide evidence that properly designed exercise interventions are effective in countering excessive age-related strength decline and adverse outcomes in healthy, community-living, older people [41]. In people with chronic diseases and functional impairment, strength training needs to be adjusted to their specific risks, However, strength improvements show the capacity for muscular and neuromuscular adaptations even in people with sarcopenia [41]. Therefore, the World Health Organization (WHO) strongly recommends to include handgrip strength and measures of functional performance in the routine geriatric assessment and progressive strength training as part of a multi-disciplinary intervention in people with decreased physical capacity [42].

However, in clinical practice, muscle wasting is often underappreciated as an agerelated disease with potentially severe negative consequences [22]. This is reflected by infrequent strength testing in routine geriatric assessment to detect probable sarcopenia [43] and a small percentage of people fulfilling the requirements for healthbeneficial physical activity and strength training [33]. One reason might be that reference values of handgrip strength, available in the booklet of the commonly used hand-held dynamometer, are limited to the age of 74 years [44]. In scientific literature, the older-old and oldest-old age groups are not considered sufficiently yet. In order to detect age-specific strength decline in all age groups, reference values for people 75 and over are required. Moreover, detection of the prevalence of probable sarcopenia is needed to increase awareness for the overall muscle status indicating physical health and risk of adverse health outcomes.

Chapter 2 addresses reference values of handgrip strength for the Swiss population 75 years and over. Chapter 3 reports on the prevalence of probable sarcopenia in community-living Swiss adults and associated activity limitations.

In institutionalized older adults, muscle strength and mass is even lower than in community-living elderly $[45,46]$ and is accompanied by a loss of independence in activities of daily living [47]. ADL performance progressively worsens in about $50 \%$ of nursing-home residents due to further functional decline [47, 48].

While institutionalized older adults are assessed for their need for support in daily activities at admission, standardized assessment of muscle status is typically not 
included in entry assessment or subsequent checks [49]. However, low strength in old people with comorbidities, even in nursing-home residents, can be improved [50,51] with important benefits for their independence in daily activities and life quality [29, 52]. Therefore, routinely performed strength assessments are necessary to screen for people at risk of further decline and to initiate timely interventions. It is not clear to date whether strength tests and prescribed cut-off values, commonly used in communityliving older people to detect probable sarcopenia, are also feasible in and applicable to nursing-home residents [53]. Moreover, the indicative value of strength tests for health-related outcomes, such as frailty and ADL dependence, in older nursing-home residents has not been explored to date. Chapter 4 addresses the feasibility and relevance of strength tests recommended to detect probable sarcopenia [22] in nursing-home residents while Chapter 5 covers the muscular determinants of ADL performance in this cohort.

\subsubsection{Significance of detection of muscle quality}

Clinically evaluated muscle strength typically involves maximal voluntary isometric muscle contraction [54]. Precondition for achieving the highest possible muscle contraction is, beside the maximal effort of the participant, the functioning and integrity of the neurological and muscular components involved in this action [12, 55, 56]. Traditionally, the main change thought to impair muscle strength was a decline in muscle mass. More recent research, however, has shown that in addition to muscle mass other neuromuscular changes also contribute to significant declines in strength [57]. According to the model of biologic mechanisms contributing to age-associated loss of strength first published over a decade ago [12], reduced muscle mass, impaired contraction quality and decreased neural output are proposed to be determinants of strength with some components having mutual impact on each other.

Muscle mass is attributed to muscle fibre size and number [12] and is e.g. reflected by the cross-sectional muscle area. The reduction in contraction quality referrers to intramuscular changes that affect the ability of muscle fibres to contract. Beside factors such as muscle architecture, protein synthesis and muscle anabolism [55], a major change that impairs strength is muscle composition [58]. In young active people, muscle mainly consists of dense muscle tissue (contractile tissue) while infiltrations of lose connective and adipose tissue among and within muscle fibres appear in old, inactive people and people with muscle diseases $[55,58]$. The neurological component reflects the sum of nerve-related changes that leads to impaired neuromuscular transmission. It includes degeneration of movement-related brain areas, decreased afferent and efferent nerve conduction and reduced number of motor neurons [56].

When low strength is detected in older people, the subsequent action needed for preventing, stopping or delaying the negative spiral of disability, is to undertake an indepth examination of the underlying cause and to initiate timely interventions. The 
cause of low muscle strength often dictates which combination of interventions (change of medications, adaptation of nutrient intake, exercise) is likely to be most effective [59]. However, the type and combination of exercises depends on the central and peripheral changes, and the relative contribution to the decline $[41,55,59]$. Particularly in people with a very low muscle condition due to poly-medication, sedentary behavior, comorbidity and malnutrition, such as in nursing-home residents $[39,45,60,61]$, the muscle might show a specific pattern of biological changes. The exercise dosage in terms of frequency of sessions per week, duration of each session, and intensity and repetitions of the exercises is relevant for specificity of the neuromuscular adaptations to training $[41,62,63]$. Modifications of exercise dosage specifically addressing neural and muscular changes that lead to low strength are expected to improve muscle strength even in oldest-old nursing-home residents and will advance intervention strategies [59].

While muscle mass increases best through resistance exercises of high intensity [41], resistance as well as endurance exercises show initial positive effects on muscle quality $[64,65]$. Cognitive-motor training and resistance exercise have shown some improvements in neuromuscular transmission along with functional benefits $[41,66]$. Despite promising results of interventions applying different muscle loading paradigms, the responsiveness to training varies a lot and the most effective combination has not been found yet [67]. More research is warranted to evaluate relationships between muscle changes, strength and physical health, indicative for the design of effective exercise interventions to improve strength and function [58].

\subsubsection{Underlying neuromuscular changes in oldest-old people}

As muscle strength decreases with age, particularly rapidly after the age of 80 years [68], the percentage contribution of muscular and neural changes leading to strength decline also changes $[57,68,69]$. While muscle mass is not consistently associated with strength in all older people, strength declines are uniformly accompanied by altered muscle quality due to e.g. altered fibre architecture and intramuscular adipose tissue [70-72]. Moreover, impairments in neural integrity substantially contribute to decreased strength in older adults [73] by impairing maximal voluntary contraction and motor unit discharge rate [74]. Since the sensitization to training is impaired in older people [59] and changes are not as reversible as in young people [75], prevention of strength decline is most important to keep lifelong muscle health. However, older people that already have sarcopenia and co-morbidities, the treatment of muscle strength is necessary to prevent negative consequences of muscle wasting and to maintain well-being [41]. Relationships between strength, muscle quality and neural components have not been explored in oldest-old people with chronic diseases. This issue is addressed in Chapter 6. 


\subsection{Aims, objectives and outline of the research}

\subsubsection{Overall research aim}

There is a discrepancy between the need for information regarding muscle strength in the oldest-old population on one hand, and the available research data on the other hand [76, 77]. In particular, basic investigations that researchers can build on to advance intervention strategies to improve strength and physical function of institutionalized seniors are lacking. The overall research aim was to contribute knowledge to the small existing body of literature about muscle strength in oldest-old people and the prevalence of low strength in community-living and institutionalized seniors to provide data for public health monitoring. Furthermore, the research aimed to provide initial evidence of relationships between low muscle strength and functional performance, as well as neuromuscular changes in nursing-home residents to underpin further investigations.

\subsubsection{Objectives and outline of the thesis}

A series of cross-sectional studies was designed to evaluate the research objectives addressing the overall aim. The specific objective of Chapter 2 was to evaluate handgrip strength in a sample of the Swiss population aged 75 years and over to provide reference values for further investigations and evaluation of clinical practice. The evaluation of prevalence of probable sarcopenia, as defined by low handgrip strength, in older community-living people in Switzerland, and the association between low handgrip strength and strength-related determinants was the objective of Chapter 3. To evaluate the feasibility of two strength tests in nursing-home residents, which are commonly used to detect probable sarcopenia in community-living people, was the objective of Chapter 4. As well, to determine the prevalence of probable sarcopenia, detected by each test, and the indicative value of low strength for overall strength, frailty and ADL performance. The specific objective of Chapter $\mathbf{5}$ was to evaluate the relationship between muscle characteristics of knee extensor and elbow flexor muscles, physical function and ADL performance in nursing-home residents. The evaluation of potential relationships between muscle strength of the knee extensor muscles and sonographic measures of muscle thickness and muscle quality, gait speed and physical activity in nursing-home residents was the objective of Chapter 6. 
Overarching question

Research objectives

\begin{abstract}
How is the overall strength of the general, older, Swiss population?
\end{abstract}

What is the
specific risk for
low strength/
probable
sarcopenia?

How is low muscle strength related to ADL independence?

Is muscle strength related to muscle quality?

Evaluation of reference values of handgrip strength in the general Swiss population 75 years and over (Chapter 2)

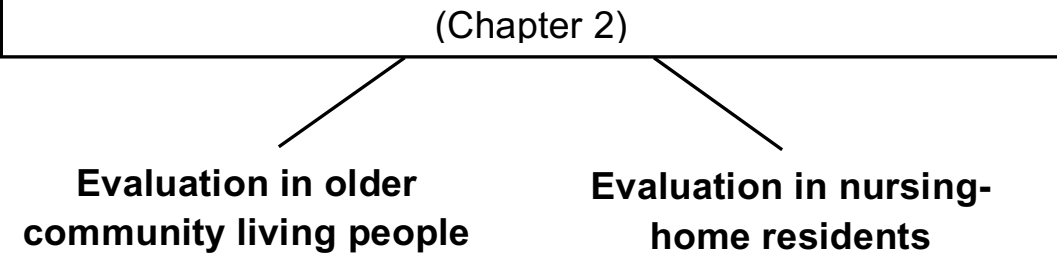

\section{Evaluation of the} prevalence of probable sarcopenia (low handgrip strength) and its relationship to ADL (Chapter 3) home residents

Evaluation of the prevalence of probable sarcopenia (low handgrip strength), feasibility and relevance of strength tests

(Chapter 4)

Evaluation of the relationship between quadriceps muscle characteristics and ADL independence (Chapter 5)

Evaluation of sonographic indices of muscle quality and their relationship with strength (Chapter 6) 


\subsection{References}

1. Kontis V, Bennett JE, Mathers CD, Li G, Foreman K, Ezzati M. Future life expectancy in 35 industrialised countries: projections with a Bayesian model ensemble. Lancet. 2017;389(10076):1323-35.

2. United Nations DoEaSA. World Population Ageing2017 January 21, 2019:[2-42 pp.].

3. Altersstruktur der ständigen Wohnbevölkerung in der Schweiz von 2009 bis 2019 [Internet]. Statista. 2020 [cited April 10th 2020].

4. Szenarien zur Bevölkerungsentwicklung der Schweiz 2015-2045 [Internet]. Bundesamt für Statistik. 2015 [cited April 10th 2020].

5. Crimmins EM. Lifespan and Healthspan: Past, Present, and Promise. Gerontologist. 2015;55(6):901-11.

6. Luppa M, Luck T, Weyerer S, Konig HH, Brahler E, Riedel-Heller SG. Prediction of institutionalization in the elderly. A systematic review. Age Ageing. 2010;39(1):31-8.

7. bfs. Gesundheit im Alter https://www.bfs.admin.ch/bfs/de/home/statistiken /gesundheit/gesundheitszustand/alter.html: Bundesamt für Statistik; 2017

8. Ludwig C, Cavalli S, Oris M. "Vivre/Leben/Vivere": An interdisciplinary survey addressing progress and inequalities of aging over the past 30 years in Switzerland. Arch Gerontol Geriatr. 2014;59(2):240-8.

9. Cao L, Morley JE. Sarcopenia Is Recognized as an Independent Condition by an International Classification of Disease, Tenth Revision, Clinical Modification (ICD-10-CM) Code. J Am Med Dir Assoc. 2016;17(8):675-7.

10. Ball JR, Miller, B. T., Balogh, E. P. In: Balogh EP, Miller BT, Ball JR, editors. Improving Diagnosis in Health Care. Washington (DC)2015.

11. Ethgen O, Beaudart C, Buckinx F, Bruyere O, Reginster JY. The Future Prevalence of Sarcopenia in Europe: A Claim for Public Health Action. Calcif Tissue Int. 2017;100(3):229-34.

12. Clark BC, Manini TM. Functional consequences of sarcopenia and dynapenia in the elderly. Curr Opin Clin Nutr Metab Care. 2010;13(3):271-6.

13. da Silva Alexandre T, de Oliveira Duarte YA, Ferreira Santos JL, Wong R, Lebrao ML. Sarcopenia according to the european working group on sarcopenia in older people (EWGSOP) versus Dynapenia as a risk factor for disability in the elderly. The journal of nutrition, health \& aging. 2014;18(5):547-53.

14. Rantanen T, Avlund K, Suominen H, Schroll M, Frandin K, Pertti E. Muscle strength as a predictor of onset of ADL dependence in people aged 75 years. Aging Clin Exp Res. 2002;14(3 Suppl):10-5.

15. Brown JC, Harhay MO, Harhay MN. Sarcopenia and mortality among a population-based sample of community-dwelling older adults. J Cachexia Sarcopenia Muscle. 2016;7(3):290-8.

16. McLeod M, Breen L, Hamilton DL, Philp A. Live strong and prosper: the importance of skeletal muscle strength for healthy ageing. Biogerontology. 2016;17(3):497-510. 
17. Sjoblom S, Suuronen J, Rikkonen T, Honkanen R, Kroger H, Sirola J. Relationship between postmenopausal osteoporosis and the components of clinical sarcopenia. Maturitas. 2013;75(2):175-80.

18. Celis-Morales CA, Welsh P, Lyall DM, Steell L, Petermann F, Anderson J, et al. Associations of grip strength with cardiovascular, respiratory, and cancer outcomes and all cause mortality: prospective cohort study of half a million UK Biobank participants. BMJ. 2018;361:k1651.

19. Daar AS, Singer PA, Persad DL, Pramming SK, Matthews DR, Beaglehole R, et al. Grand challenges in chronic non-communicable diseases. Nature. 2007;450(7169):494-6.

20. Yeung SSY, Reijnierse EM, Pham VK, Trappenburg MC, Lim WK, Meskers CGM, et al. Sarcopenia and its association with falls and fractures in older adults: A systematic review and meta-analysis. J Cachexia Sarcopenia Muscle. 2019;10(3):485-500.

21. Elliott JE, Greising SM, Mantilla CB, Sieck GC. Functional impact of sarcopenia in respiratory muscles. Respir Physiol Neurobiol. 2016;226:137-46.

22. Cruz-Jentoft AJ, Bahat G, Bauer J, Boirie Y, Bruyere O, Cederholm T, et al. Sarcopenia: revised European consensus on definition and diagnosis. Age Ageing. 2019.

23. Cesari M, Landi F, Vellas B, Bernabei R, Marzetti E. Sarcopenia and physical frailty: two sides of the same coin. Front Aging Neurosci. 2014;6:192.

24. Fried LP, Tangen CM, Walston J, Newman AB, Hirsch C, Gottdiener J, et al. Frailty in older adults: evidence for a phenotype. J Gerontol A Biol Sci Med Sci. 2001;56(3):M146-56.

25. Rantanen T, Masaki K, He Q, Ross GW, Willcox BJ, White L. Midlife muscle strength and human longevity up to age 100 years: a 44-year prospective study among a decedent cohort. Age. 2012;34(3):563-70.

26. de Souto Barreto P, Morley JE, Chodzko-Zajko W, K HP, Weening-Djiksterhuis E, Rodriguez-Manas L, et al. Recommendations on Physical Activity and Exercise for Older Adults Living in Long-Term Care Facilities: A Taskforce Report. J Am Med Dir Assoc. 2016;17(5):381-92.

27. Buckinx F, Reginster JY, Gillain S, Petermans J, Brunois T, Bruyere $O$. Prevalence of Frailty in Nursing Home Residents According to Various Diagnostic Tools. J Frailty Aging. 2017;6(3):122-8.

28. Renne I, Gobbens RJ. Effects of frailty and chronic diseases on quality of life in Dutch community-dwelling older adults: a cross-sectional study. Clin Interv Aging. 2018;13:325-34.

29. Kane RA, Kling KC, Bershadsky B, Kane RL, Giles K, Degenholtz HB, et al. Quality of life measures for nursing home residents. J Gerontol A Biol Sci Med Sci. 2003;58(3):240-8.

30. Zhang X, Wang C, Dou Q, Zhang W, Yang Y, Xie X. Sarcopenia as a predictor of all-cause mortality among older nursing home residents: a systematic review and meta-analysis. BMJ open. 2018;8(11):e021252. 
31. Personen in Alters- und Pflegeheimen 2017 [Internet]. http://www.statistik.ch/. 2017.

32. Beaudart C, Zaaria M, Pasleau F, Reginster JY, Bruyere O. Health Outcomes of Sarcopenia: A Systematic Review and Meta-Analysis. PLoS One. 2017;12(1):e0169548.

33. Liguori I, Russo G, Aran L, Bulli G, Curcio F, Della-Morte D, et al. Sarcopenia: assessment of disease burden and strategies to improve outcomes. Clin Interv Aging. 2018;13:913-27.

34. Bohannon RW. Grip Strength: An Indispensable Biomarker For Older Adults. Clin Interv Aging. 2019;14:1681-91.

35. Rantanen T, Volpato S, Ferrucci L, Heikkinen E, Fried LP, Guralnik JM. Handgrip strength and cause-specific and total mortality in older disabled women: exploring the mechanism. J Am Geriatr Soc. 2003;51(5):636-41.

36. Lauretani F, Russo CR, Bandinelli S, Bartali B, Cavazzini C, Di lorio A, et al. Ageassociated changes in skeletal muscles and their effect on mobility: an operational diagnosis of sarcopenia. J Appl Physiol. 2003;95(5):1851-60.

37. McGrath RP, Kraemer WJ, Snih SA, Peterson MD. Handgrip Strength and Health in Aging Adults. Sports Med. 2018;48(9):1993-2000.

38. Cruz-Jentoft AJ, Sayer AA. Sarcopenia. Lancet. 2019;393(10191):2636-46.

39. Maher RL, Hanlon J, Hajjar ER. Clinical consequences of polypharmacy in elderly. Expert Opin Drug Saf. 2014;13(1):57-65.

40. Narici MV, Reeves ND, Morse Cl, Maganaris CN. Muscular adaptations to resistance exercise in the elderly. J Musculoskelet Neuronal Interact. 2004;4(2):161-4.

41. Fragala MS, Cadore EL, Dorgo S, Izquierdo M, Kraemer WJ, Peterson MD, et al. Resistance Training for Older Adults: Position Statement From the National Strength and Conditioning Association. Journal of strength and conditioning research / National Strength \& Conditioning Association. 2019;33(8):2019-52.

42. World Health Organisation. Guidelines on Integrated Care for Older People (ICOPE). http://www.who.int/ageing/publications/guidelines-icope/en/; 2017.

43. Keller K. Sarcopenia. Wien Med Wochenschr. 2019;169(7-8):157-72.

44. Mathiowetz V, Kashman N, Volland G, Weber K, Dowe M, Rogers S. Grip and pinch strength: normative data for adults. Arch Phys Med Rehabil. 1985;66(2):69-74.

45. Shen Y, Chen J, Chen X, Hou L, Lin X, Yang M. Prevalence and Associated Factors of Sarcopenia in Nursing Home Residents: A Systematic Review and Meta-analysis. J Am Med Dir Assoc. 2019;20(1):5-13.

46. Akima $\mathrm{H}$, Kano $\mathrm{Y}$, Enomoto $\mathrm{Y}$, Ishizu $\mathrm{M}$, Okada $\mathrm{M}$, Oishi $\mathrm{Y}$, et al. Muscle function in 164 men and women aged 20--84 yr. Med Sci Sports Exerc. 2001;33(2):2206.

47. Laffon de Mazieres C, Morley JE, Levy C, Agenes F, Barbagallo M, Cesari M, et al. Prevention of Functional Decline by Reframing the Role of Nursing Homes? J Am Med Dir Assoc. 2017;18(2):105-10. 
48. Jerez-Roig J, de Brito Macedo Ferreira LM, Torres de Araujo JR, Costa Lima K. Functional decline in nursing home residents: A prognostic study. PLoS One. 2017;12(5):e0177353 (1-14).

49. Onder G, Carpenter I, Finne-Soveri H, Gindin J, Frijters D, Henrard JC, et al. Assessment of nursing home residents in Europe: the Services and Health for Elderly in Long TERm care (SHELTER) study. BMC Health Serv Res. 2012;12:5.

50. Hassan BH, Hewitt J, Keogh JW, Bermeo S, Duque G, Henwood TR. Impact of resistance training on sarcopenia in nursing care facilities: A pilot study. Geriatr Nurs. 2016;37(2):116-21.

51. Krist L, Dimeo F, Keil T. Can progressive resistance training twice a week improve mobility, muscle strength, and quality of life in very elderly nursing-home residents with impaired mobility? A pilot study. Clin Interv Aging. 2013;8:443-8.

52. Crocker T, Young J, Forster A, Brown L, Ozer S, Greenwood DC. The effect of physical rehabilitation on activities of daily living in older residents of long-term care facilities: systematic review with meta-analysis. Age Ageing. 2013;42(6):682-8.

53. Beaudart C, Rolland Y, Cruz-Jentoft AJ, Bauer JM, Sieber C, Cooper C, et al. Assessment of Muscle Function and Physical Performance in Daily Clinical Practice : A position paper endorsed by the European Society for Clinical and Economic Aspects of Osteoporosis, Osteoarthritis and Musculoskeletal Diseases (ESCEO). Calcif Tissue Int. 2019;105(1):1-14

54. Mijnarends DM, Meijers JM, Halfens RJ, ter Borg S, Luiking YC, Verlaan S, et al. Validity and reliability of tools to measure muscle mass, strength, and physical performance in community-dwelling older people: a systematic review. J Am Med Dir Assoc. 2013;14(3):170-8.

55. Fragala MS, Kenny AM, Kuchel GA. Muscle quality in aging: a multi-dimensional approach to muscle functioning with applications for treatment. Sports Med. 2015;45(5):641-58.

56. Borzuola R, Giombini A, Torre G, Campi S, Albo E, Bravi M, et al. Central and Peripheral Neuromuscular Adaptations to Ageing. J Clin Med. 2020;9(3).

57. Delmonico MJ, Harris TB, Visser M, Park SW, Conroy MB, Velasquez-Mieyer P, et al. Longitudinal study of muscle strength, quality, and adipose tissue infiltration. Am J Clin Nutr. 2009;90(6):1579-85.

58. Addison O, Marcus RL, Lastayo PC, Ryan AS. Intermuscular fat: a review of the consequences and causes. Int J Endocrinol. 2014;2014:309570.

59. Brook MS, Wilkinson DJ, Phillips BE, Perez-Schindler J, Philp A, Smith K, et al. Skeletal muscle homeostasis and plasticity in youth and ageing: impact of nutrition and exercise. Acta Physiol (Oxf). 2016;216(1):15-41.

60. Moore KL, Boscardin WJ, Steinman MA, Schwartz JB. Patterns of chronic comorbid medical conditions in older residents of U.S. nursing homes: differences between the sexes and across the agespan. The journal of nutrition, health \& aging. 2014;18(4):429-36. 
61. Buckinx F, Mouton A, Reginster JY, Croisier JL, Dardenne N, Beaudart C, et al. Relationship between ambulatory physical activity assessed by activity trackers and physical frailty among nursing home residents. Gait Posture. 2017;54:56-61.

62. Coetsee C, Terblanche E. The effect of three different exercise training modalities on cognitive and physical function in a healthy older population. Eur Rev Aging Phys Act. 2017;14:13.

63. Takeshima N, Rogers NL, Rogers ME, Islam MM, Koizumi D, Lee S. Functional fitness gain varies in older adults depending on exercise mode. Med Sci Sports Exerc. 2007;39(11):2036-43.

64. Taaffe DR, Henwood TR, Nalls MA, Walker DG, Lang TF, Harris TB. Alterations in muscle attenuation following detraining and retraining in resistance-trained older adults. Gerontology. 2009;55(2):217-23.

65. Goodpaster BH, Chomentowski P, Ward BK, Rossi A, Glynn NW, Delmonico MJ, et al. Effects of physical activity on strength and skeletal muscle fat infiltration in older adults: a randomized controlled trial. Journal of applied physiology. 2008;105(5):1498-503.

66. de Bruin ED, Patt N, Ringli L, Gennaro F. Playing Exergames Facilitates Central Drive to the Ankle Dorsiflexors During Gait in Older Adults; a Quasi-Experimental Investigation. Front Aging Neurosci. 2019;11:263.

67. Buford TW, Anton SD, Clark DJ, Higgins TJ, Cooke MB. Optimizing the benefits of exercise on physical function in older adults. PM R. 2014;6(6):528-43.

68. Hunter SK, Pereira HM, Keenan KG. The aging neuromuscular system and motor performance. Journal of applied physiology. 2016;121(4):982-95.

69. Lamoureux EL, Sparrow WA, Murphy A, Newton RU. Differences in the neuromuscular capacity and lean muscle tissue in old and older communitydwelling adults. J Gerontol A Biol Sci Med Sci. 2001;56(6):M381-5.

70. Fukumoto Y, Ikezoe T, Yamada Y, Tsukagoshi R, Nakamura M, Mori N, et al. Skeletal muscle quality assessed from echo intensity is associated with muscle strength of middle-aged and elderly persons. Eur $\mathrm{J}$ Appl Physiol. 2012;112(4):1519-25.

71. Watanabe $Y$, Yamada $Y$, Fukumoto $Y$, Ishihara T, Yokoyama K, Yoshida T, et al. Echo intensity obtained from ultrasonography images reflecting muscle strength in elderly men. Clin Interv Aging. 2013;8:993-8.

72. Rech A, Radaelli R, Goltz FR, da Rosa LH, Schneider CD, Pinto RS. Echo intensity is negatively associated with functional capacity in older women. Age. 2014;36(5):9708.

73. Manini TM, Hong SL, Clark BC. Aging and muscle: a neuron's perspective. Curr Opin Clin Nutr Metab Care. 2013;16(1):21-6.

74. Clark BC. Neuromuscular Changes with Aging and Sarcopenia. J Frailty Aging. 2019;8(1):7-9.

75. Oikawa SY, Holloway TM, Phillips SM. The Impact of Step Reduction on Muscle Health in Aging: Protein and Exercise as Countermeasures. Front Nutr. 2019;6:75. 
76. Knechel NA. The challenges of enrolling older adults into intervention studies. Yale J Biol Med. 2013;86(1):41-7.

77. Mody L, Miller DK, McGloin JM, Freeman M, Marcantonio ER, Magaziner J, et al. Recruitment and retention of older adults in aging research. J Am Geriatr Soc. 2008;56(12):2340-8. 


\section{Chapter 2}

\section{Handgrip strength in old and oldest old Swiss adults - a cross-sectional study}

This study was designed to address research aim 1 and evaluated handgrip strength in the Swiss population aged 75 years and over to provide reference values for further investigations and measures of clinical practice.

The chapter has been reformatted from the published article:

Wearing J, Konings P, Stokes M, de Bruin ED: Handgrip strength in old and oldest old Swiss adults - a cross-sectional study. BMC Geriatrics (2018) 18:266.

Contributions of co-authors:

P. Konings contributed to study design, participant recruitment and data collection, and preparation of the manuscript.

M. Stokes contributed to study design, data interpretation, and preparation of the manuscript.

E.D. de Bruin contributed to study conception and design, data analysis and interpretation, and preparation of the manuscript. 


\subsection{Abstract}

Background: Handgrip strength is indicative of overall physical health and mobility in the elderly. A reduction in strength below a certain threshold severely increases the risk of mobility limitations and is predictive for adverse outcomes such as functional impairment and mortality. An overview of age- and geography- specific handgrip strength values in older adults provide a reference for further investigations and measures in clinical practice to identify people at risk for clinically meaningful weakness.

Methods: In a cross-sectional study, maximal isometric handgrip strength of the dominant hand was evaluated in a sample of 244 Swiss people aged 75 years and over (62.7\% women), with mean age (SD) of 84.5 (5.6) years in men and 83.1 (5.9) years in women. Demographic data and information about comorbidities, medication, fall history, global cognitive function, self-reported physical activity and dependence in activities of daily living were collected, and correlated with grip strength measures. Age- and gender specific grip strength values are reported as means, standard deviations and standard error of mean.

Results: Sex-stratified handgrip strength significantly decreased with age in men $(p<.01)$, from $37.7(6.5) \mathrm{kg}$ to $25.6(7.6) \mathrm{kg}$ and in women ( $p<.01)$ from 22.2 (4.0) kg to 16.5 (4.7) $\mathrm{kg}$. Handgrip strength in our sample was significantly higher than in Southern European countries. Handgrip strength was independently associated with age, height and $A D L$ dependence in men and women. Overall, $44 \%$ of men and $53 \%$ of women had handgrip strength measures that were below the clinically relevant threshold (32 kg in men and $20 \mathrm{~kg}$ in women) for mobility limitations.

Conclusion: This study reports the age- and sex-stratified reference values for handgrip strength in a representative sample of the Swiss population, aged 75 - 99 years. Although grip strength decreased with age in both sexes; the relative decline was greater in men than women. Nonetheless men had significantly higher grip strength in all age groups. While the Swiss population sampled had a greater grip strength than that reported in other European countries, about $50 \%$ were still classified as at risk of mobility limitations. 


\subsection{Background}

Muscle strength is an important determinant of healthy aging [1]. A reduction in muscle mass and strength is known to impair physical function and can have substantial consequences directly for the individual but also for economic costs [2]. Physical impairment initially results in difficulties in performing common daily activities such as carrying household items; however, once body strength drops below a clinically relevant threshold, physical limitations increase and can affect mobility and independence in basic daily life activities $[3,4]$. Loss of independence requires the support of care-givers and often leads to social withdrawal and negatively effects on wellbeing and quality of life [2]. Early detection of strength loss in the elderly may help identify those at risk of physical impairment and apply interventions to avoid or slow down the spiral of negative outcomes.

Muscle deterioration in old age is primarily explained by neural and muscular decline due to the aging process and concomitant physical inactivity and malnutrition [1]. However, mobility-limiting muscle weakness can potentially be counteracted or improved through preventive exercise and rehabilitation respectively [1,5]. Increased physical activity and resistance exercise have been shown to improve muscle strength and -function even in older people with severe disability [6].

An easily applicable measure of muscle strength is hand-held dynamometry. Maximal isometric handgrip strength, measured with a dynamometer in a standard procedure, has high to excellent inter-tester and test-retest reliability [7]. Low handgrip strength is indicative for decline of upper extremity strength [8] and lower extremity function [9] with high predictive value of adverse outcomes [10]. In clinical research, grip strength is often used in detection of age-related loss of muscle strength, associated with sarcopenia [11] and frailty [12]. Low grip strength is related to poor mobility of the elderly [13] and dependence in activities of daily living [14], and even predicts decline in physical functioning and mortality [10].

Moreover, measurement of grip strength alone has been proposed to be a reliable marker of frailty [15] and has, in combination with gait speed, a positive predictive value of $87.5 \%$ to identify frailty [16]. Handgrip strength in older adults is considered a meaningful measure of current physical decline and future outcome by the World Health Organization [17].

Theoretical models of demographic trends show an increasing average life expectancy in industrial countries [18]. Particularly the percentage of older adults over 65 years will expand, in Switzerland from 18\% in 2015 to $26 \%$ in 2045, whereas the old and oldest old age group (75 years and over) will increase the most. $60 \%$ of the over 80 year olds in Switzerland seek private help or live in old peoples- or nursinghomes because of limitations in basic and/or complex activities in daily living [19,20]. 
The severity of consequences of age-associated muscle weakness provide significance to determine strength across all ages, particularly in the 75 years and over group. In this context, "hand-grip dynamometry can be considered a fundamental element of the physical examination of patients, particularly if they are older adults" [21].

Although many studies have collected grip strength data in the elderly, only few have systematically assessed grip strength in the most advanced age groups spanning the range from 90 up to 100 years and over [22,23]. To the best of our knowledge, so far only one study evaluated grip strength in the Swiss population [24]. Since average grip strength differs depending on geographic regions [25, 26], an extension of Swiss reference values is important for interpreting region-specific handgrip strength measures in clinical practice.

This study aimed to assess handgrip strength in the Swiss population aged 75 years and above to provide reference values for further investigations and measures in clinical practice. 


\subsection{Methods}

Study design

A cross-sectional study of handgrip strength involving older people living in two different urban regions (Basel and St Gallen) of the German-speaking part of Switzerland was undertaken. Recruitment targeted community-living elderly, as well as those dwelling in assisted living apartments, and residential aged-care/nursing homes to ensure a broad representative sample of the general older population. Participants meeting the following inclusion criteria were eligible for the study: male and female adults aged 75 years or older, able to follow verbal instructions in German, able and willing to sign informed consent. Participants were excluded from the study based on the following criteria: self-reported upper extremity pain, aching or stiffness of the upper extremity on most days (over $50 \%$ ) of the past month, injury or surgery or acute diseases of upper extremity within the past 6 months, and inability to follow the procedures of the study.

\section{Sample size}

Participant numbers $(n=240)$ were estimated a priori based on previously published grip strength data for Swiss older adults (Werle et al., 2009). The number would be sufficient to detect a $30 \%$ difference in grip strength for each 10-years age group cluster at an alpha (a) level of .05 and with $80 \%$ power $(\beta=.20)$.

Data collection and methods

Prior to data collection, research assistants at both study sites were trained in conducting the interview of the participants and in using the study equipment for measuring handgrip strength according to the study protocol. Factors previously shown to influence handgrip strength including demographic characteristics, medication and fall history, osteoarthritis of the hands, global cognitive function, physical activity and dependence in activities of daily living were also collected.

Information about the intake of sedative medication, fall history and osteoarthritis of the hands were self-reported by the participants.

Measurements of body height were made to the nearest centimeter with a stadiometer and body weight was measured to the nearest kilogram on a digital weigh scale.

Global cognitive function was evaluated with the Mini Mental State Exam (MMSE) [27] and expressed as a score out of 30 . The MMSE has a reported sensitivity of $77 \%$ and specificity of $91 \%$ in detecting cognitive impairment in older, community dwelling, hospitalized and institutionalized adults [28].

Independence in daily activities was assed via two questionnaires; the Barthel Index, which assesses basic activities of daily living (ADL) [29], and the Lawton Scale which evaluates instrumental activities of daily living (IADL) such as telephone use, shopping 
and food preparation [30]. Both self-rated assessments are widely used in elderly cohorts and have been shown to have high levels of reliability (Intra Class Correlation and Cronbach's alpha 0.9) [31,32]. The questionnaires were conducted as interviews and categorized participants as either independent (when all activities were scored highest), dependent in IADL (when at least one complex activity was rated with 0 points) or dependent in ADL (when at least one basic activity was rated with less than maximum score).

Physical activity was assessed with the Freiburg Questionnaire of Physical Activity; a self-reported questionnaire comprised of 8 items evaluating occupational, household, and leisure activities during the previous 7-day/30-day period [33]. Energy cost per week was quantified using a specific coding scheme that classifies physical activity by rate of energy expenditure [34, 35].

Handgrip strength was assessed using a hydraulic hand dynamometer (Jamar®) according to the standardized protocol recommended by the American Society of hand therapists [36]. The participant was seated in a chair without arm support, and with their hips flexed at $90^{\circ}$ and feet resting on the floor. The elbow of the test arm was flexed to $90^{\circ}$, the forearm in neutral, and the wrist positioned at $15-30^{\circ}$ of extension (dorsiflexion) and $0-15^{\circ}$ of ulnar deviation. The examiner supported the base of the dynamometer for testing and the second smallest dynamometer handle position was used. Following a demonstration of the protocol, the participant was asked to squeeze the handle with as much force as possible for three seconds. Three repeated trials were recorded for both hands with a rest period of at least 15 seconds between trials. The maximum value of the three trials was used for analysis and data presentation. To enable comparison of results with those of other authors, the mean value of three trials was also reported. Hand dominance was self-reported by the participant based on their preferred hand use in activities including writing and brushing teeth, according to the Edinburgh Handedness Inventory [37].

IBM SPSS Statistics, Version 23 was used for statistical analysis. Descriptive statistics for categorical variables were expressed in percentage frequency distribution, for continuous variables mean and standard deviation was used. Grip strength of the dominant hand (mean and maximum value of three trials) was reported as means and standard deviations (SD) and standard error of mean (SEM) for men and women by age group. Measures of handgrip strength controlled for height were also presented. Spearman's correlation coefficient and multiple regression analysis was used to calculate relationships of grip strength with demographic data and information about comorbidities, medication, fall history, global cognitive function, self-reported physical activity and dependence in activities of daily living. Multivariate analysis of variance with Bonferroni-adjusted post-hoc analysis was used to detect strength differences between age groups and sexes.

This manuscript adheres to reporting guidelines for cross-sectional studies [38]. 


\subsection{Results}

A total of 244 participants were recruited in the period from June 2016 to march 2017 , including 164 people from the canton Basel and 80 from the canton St Gallen. There was no statistically significant difference in mean age- and sex-stratified grip strength between the two sites $(p=.24)$.

Characteristics of participants (62.7\% female) and mean grip strength are shown in Table 1. There were no differences between sexes for age, global cognitive function, dependence in activities in daily living, amount of people living in assisted-living facilities, taking sedative medication or experiencing a fall but males were significantly taller, heavier, stronger, more physically active and had less hand osteoarthritis than females.

Table 1: Participants characteristics

\begin{tabular}{lcc}
\hline Characteristic & $\begin{array}{c}\text { men } \\
\text { mean (SD) or \% }\end{array}$ & $\begin{array}{c}\text { women } \\
\text { mean (SD) or } \\
\%\end{array}$ \\
\hline age (years) & $83.1(5.6)$ & $84.5(5.9)$ \\
height (m) & $1.73(0.7)$ & $1.59(0.7)^{*}$ \\
weight (kg) & $75.2(10.4)$ & $63.3(13.2)^{*}$ \\
handgrip strength (kg) & $32.0(8.2)$ & $19.4(4.3)^{*}$ \\
Global cognitive function (points) & $27.6(2.4)$ & $26.9(3.1)$ \\
Physical activity (kcal/week) & $1467.4(1435.9)$ & $828.2(1005.1)^{*}$ \\
ADL dependence & & \\
$\quad$ in instrumental activities of daily living & 18.2 & 16.0 \\
in instrumental and basic activities of daily & 17.0 & 23.7 \\
living & & \\
Living in assisted-living facilities/ & 6.8 & 9.6 \\
nursing homes & & \\
Medication & 23.9 & 34.0 \\
Osteoarthritis in hands & 11.4 & $27.6^{*}$ \\
Fall history & 52.3 & 64.7 \\
\hline
\end{tabular}

* significant difference between values of men and women with $p<.05$

Handgrip strength in men significantly correlated with age $(\rho=-.41, p<.01)$, height $(\rho$ $=.31, p<.01)$ and ADL dependence $(\rho=-.42, p<.01)$. After multiple regression analysis, all three variables showed independent association with grip strength, with a regression coefficient of -.4 for age in years and .3 for height in $\mathrm{m}$ and -7.5 for ADL dependence. In women, handgrip strength significantly correlated with age $(\rho=-.49$, 
$p<.01)$, weight $(\rho=.20, p<.02)$, height $(\rho=.30, p<.01)$ and ADL dependence $(\rho=$ $-.49, p<.01)$. After multiple regression analysis, only sex, age, height and ADL dependence were independently associated with grip strength, with a regression coefficient of -.2 for age in years and .1 for height in $\mathrm{m}$ and -2.8 for ADL dependence.

For presentation of handgrip strength results as reference values and to aid comparisons with previous research, mean as well as maximum values of three trials were given for participants categorized into four age groups: $75-79$ years, 80-84 years, 85-89 years, 90-99 years. Age distribution is presented in Table 2. Handgrip strength was calculated for men and women separately. Handgrip strength results in $\mathrm{kg}$ of male and female participants are presented with and without controlling the values for height (assuming all males and females had the same height within their respective groups) in Tables 3 and 4, respectively. Unadjusted maximum handgrip strength is graphically shown in figure 1.

Table 2: Number of participants per age group in absolute $(\mathrm{n})$ and percentage values $(\%)$

\begin{tabular}{|c|c|c|c|c|}
\hline Age (years) & $75-79$ & $80-84$ & $85-89$ & $90-99$ \\
\hline \multicolumn{5}{|l|}{ Men } \\
\hline Absolute $\quad n$ & 30 & 28 & 17 & 13 \\
\hline $\begin{array}{l}\text { percentage \% } \\
\text { Women }\end{array}$ & 34.1 & 31.8 & 19.3 & 14.8 \\
\hline absolute & 37 & 45 & 37 & 37 \\
\hline percentage $\%$ & 23.7 & 28.8 & 23.7 & 23.7 \\
\hline
\end{tabular}

Table 3: Height-adjusted handgrip strength of the dominant hand, categorized in age groups

\begin{tabular}{lllll}
\hline Age (years) & $75-79$ & $80-84$ & $85-89$ & $90-99$ \\
\hline Men & & & & \\
mean of 3 trials $(\mathrm{kg})$ & $35.9 \pm 6.3$ & $27.5 \pm 7.7$ & $30.6 \pm 6.2$ & $24.7 \pm 7.2$ \\
max of 3 trials $(\mathrm{kg})$ & $37.7 \pm 6.5$ & $28.8 \pm 7.7$ & $32.1 \pm 5.9$ & $26.1 \pm 8.2$ \\
& & & & \\
Women & & & & \\
mean of 3 trials $(\mathrm{kg})$ & $21.0 \pm 3.9$ & $18.2 \pm 3.0$ & $18.0 \pm 3.7$ & $15.4 \pm 4.6$ \\
max of 3 trials $(\mathrm{kg})$ & $22.2 \pm 4.0$ & $19.7 \pm 3.0$ & $19.0 \pm 3.8$ & $16.5 \pm 4.7$ \\
\hline
\end{tabular}

Handgrip strength is presented as maximum value of three trials and mean value of three trials $\pm S D$ 
Table 4: Handgrip strength (unadjusted to height) of the dominant hand, categorized in age groups

\begin{tabular}{lllll}
\hline Age (years) & $75-79$ & $80-84$ & $85-89$ & $90-99$ \\
\hline Men & & & & \\
mean of 3 trials $(\mathrm{kg})$ & $35.9 \pm 6.3(1.2)$ & $27.5 \pm 7.7(1.5)$ & $30.6 \pm 6.2(1.5)$ & $24.1 \pm 7.2(2.0)$ \\
max of 3 trials $(\mathrm{kg})$ & $37.7 \pm 6.5(1.2)$ & $28.8 \pm 7.7(1.5)$ & $32.1 \pm 5.9(1.4)$ & $25.6 \pm 7.6(2.1)$ \\
& & & & \\
Women & & & & \\
mean of 3 trials $(\mathrm{kg})$ & $21.0 \pm 3.9(0.6)$ & $18.2 \pm 3.0(0.4)$ & $18.1 \pm 3.7(0.6)$ & $15.3 \pm 4.6(0.8)$ \\
max of 3 trials $(\mathrm{kg})$ & $22.2 \pm 4.0(0.7)$ & $19.7 \pm 3.0(0.4)$ & $19.0 \pm 3.8(0.6)$ & $16.5 \pm 4.7(0.8)$ \\
\hline
\end{tabular}

Handgrip strength is presented as maximum value of three trials and mean value of three trials \pm SD (SEM - standard error of mean)

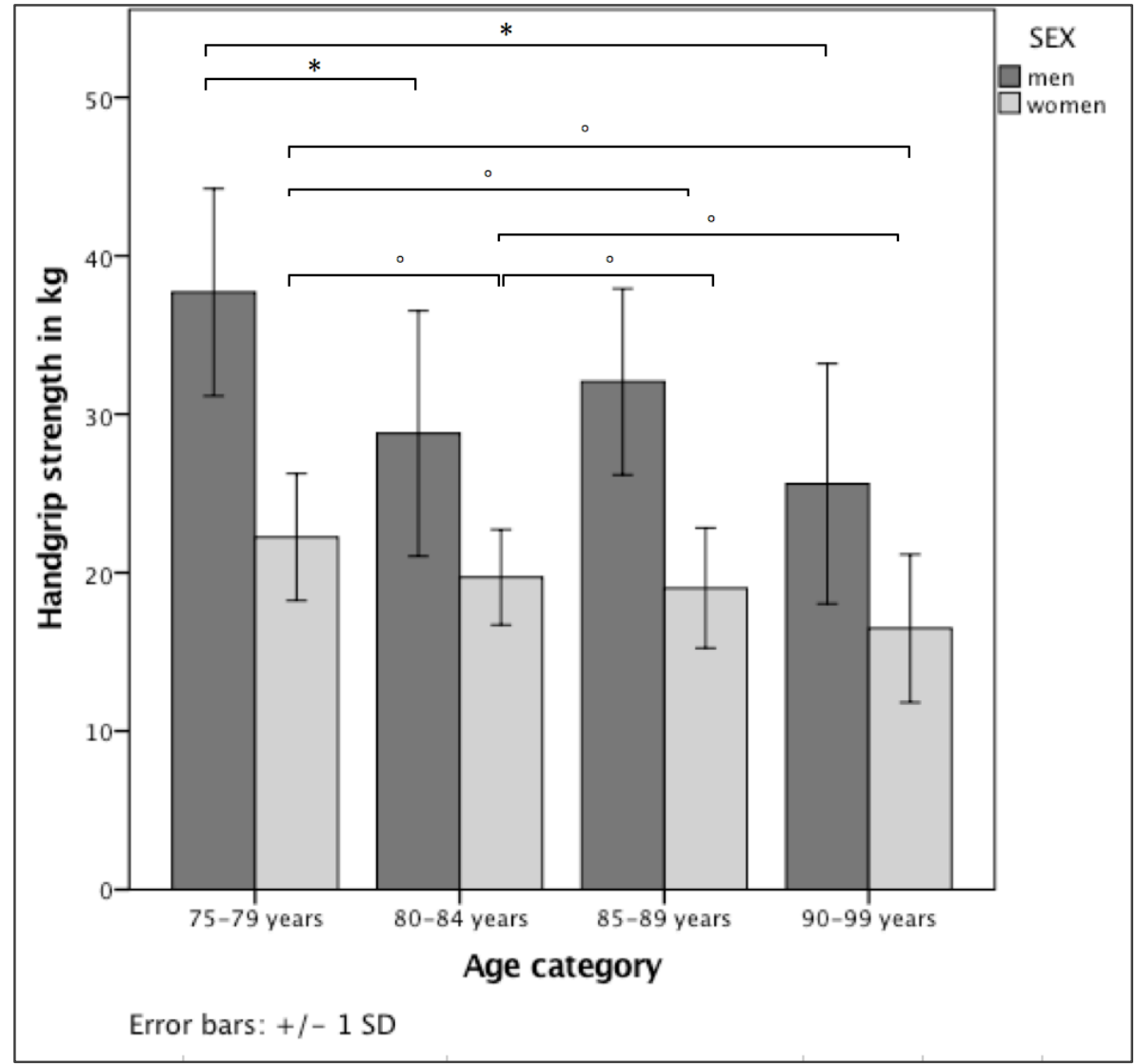

Figure 1: Maximum handgrip strength in $\mathrm{kg}$ of the Swiss population 75 years and over

* Significant difference in grip strength in men $(p<.05)$

- Significant difference in grip strength in women $(p<.05)$ 
Analysis of variance for maximum handgrip strength in men showed that age group 75-79 was significantly stronger than age group $80-84(p<.01,95 \% \mathrm{Cl} 4.0-13.9)$ and $90-99(p<.01,95 \% \mathrm{Cl} 5.8-18.4)$, and not than age group $85-89(p=.56,95 \% \mathrm{Cl}-.1$ $-11.4)$. Handgrip strength of the other age groups did not significantly differ from each other $(p=.79-1.0)$.

Loss in mean handgrip strength was $8.9 \pm 1.8 \mathrm{~kg}(23.6 \pm 4.7 \%)$ between the youngest two age groups (75-79 and 80-84) and $12.1 \pm 2.3 \mathrm{~kg}(32.1 \pm 6.1 \%)$ between the youngest and the oldest (75-79 and 90-99).

In women, analysis of variance for handgrip strength was significantly higher in age group 75-79 than in the other three groups (80-84, $\mathrm{p}=.02,95 \% \mathrm{Cl} 0.2-4.8 ; 85-89, \mathrm{p}$ $<.01,95 \% \mathrm{Cl} 0.8-5.6$; and $90-99, \mathrm{p}<.01,95 \% \mathrm{Cl} 3.4-8.2$ ). Handgrip strength of age group 80-84 and 85-89 were significantly stronger than age group $90-99(p<.01,95 \%$ $\mathrm{Cl} 0.9-5.5 ; p=.03,95 \% \mathrm{Cl} 0.1-5.0)$, but did not differ from each other $(p=1.0)$.

Loss in mean handgrip strength was $2.5 \mathrm{~kg} \pm 0.9(11.3 \pm 4.1 \%)$ between the youngest two age groups (75-79 and 80-84) and $5.8 \pm 0.9 \mathrm{~kg}(26.1 \pm 4.1 \%)$ between the youngest and the oldest (75-79 and 90-99).

For identification of participants with clinically meaningful weakness, handgrip strength was classified in three categories: weak, intermediate and normal, according to cutoff values published by Alley et al. [3]. Allocation of participants to individual categories is presented in Table 5. Men and women show equal percentage distribution for each category except for intermediate strength, where women were significantly higher. About $50 \%$ of both sexes have normal strength and $50 \%$ were categorised as having reduced strength (category weak and intermediate). The percentage distribution of participants living in assisted-living facilities did not differ between sexes but significantly differed between categories. In men and women, more people categorised as weak lived in assisted-living facilities than people with intermediate or normal strength. 
Table 5: Classification of participants (\%) into three handgrip strength categories

\begin{tabular}{lll}
\hline & men (\%) & women (\%) \\
\hline Weak (men < 26 kg, women < 16 kg) & 22.7 & 18 \\
assisted-living (\%) & $20^{\wedge}$ & $21^{\wedge}$ \\
community-living (\%) & 80 & 79 \\
& & \\
Intermediate (men $\geq 26<32 \mathrm{~kg}$, women $\geq 16<20 \mathrm{~kg}$ & 21.6 & $35.3^{*}$ \\
assisted-living (\%) & 7 & 10 \\
community-living (\%) & 93 & 90 \\
& & \\
Normal (men $\geq 32 \mathrm{~kg}$, women $\geq 20 \mathrm{~kg})$ & 55.7 & 46.7 \\
assisted-living & 4 & 5 \\
community-living & 96 & 95 \\
\hline
\end{tabular}

Three groups for handgrip strength: weak, intermediate and normal. Percentage of people living in assisted-living facilities per group is presented in \%.

* Significant difference between men and women, $p<.05$. "Significant difference of people living assisted (\%) between strength categories, $p<.05$. 


\subsection{Discussion}

The present study evaluated handgrip strength in a sample of Swiss individuals aged 75 years and over to provide reference values for further investigations and measures in clinical practice. Our study results showed handgrip strength values confirm and equal previously published data in the Swiss population $75-85$ years [24] and confirmed the validity of provided reference values for this geographic region. For the first time, additional reference values specifically for the age groups 85-90 and $90-99$ years of the Swiss population are presented.

Compared to grip strength data of a previously published Swiss sample (up to 85 years of age) [24], the older people in our study presented with comparable strength values (mean of three trials) in all age groups, except from women aged 75-79 years who were significantly weaker in the present study. Where Werle et al. included communityliving older adults and elderly living in senior residences, our sample included nursing home dwellers as well. It is possible, therefore, that our sample had a lower level of physical condition than participants in the Werle et al. study. Therefore, handgrip strength could be expected to be lower in our sample as seen in women aged 75-79 years. The age group $85+$ reported in the study of Werle et al. could not be compared to our sample since information on average age of their $85+$ cohort was not provided. In comparison to handgrip strength values published by other authors who included a random sample of the general nonagenarian population [22, 23], mean handgrip strength of the 90-99-year-old participants were significantly higher than in Southern France and Italy. These findings are consistent with previous comparisons among different European countries showing a North-South slope [22, 25]. Contrasting our results with studies of two cohorts from Denmark (mean age 96.8 years in men and 100 years in women, 92-92 years in men and women respectively) who included volunteers of oldest old people registered in the national civil registration system [22, 23], men of our Swiss sample were similar in strength, whereas women were significantly stronger. The difference could be due to variances in mean age, with women of one Danish cohort being 7 years older on average, as well as due to higher percentage of the participants living in assisted living facilities/nursing homes in both Danish samples (30.6\% [22] and $47.6 \%$ [23] versus $8.4 \%$ in our sample).

The differences in age- and gender-specific grip strength among different countries likely vary due to e.g. birth weight, lifestyle and health care in the elderly [25]. In the Swiss population, these factors are above average on international comparison, which might contribute to the higher grip strength observed in the elderly Swiss. More specifically, the average birth weight $(3.3 \mathrm{~kg})$ of Swiss newborns in 2016 [39] corresponds with the average value of international standards for newborns [40]. However, at 83.3 years, the Swiss population had the second highest life expectancy at birth in 2016 [41]. Moreover, 56\% of the population aged 75 years and over met the WHO-recommendations for physical activity in 2016, and therefore were within the highest quartile of the prevalence range $(20-60 \%)$ of physical activity in older adults 
[42]. Remarkably, Switzerland has the highest social and economic wellbeing of older people worldwide, considering income and health status, education and employment, and enabling environment [43], which may be important preconditions for remaining active in old age.

Another finding of our study, consistent with previous research in the elderly [14, 25], was that handgrip strength in men and women was independently associated with age, height and $A D L$ dependence. Handgrip strength decreased significantly with age in men and women. Between 75 and 99 years, men demonstrated a greater decrease in strength than women but had still higher overall values even in the oldest age group. When considering the entire age range (75- 99 years), the largest reduction in grip strength occurred in men in their early 80's while the biggest difference in women's strength appeared in their early 90's. The finding is consistent with a longitudinal study of Danish older adults, in which males lost handgrip strength more rapidly than females but were still stronger in absolute values [44] and less dependent in daily living [23]. As more women aged 90-99 years in the current study were dependent in daily activities than men ( $51 \%$ of women, $31 \%$ men), it would appear that absolute strength rather than the relative loss in grip strength may be more important for remaining independent in daily living in the elderly.

To identify people with a clinically meaningful reduction in handgrip strength in our sample of Swiss older adults, we applied cut-off values for detection of people at risk for mobility impairment, associated with sarcopenia/ dynapenia [2, 3]. According to cut off values published by Alley et al. [3] classifying people as weak (grip strength less than $26 \mathrm{~kg}$ for men and $16 \mathrm{~kg}$ for women), $22.7 \%$ male and $18 \%$ female participants in our sample were in this category. These individuals have a 7.6 (men) and 4.4 (women) times increased risk for mobility impairment, compared to older people with normal strength. In addition, $35.3 \%$ of the women and $21.6 \%$ of the men had "intermediate strength" (cut-off thresholds of $32 \mathrm{~kg}$ in men and $20 \mathrm{~kg}$ in women), with concomitant 3.6 (men) and 2.4 (women) times higher risk of impairment compared to older adults with normal strength values. In total, the percentage of participants with reduced strength according the proposed thresholds is $44 \%$ in men and $53 \%$ in women. Comparing the men and women with normal strength to the at risk of mobility impairment groups regarding dependency in daily living, those with normal strength were more than 2-5 times less likely living in a care home facility.

Even though cut-off values are not confirmed to be valid in detecting mobility impairment in the Swiss population yet, these results might give insight into current physical health and might indicate future need for help and care in the Swiss population.

In this study, handgrip strength was evaluated in two urban regions of Germanspeaking Switzerland with comparable handgrip strength observed at both sites. The age- and gender- distribution, as well as the percentage of people dependent in daily 
activities, were comparable with the Swiss population of the same geographic region $[19,20]$. Hence, grip strength values reported in this study are likely representative of the urban, German-Swiss population. We cannot rule out, however, that handgrip strength may differ in French-, Italian- and Romansh-speaking areas of Switzerland.

\section{Limitations}

Although this study included grip strength data in one of the most advanced age groups reported within the literature, only a limited number of male participants ( $n=$ 13) were able to be recruited from the oldest age group (90-99 years). Handgrip strength values might still be externally valid since geographically comparable data of other authors show equal results in a high number of nonagenarians. Secondly, this study recruited people from urban rather than rural areas of Switzerland. As people from rural backgrounds have been shown to have greater grip strength than those from urban environments [45], reference values in this study may be viewed as lower estimates of grip strength in the Swiss population. It is noteworthy, however, that our data are comparable with previously published grip strength in Swiss adults (aged 7585 ) which included urban, suburban and rural populations.

\section{Conclusion}

This study reports the age- and sex-stratified reference values for handgrip strength in a representative sample of the Swiss population, aged 75 - 99 years. Grip strength decreased with age in both sexes with the relative decline being greater in men than in women. Nonetheless, men had significantly higher grip strength values in all age groups. While the Swiss population sample had a greater grip strength than that reported in other European countries, $44 \%$ (men) and 53\% (women) were still classified as being at risk of developing mobility limitations. 


\subsection{References}

1. McLeod M, Breen L, Hamilton DL, Philp A. Live strong and prosper: the importance of skeletal muscle strength for healthy ageing. Biogerontology. 2016;17(3):497-510.

2. Clark BC, Manini TM. Functional consequences of sarcopenia and dynapenia in the elderly. Curr Opin Clin Nutr Metab Care. 2010;13(3):271-6.

3. Alley DE, Shardell MD, Peters KW, McLean RR, Dam TT, Kenny AM, et al. Grip strength cutpoints for the identification of clinically relevant weakness. The journals of gerontology Series A, Biological sciences and medical sciences. 2014;69(5):559-66.

4. Hasegawa R, Islam MM, Lee SC, Koizumi D, Rogers ME, Takeshima N. Threshold of lower body muscular strength necessary to perform ADL independently in community-dwelling older adults. Clin Rehabil. 2008;22(1011):902-10.

5. Manini TM, Clark BC. Dynapenia and aging: an update. The journals of gerontology Series A, Biological sciences and medical sciences. 2012;67(1):2840.

6. de Souto Barreto P, Morley JE, Chodzko-Zajko W, K HP, Weening-Djiksterhuis E, Rodriguez-Manas L, et al. Recommendations on Physical Activity and Exercise for Older Adults Living in Long-Term Care Facilities: A Taskforce Report. J Am Med Dir Assoc. 2016;17(5):381-92.

7. Mathiowetz V, Weber K, Volland G, Kashman N. Reliability and validity of grip and pinch strength evaluations. The Journal of hand surgery. 1984;9(2):222-6.

8. Bohannon RW. Hand-grip dynamometry provides a valid indication of upper extremity strength impairment in home care patients. Journal of hand therapy: official journal of the American Society of Hand Therapists. 1998;11(4):258-60.

9. Fragala MS, Alley DE, Shardell MD, Harris TB, McLean RR, Kiel DP, et al. Comparison of Handgrip and Leg Extension Strength in Predicting Slow Gait Speed in Older Adults. Journal of the American Geriatrics Society. 2016;64(1):144-50.

10. Rijk JM, Roos PR, Deckx L, van den Akker M, Buntinx F. Prognostic value of handgrip strength in people aged 60 years and older: A systematic review and meta-analysis. Geriatr Gerontol Int. 2016;16(1):5-20.

11. Cruz-Jentoft AJ, Baeyens JP, Bauer JM, Boirie Y, Cederholm T, Landi F, et al. Sarcopenia: European consensus on definition and diagnosis: Report of the European Working Group on Sarcopenia in Older People. Age Ageing. 2010;39(4):412-23.

12. Fried LP, Tangen CM, Walston J, Newman AB, Hirsch C, Gottdiener J, et al. Frailty in older adults: evidence for a phenotype. The journals of gerontology Series A, Biological sciences and medical sciences. 2001;56(3):M146-56.

13. Lauretani F, Russo CR, Bandinelli S, Bartali B, Cavazzini C, Di lorio A, et al. Ageassociated changes in skeletal muscles and their effect on mobility: an operational diagnosis of sarcopenia. J Appl Physiol. 2003;95(5):1851-60. 
14. Matsui Y, Fujita R, Harada A, Sakurai T, Nemoto T, Noda N, et al. Association of grip strength and related indices with independence of activities of daily living in older adults, investigated by a newly-developed grip strength measuring device. Geriatr Gerontol Int. 2014;14 Suppl 2:77-86.

15. Syddall $H$, Cooper $C$, Martin F, Briggs $R$, Aihie Sayer A. Is grip strength a useful single marker of frailty? Age Ageing. 2003;32(6):650-6.

16. Lee L, Patel T, Costa A, Bryce E, Hillier LM, Slonim K, et al. Screening for frailty in primary care: Accuracy of gait speed and hand-grip strength. Can Fam Physician. 2017;63(1):e51-e7.

17. WHO. Guidelines on Integrated Care for Older People (ICOPE). 2017. http://www.who.int/ageing/publications/guidelines-icope/en/; Accessed 27 June 2018.

18. Kontis V, Bennett JE, Mathers CD, Li G, Foreman K, Ezzati M. Future life expectancy in 35 industrialised countries: projections with a Bayesian model ensemble. Lancet. 2017;389(10076):1323-35.

19. BfS. Betagte Personen in 2011. https://www.bfs.admin.ch/bfs/en/home/news/whatsnew.assetdetail.348174.html: Bundesamt für Statistik BFS; 23. June 2018

20. BfS. Functional health of older, community-living people. 2014. https://www.bfs.admin.ch/bfs/de/home/statistiken/gesundheit/gesundheitszusta nd/alter.assetdetail.349311.html: Bundesamt für Statistik BFS; 23. June 2018

21. Bohannon RW. Muscle strength: clinical and prognostic value of hand-grip dynamometry. Curr Opin Clin Nutr Metab Care. 2015;18(5):465-70.

22. Jeune B, Skytthe A, Cournil A, Greco V, Gampe J, Berardelli M, et al. Handgrip strength among nonagenarians and centenarians in three European regions. The journals of gerontology Series A, Biological sciences and medical sciences. 2006;61(7):707-12.

23. Nybo H, Gaist D, Jeune B, McGue M, Vaupel JW, Christensen K. Functional status and self-rated health in 2,262 nonagenarians: the Danish 1905 Cohort Survey. Journal of the American Geriatrics Society. 2001;49(5):601-9.

24. Werle S, Goldhahn J, Drerup S, Simmen BR, Sprott H, Herren DB. Age- and gender-specific normative data of grip and pinch strength in a healthy adult Swiss population. The Journal of hand surgery, European volume. 2009;34(1):76-84.

25. Andersen-Ranberg K, Petersen I, Frederiksen H, Mackenbach JP, Christensen K. Cross-national differences in grip strength among 50+ year-old Europeans: results from the SHARE study. Eur J Ageing. 2009;6(3):227-36.

26. Leong DP, Teo KK, Rangarajan S, Kutty VR, Lanas F, Hui C, et al. Reference ranges of handgrip strength from 125,462 healthy adults in 21 countries: a prospective urban rural epidemiologic (PURE) study. Journal of cachexia, sarcopenia and muscle. 2016;7(5):535-46.

27. Folstein MF, Folstein SE, McHugh PR. "Mini-mental state". A practical method for grading the cognitive state of patients for the clinician. J Psychiatr Res. 1975;12(3):189-98. 
28. Thalmann B, Spiegel R, Stähelin HB, Brubacher D, Ermini-Fünfschilling D, Bläsi $S$, et al. Dementia Screening in General Practice: Optimised Scoring for The Clock Drawing Test. Brain Aging. 2002;2(2):36-43.

29. Mahoney FI, Barthel DW. Functional Evaluation: The Barthel Index. Md State Med J. 1965;14:61-5.

30. Lawton MP, Brody EM. Assessment of older people: self-maintaining and instrumental activities of daily living. Gerontologist. 1969;9(3):179-86.

31. Hokoishi K, Ikeda M, Maki N, Nomura M, Torikawa S, Fujimoto N, et al. Interrater reliability of the Physical Self-Maintenance Scale and the Instrumental Activities of Daily Living Scale in a variety of health professional representatives. Aging Ment Health. 2001;5(1):38-40.

32. Minosso JSM, Amendola F, Alvarenga MRM, de Campos Oliveira MA. Validation of the Barthel Index in elderly patients attended in outpatient clinics, in Brazil. Acta Paul Enferm. 2010;23(2):218-23.

33. Frey I, Berg A, Grathwohl D, Keul J. [Freiburg Questionnaire of physical activity-development, evaluation and application]. Soz Praventivmed. 1999;44(2):55-64.

34. Ainsworth BE, Haskell WL, Leon AS, Jacobs DR, Jr., Montoye HJ, Sallis JF, et al. Compendium of physical activities: classification of energy costs of human physical activities. Medicine and science in sports and exercise. 1993;25(1):7180.

35. Ainsworth BE, Haskell WL, Whitt MC, Irwin ML, Swartz AM, Strath SJ, et al. Compendium of physical activities: an update of activity codes and MET intensities. Medicine and science in sports and exercise. 2000;32(9 Suppl):S498504.

36. Shechtman O, Sindhu BS. Grip Strength. In: ASTH, editor. Clinical Assessment Recommendations, 3rd edition2013.

37. Oldfield RC. The assessment and analysis of handedness: the Edinburgh inventory. Neuropsychologia. 1971;9(1):97-113.

38. von Elm E, Altman DG, Egger M, Pocock SJ, Gotzsche PC, Vandenbroucke JP, et al. The Strengthening the Reporting of Observational Studies in Epidemiology (STROBE) Statement: guidelines for reporting observational studies. Int J Surg. 2014;12(12):1495-9.

39. BfS. Health of newborns.2016.

https://www.bfs.admin.ch/bfs/de/home/statistiken/gesundheit/gesundheitszusta nd/gesundheit-neugeborenen.html: Bundesamt für Statistik BFS; 23 June 2018

40. Villar J, Cheikh Ismail L, Victora CG, Ohuma EO, Bertino E, Altman DG, et al. International standards for newborn weight, length, and head circumference by gestational age and sex: the Newborn Cross-Sectional Study of the INTERGROWTH-21st Project. Lancet. 2014;384(9946):857-68.

41. WHO. Life expectancy at birth. 2015.

http://www.who.int/gho/mortality_burden_disease/life_tables/situation_trends/e n/: who.int; Accessed 23. June 2018

42. Sun F, Norman IJ, While AE. Physical activity in older people: a systematic review. BMC Public Health. 2013;13:449. 
43. helpage. Global AgeWatch Index 2015 [web page].

http://www.helpage.org/global-agewatch/population-ageing-data/globalrankings-table/: helpage.org; 2015 [

44. Oksuzyan A, Maier H, McGue M, Vaupel JW, Christensen K. Sex differences in the level and rate of change of physical function and grip strength in the Danish 1905-cohort study. J Aging Health. 2010;22(5):589-610.

45. Carvalho Sampaio RA, Sewo Sampaio PY, Yamada M, Ogita M, Arai H. Urbanrural differences in physical performance and health status among older Japanese community-dwelling women. Journal of Clinical Gerontology and Geriatrics. 2012;3(4):127-31. 


\section{Chapter 3}

\section{Prevalence of probable sarcopenia in community-dwelling older Swiss people - a cross-sectional study}

This study was designed to address research aim 2 and evaluated the prevalence of probable sarcopenia, as defined by low handgrip strength, in older people in Switzerland. The association between low handgrip strength and strength-related determinants was evaluated to determine predictors of probable sarcopenia.

The chapter has been reformatted from the published article:

Wearing J, Konings $\mathrm{P}$, Stokes $\mathrm{M}$, de Bie R, de Bruin ED: Prevalence of probable sarcopenia in community-dwelling older Swiss people - a cross-sectional study. BMC Geriatrics (2020) 20:307.

Contributions of co-authors:

P. Konings contributed to study design, participant recruitment and data collection, and critical revision of the manuscript.

M. Stokes contributed to study design, statistical analysis, data interpretation, and preparation critical revision of the manuscript.

R.A. de Bie contributed to study conception and design, data interpretation, and preparation and critical revision of the manuscript.

E.D. de Bruin contributed to study conception and design, statistical analysis and interpretation, and preparation and critical revision of the manuscript. 


\subsection{Abstract}

Background: The European Working Group on Sarcopenia in Older People has recently defined new criteria for identifying "(probable) sarcopenia" (EWGSOP2). However, the prevalence of probable sarcopenia, defined by these guidelines, has not been determined extensively, especially in the oldest old. This study aims to determine the prevalence of probable sarcopenia in older, community-living people and its association with strength-related determinants.

Methods: Handgrip strength and reported determinants (age, height, weight, osteoarthritis of hands, medications, fall history, physical activity, activities of daily living (ADL) and global cognitive function) were collected in a cross-sectional study of 219 community-living Swiss people (75 years and over). Probable sarcopenia was estimated based on cut-off values for handgrip strength as recommended by EWGSOP2. Spearman correlations, binary-regression analyses and contingency tables were used to explore relationships between variables.

Results: The prevalence of probable sarcopenia in women $(n=137$, age $84.1 \pm 5.7$ years) and men ( $n=82$, age $82.6 \pm 5.2$ years) was $26.3 \%$ and $28.0 \%$, respectively. In women, probable sarcopenia correlated positively with age and falls ( $r$ range 0.332 $0.195, p<.05$ ), and negatively with weight, cognition, physical activity, using stairs regularly, participating in sports activities and ADL performance ( $r$ range $=-0.141$ - $0.409, p<.05)$. The only significant predictor of probable sarcopenia at the multivariate level was $A D L$ performance (Wald $(1)=5.51, p=.019)$. In men, probable sarcopenia was positively correlated with age $\left(r_{s}=0.33, p<.05\right)$ and negatively with physical activity, participation in sports and ADL performance $\left(r_{s}\right.$ range $-0.221--0.353, p<$ .05 ). ADL performance and age (Wald $(1)=4.46, p=.035$ and Wald $(1)=6.30, p=$ .012 ) were the only significant predictors at the multivariate level. Men and women with probable sarcopenia were 2.8 times more likely to be dependent in ADL than those without.

Conclusion: Probable sarcopenia affected one in every four community-living, oldest old people and was independently associated with impaired ADL performance in both sexes. This highlights the importance of detection of handgrip strength in this age group in clinical practice. Although prospective studies are required, independence in ADL might help to protect against probable sarcopenia. 


\subsection{Background}

Sarcopenia is a generalized, progressive muscle disease/disorder [1] that has considerable, negative health-related consequences such as an increased rate of falls and incidence of hospitalization [2]. It is characterized by quantitative and qualitative alterations in muscles that may emerge from middle age onwards [3] and cumulatively occur in people with chronic diseases and an inactive lifestyle [4]. The prevalence of sarcopenia in Europe was between $11 \%-20 \%$ in healthy men and women aged $\geq 60$ years in $2016[5,6]$ and an accumulated $17 \%$ in a recently studied Swiss sample in the Italian speaking part of Switzerland where seven different Sarcopenia definitions were applied [7]. The prevalence significantly increases with age and is expected to rise within the next 30 years, particularly in the highest age groups [5]. Through concomitant diseases, sarcopenia is accompanied by a high personal and social burden when it remains untreated [1]. Sarcopenia can be prevented, delayed and probably counteracted by physical training and nutritional adaptations [4, 8]. However, in clinical practice sarcopenia is not contemplated sufficiently as a determinant of health deterioration [9] notwithstanding the fact that an ICD-10-CM code for sarcopenia was established in 2016. Therefore, sarcopenia can gradually lead to mobility limitations with loss of independence in activities of daily living (ADL) [10] and a decrease of life quality [11]. The European Working Group on Sarcopenia in Older People (EWGSOP) published a consensus paper in 2010 on the definition of sarcopenia in older people based on clinical measures [6]. Pre-sarcopenia was diagnosed by low muscle mass, and sarcopenia was defined by low muscle mass and either low muscle strength (e.g. handgrip strength) or low muscle performance (e.g. low gait speed). Certain cut-off values were set for each assessment. In 2018, the algorithm of clinical measures was updated based on scientific evidence of the previous decade (EWGSOP2) [1] and takes into account the dominant role of muscle strength in age-associated muscle wasting rather than muscle mass. According to the new guidelines, a muscle strength test, such as handgrip strength, is recommended as the initial assessment in detecting sarcopenia, therewith identifying individuals with probable sarcopenia when handgrip strength is $<16 \mathrm{~kg}$ for women and $<27 \mathrm{~kg}$ for men. Confirmation of the diagnosis sarcopenia is received by an additional detection of low muscle mass or quality. However, low strength on its own is considered enough to initiate interventions [1] since negative consequences of untreated muscle weakness, even without low muscle mass and quality, can be immense for the individual and in terms of health care costs [2]. The evaluation of probable sarcopenia provides important information, relevant for sarcopenia prevention and health promotion. 
The handgrip strength test is easily applicable to older adults and provides important information on current and future health status. Low muscle strength increases the probability of mobility limitations [12], impaired performance in daily activities [13-15] and is a marker of frailty [16]. In older people, high grip strength has a protective effect for developing disability [17] while low handgrip strength is a direct, diseaseindependent predictor of mortality $[18,19]$. Therefore, detection of low handgrip strength in older individuals is particularly important to evaluate the status of sarcopenia, which bears relevance for timely initiation of preventive or curative interventions [1]. Since the detection of pre-/probable sarcopenia is now based on muscle strength rather than muscle mass, applying the new guidelines (EWGSOP2) might lead to different population proportions identified with pre-sarcopenia that would qualify for preventive or curative associated care.

To date, information about the prevalence of probable sarcopenia, defined by low muscle strength according to the latest guidelines of the EWGSOP is rare, especially in oldest old men, and not evaluated yet for community living, non-hospitalized women [20-23]. The primary objective of this study was, therefore, to provide data regarding the prevalence of probable sarcopenia in older, community-living women and men in Switzerland. The secondary objective was to evaluate the association between probable sarcopenia and strength-related determinants. 


\subsection{Methods}

\section{Study design}

A cross-sectional study, adhering to reporting guidelines [24], was carried out between June 2016 and March 2017 in the Basel and St Gallen urban regions of Switzerland. The aim was to evaluate handgrip strength of community-living Swiss-German older adults. Recruitment was targeted towards people 75 years and over, living independently at their own home. Written information about the study was given to the target population through employees of the study sites (relatives, friends, communities) and organizations for seniors (senior education center and service organization) in the related cities. Interested potential participants were screened for inclusion and exclusion criteria via phone call. Volunteers were included when they had no self-reported upper extremity pain or stiffness on more than $50 \%$ of days of the past month, no acute diseases, no injury or surgery of the upper extremity within the past 6 months, were able to understand instructions in German and to sign informed consent. People were excluded when they did not meet the inclusion criteria. Of the potential participants, $n=2$ had to be excluded due to pain in their hands. The recruitment process was finished when a priori calculated sample size was attained.

\section{Sample size}

Participant numbers $(n=219)$ were estimated a priori based on previously published prevalence data for Swedish older adults [20]. The estimated number would be sufficient to detect a prevalence of $28 \%$ at a level of confidence of 0.1 and with $95 \%$ precision $(d=0.05)$.

\section{Data collection}

The assessors were trained and experienced in all testing procedures.

Handgrip strength was evaluated with a calibrated hydraulic hand dynamometer (Jamar $\left.{ }^{\circledR}\right)$ in accordance with the standardized procedure defined by the American Society of Hand Therapists [25]. In brief, participants were seated with their elbow flexed at $90^{\circ}$ and holding the dynamometer in their dominant hand. The handle grip of the dynamometer was standardized to the second smallest grip position. The weight of the dynamometer was counterbalanced by the examiner throughout testing. Based on the cut off value of handgrip strength for probable sarcopenia in women and men, defined by the EWGSOP, the participants were categorized in two groups: category 1 $=$ "probable sarcopenia" (handgrip strength $<16 \mathrm{~kg}$ and $<27$ respectively) and category $0=$ "no probable sarcopenia" (handgrip strength $\geq 16 \mathrm{~kg}$ and $\geq 27 \mathrm{~kg}$ ).

Factors associated with handgrip strength, as reported in the literature, were also assessed. These were age, height, weight, sedative medication, fall history, osteoarthritis of the hands, global cognitive function, physical activity and basic and instrumental activities of daily living. Data collection is outlined briefly in Table 1, for more detailed explanations we refer to [26]. 
Table 1: Measured variables

\section{\begin{tabular}{lll}
\hline Grip strength-related factors & Measure & Rating, categorization
\end{tabular}}

\begin{tabular}{ll}
\hline Demographic characteristics & Self-reported age, \\
{$[3,27]$} & height and weight
\end{tabular}

Sedative medication intake [28]

Fall history [29]

Osteoarthritis of the hands [30] self-reported

Global cognitive function [31]

Physical activity [27]

Basic activities of daily living (ADL) [36]

Instrumental activities of daily living (IADL) [38] self-reported

self-reported

category 0: no sedative medication

category $1: \geq 1$ medication

category 0 : no falls

category $1: \geq 1$ fall

category 0: yes

category 1 : no

Mini Mental State points 0-30

Exam (MMSE) [32]

Freiburg

Questionnaire of

Physical Activity

[33]

the Barthel Index [37]

Questionnaire as interview

Lawton Scale [39] Questionnaire as interview energy expenditure in

$\mathrm{kcal} /$ week [34, 35]

category 0 : independent in IADL and ADL

highest value in every instrumental and basic activity

category 1 (dependent in IADL and/or ADL): 0 points in at least one instrumental activity and less than highest value in at least one basic activity 


\section{Statistical Analysis}

IBM SPSS Statistics, Version 23 was used for statistical analysis. Normal distribution of continuous and categorical variables was tested with the Kolmogorov Smirnov and the Shapiro Wilk test. For further analyses, parametric tests were used for data with a normal distribution and non-parametric tests for non-normal distributed data and categorical variables. Prevalence of probable sarcopenia was estimated by the percentage of individuals with handgrip strength below the cut off value per gender. Correlations between sarcopenia-categorizations and independent variables were analyzed using Spearman's correlation coefficient and binary-logistic regression. Prevalence of ADL performance in people with probable sarcopenia was evaluated by $2 \times 2$ contingency tables, calculating the ratio of: number of ADL dependent participants affected by the disease/total cases affected by the disease and number of ADL dependent participants not affected by the disease/total cases not affected by the disease. Pairwise deletion was used in statistical analysis of missing data.

\subsection{Results}

The prevalence analysis of probable sarcopenia in community-living older people was based on a representative sample of 219 older adults, aged 75 years and over, mean age $83.6( \pm 5.6)$ years $(n=137$ women, $n=82$ men) from two urban, German-speaking areas in Switzerland. Mean (SD) handgrip strength in women was $18.4 \mathrm{~kg}$ (4.15) and in men $30.9 \mathrm{~kg}$ (7.92). The overall percentage of people independent in IADL and ADL was $66 \%$.

Prevalence of probable sarcopenia

The prevalence of probable sarcopenia, detected by gender-specific handgrip strength cut-off values, was $26.3 \%$ in women $(n=36)$ and $28 \%$ in men $(n=23)$.

Associations of probable sarcopenia with factors related to handgrip strength The variables that were associated with the sarcopenia category (no probable sarcopenia/ probable sarcopenia) varied between sexes. Therefore, further analysis was performed separately for women and men.

\section{Correlation analysis}

In women, probable sarcopenia correlated positively with age and falls ( $r_{\mathrm{s}}$ range 0.332 $-0.195, p<.05)$, and negatively with body weight, cognition, physical activity, using stairs regularly, participating in sports activities and ADL performance $\left(r_{s}\right.$ range = $0.141--0.409, \mathrm{p}<.05)$.

In men, probable sarcopenia was positively correlated with age $\left(r_{s}=0.33, p<.05\right)$ and negatively with physical activity, participation in sports and ADL performance $\left(r_{s}\right.$ range $-0.221--0.353, p<.05)$. ADL performance had the highest correlation of the independent variables in both sexes (Table 2). 
Table 2: Correlations between sarcopenia category and independent variables in women and men

\begin{tabular}{|c|c|c|c|c|}
\hline \multirow[t]{2}{*}{ Independent variables } & \multicolumn{2}{|l|}{ women } & \multicolumn{2}{|l|}{ men } \\
\hline & $\begin{array}{l}\text { Correlation } \\
\text { coefficient }\end{array}$ & $\begin{array}{l}\text { Level of } \\
\text { Significance }\end{array}$ & $\begin{array}{l}\text { Correlation } \\
\text { coefficient }\end{array}$ & $\begin{array}{l}\text { Level of } \\
\text { Significance }\end{array}$ \\
\hline age & $r_{s}=0.332^{*}$ & $p<.001$ & $r_{s}=0.33^{x}$ & $p=.002$ \\
\hline height & $r_{s}=-0.141$ & $p=.100$ & $r_{s}=0.095$ & $p=.394$ \\
\hline weight & $r_{s}=-0.176^{*}$ & $p=.039$ & $r_{s}=-0.187$ & $p=.092$ \\
\hline medication & $r_{s}=0.091$ & $p=.291$ & $r_{s}=0.062$ & $p=.578$ \\
\hline falls & $r_{s}=0.195^{*}$ & $p=.022$ & $r_{s}=0.136$ & $p=.224$ \\
\hline osteoarthritis in hands & $r_{s}=-0.037$ & $p=.672$ & $r_{s}=0.073$ & $p=.515$ \\
\hline cognition & $r_{s}=-0.242^{*}$ & $p=.005$ & $r_{s}=-0.004$ & $p=.975$ \\
\hline physical activity & $r_{s}=-0.323^{*}$ & $p<.001$ & $r_{s}=-0.234^{*}$ & $P=.034$ \\
\hline taking stairs regularly & $r_{s}=-0.224^{*}$ & $p=.009$ & $r_{s}=0.001$ & $p=.995$ \\
\hline $\begin{array}{l}\text { participating in Sport } \\
\text { activities }\end{array}$ & $r_{s}=-0.258^{*}$ & $p<.001$ & $r_{s}=-0.221^{*}$ & $p=.046$ \\
\hline ADL performance & $r_{s}=-0.409^{*}$ & $p<.001$ & $r_{s}=-0.353^{*}$ & $p<.001$ \\
\hline
\end{tabular}

"significant correlation $(p<.05)$

\section{Regression analysis}

In women, regression analysis showed that the significantly correlating variables age, weight, cognition, physical activity, regularly climbing stairs, participating in sports activities, falls and ADL performance explained whether a participant had probable sarcopenia or not to 32.5\% (Nagelkerke's R2=0.325, Chi-squared $(8)=33.606, p<$ $.000)$. ADL performance was the only variable significantly impacting on sarcopenia category (Wald $(1)=5.516, p=.019$ ) with an Odd's ratio of 0.263 (Table 3 ).

In men, the significantly correlating variables age, physical activity, participating in sports activities and ADL performance explained the outcome of no probable sarcopenia/ probable sarcopenia to $29.3 \%$ (Nagelkerke's R2 $=0.293$, Chi-squared (4) $=18.667, p=.001$. Higher age and lower ADL performance had significant impact on having probable sarcopenia (Wald $(1)=6.298, p=.012$; Wald $(1)=4.461, p=.035$ ), age with an Odd's ratio of 1.153 , ADL performance with an Odd's ratio of 0.295 (Table 4). 
Table 3: Regression analysis of sarcopenia category by correlated variables in women

\begin{tabular}{lllllll}
\hline Variables & Wald & $\begin{array}{l}\text { Degrees } \\
\text { of } \\
\text { freedom }\end{array}$ & $\begin{array}{l}\text { Sig- } \\
\text { nifica } \\
\text { nce }\end{array}$ & $\begin{array}{l}\text { Exp(B)/ } \\
\text { Odd's } \\
\text { ratio }\end{array}$ & \multicolumn{2}{l}{$\begin{array}{l}\text { 95\% Confidence } \\
\text { intervall } \\
\text { Exp(B) }\end{array}$} \\
\cline { 5 - 7 } & & & $\mathrm{p}$ & & lower & upper \\
\hline age & 3.211 & 1 & .073 & 1.093 & .992 & 1.205 \\
weight & .429 & 1 & .512 & .987 & .951 & 1.026 \\
fall & 1.628 & 1 & .202 & 1.959 & .697 & 5.503 \\
cognition & .931 & 1 & .335 & 1.090 & .915 & 1.298 \\
physical activity & .067 & 1 & .796 & 1.000 & .999 & 1.001 \\
participating in Sport & .603 & 1 & .438 & .592 & .158 & 2.224 \\
activities & & & & & & \\
taking stairs regularly & 2.208 & 1 & .137 & .486 & .188 & 1.259 \\
ADL & 5.516 & 1 & .019 & .263 & .086 & .802 \\
constant & 2.725 & 1 & .099 & .000 & &
\end{tabular}

Table 4: Regression analysis of sarcopenia category by correlated variables in men

\begin{tabular}{lllllll}
\hline Variables & Wald & $\begin{array}{l}\text { Degrees of } \\
\text { freedom }\end{array}$ & $\begin{array}{l}\text { Sig- } \\
\text { nificance } \\
\text { p }\end{array}$ & $\begin{array}{l}\text { Exp(B)/ } \\
\text { Odd's } \\
\text { ratio }\end{array}$ & \multicolumn{2}{l}{$\begin{array}{l}\text { 95\% Confidence } \\
\text { intervall for Exp(B) }\end{array}$} \\
\cline { 6 - 8 } & & & & lower & upper \\
\hline age & 6.298 & 1 & .012 & 1.153 & 1.032 & 1.289 \\
physical activity & .432 & 1 & .511 & 1.000 & .999 & 1.000 \\
participating in & .655 & 1 & .418 & .554 & .132 & 2.318 \\
$\begin{array}{l}\text { Sport activities } \\
\text { ADL }\end{array}$ & & & & & & \\
constant & 4.461 & 1 & .035 & .295 & .095 & .916 \\
& 5.989 & 1 & .014 & .000 & &
\end{tabular}

Prevalence of ADL performance with and without probable sarcopenia Of the women with probable sarcopenia $(n=36), 70 \%(n=25)$ were dependent in IADL and/or ADL. In the group of women without probable sarcopenia $(n=101)$ only $25 \%$ $(n=25)$ were dependent in IADL and/or ADL. In the 23 men with probable sarcopenia, $57 \%(n=13)$ were dependent in IADL and/or ADL, while in the 59 without probable sarcopenia only $20 \%(n=12)$ were dependent in IADL and/or ADL. Women and men with probable sarcopenia were 2.8 times more likely to be dependent in ADL than those without (Table 5). 
Table 5: Prevalence of ADL dependence in people with and without probable sarcopenia

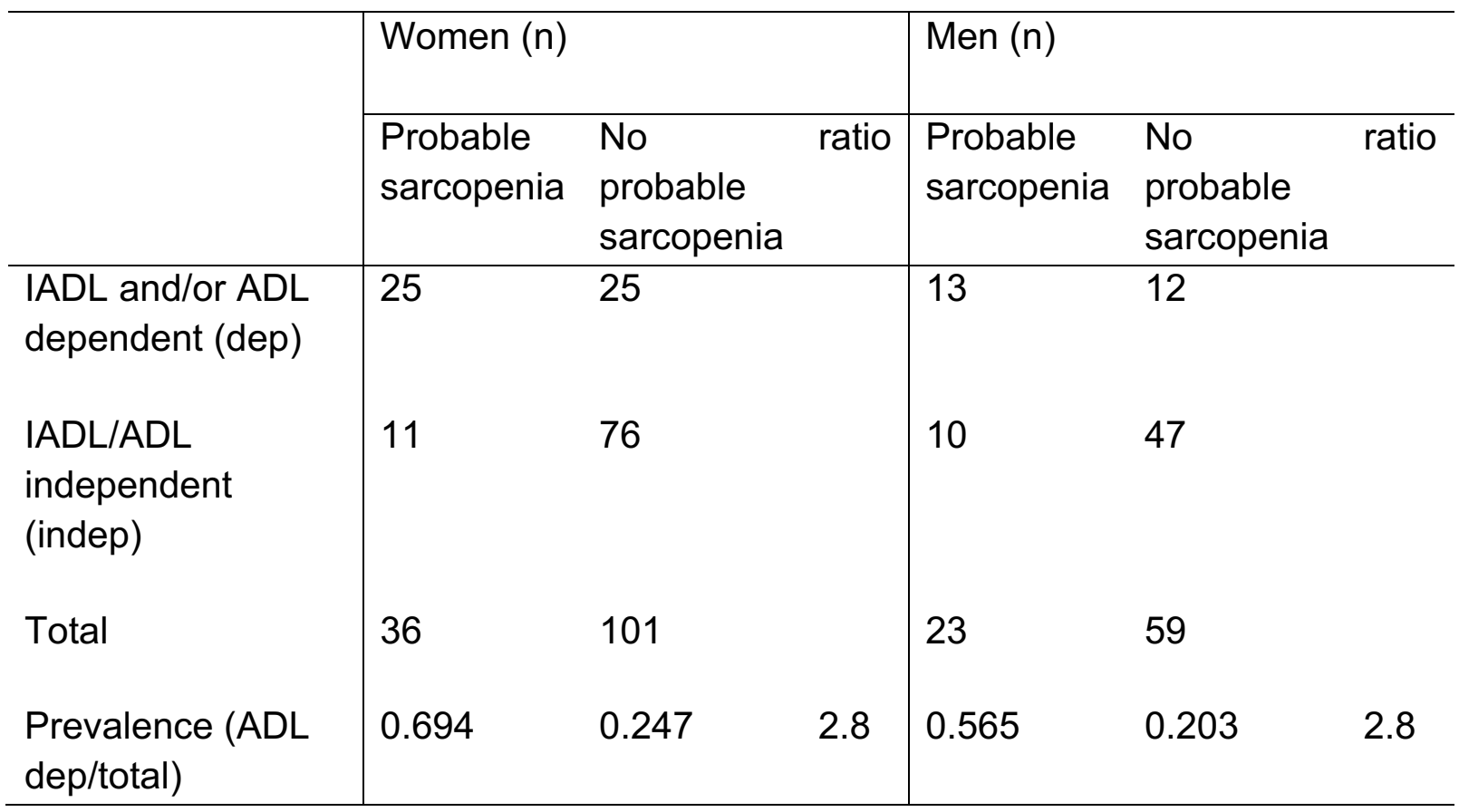




\subsection{Discussion}

The sample complies with the oldest old population of Switzerland in regard to mean age, gender participation and functional performance in ADL [40]. Handgrip strength of this sample is in accordance with strength values previously evaluated in the German-Swiss population of similar age [41]. Therefore, the study sample can be considered representative of the oldest old population in Switzerland.

This study has applied updated EWGSOP2 guidelines to give insights into probable sarcopenia in community-living, non-hospitalized, oldest old women. Thereby, it provides important health-related data of a group not previously studied. The results demonstrate that a high percentage of community-living older women has such low strength that negative consequences, such as dependence in ADL, are likely to occur when strength decline is not counteracted.

The findings build on existing evidence of probable sarcopenia in oldest old men, in which the prevalence of probable sarcopenia is reportedly $28 \%$ [21], to also include new data in oldest old women. In the current study, the prevalence of probable sarcopenia in community-living older people aged 75 years and over was $26.3 \%$ in women and $28 \%$ in men. These results are in accordance with studies in other countries that assessed people of the same age group [20, 21]. Reiss et al. detected a prevalence of low handgrip strength of $28 \%$ in women, and $33 \%$ in men in 144 geriatric inpatients (mean age 80.7 years) [21] while Franzon et al. evaluated a $28 \%$ prevalence in 287 community-living Swedish men (mean age 86 years) [20]. Two studies of younger populations from Korea and Japan reported lower prevalences of people with low handgrip strength $(14.6 \%$ in men and women combined [22], $17.2 \%$ in men and $10.1 \%$ in women [23]). The differences between the previous studies and the present results may be explained by the age differences (mean age 76 years in their studies versus 83 years in the present study) and/or ethnic origin of the study population [22, 23], since handgrip strength declines with age [26] and is reportedly lower in Asian than in European countries [42].

Studies that applied the updated guideline EWGSOP2, as in the present study, but used different measures than handgrip strength for the detection of probable sarcopenia, showed higher prevalences [20,23]. One study defined male participants (mean age 87 years) as having probable sarcopenia when handgrip strength and/or chair stand test was below cut-off values [20]. This resulted in a prevalence of $73 \%$ of which $61 \%$ was due to participants who performed poorly in the chair stand test. Another study, applying the same assessment method, also found higher prevalences in comparison to a handgrip strength test alone ( $23.5 \%$ versus $13.7 \%)$, even though the participants were younger (mean age 75 years) [23]. Prevalence of probable sarcopenia was shown to be dependent on applied measures of detection in previous literature. However, it is not clear yet which of the strength tests detecting probable sarcopenia is most likely to predict people developing sarcopenia. 
However, all studies indicate that handgrip strength below a cut-off value of $<16 \mathrm{~kg}$ for women and $<27 \mathrm{~kg}$ for men is present in a substantial percentage of the older old population, even in non-institutionalized people. The results have clinical implications since they may increase the awareness of older individuals but also medical doctors and insurance companies about the importance of low muscle strength and the associated high risk of developing sarcopenia. Since probable sarcopenia is a prestage of sarcopenia, early detection of low muscle strength is crucial to prevent further decline. These data show that about $27 \%$ would benefit from further sarcopenia assessment and specific interventions to avoid the consequences of untreated muscle wasting.

Associations of probable sarcopenia with factors related to handgrip strength Factors related to handgrip strength differed between sexes. Low handgrip strength in men was related to higher age, low physical activity and dependence in ADL. In addition, it was also associated with less weight, falls and less cognition in women. ADL performance was independently associated with probable sarcopenia in women and men. Dependence in instrumental and/or basic ADL was 2.8 times more likely in participants with probable sarcopenia than in participants without. Previous crosssectional studies have shown that handgrip strength, gait speed and chair stand abilities were correlated with restrictions in ADL in older adults [38, 43]. The results of the present study demonstrate the specific risk of ADL dependence, when handgrip strength is below the proposed cut off value by the EWGSOP2.

Low handgrip strength has been shown to be an important indicator of future ADL performance [13-15]. However, it would seem not only important to maintain adequate handgrip strength to ensure independence in daily activity, but also to remain as independent as possible to maintain handgrip strength. The present data may also suggest that independence in ADL execution might help to protect people from probable sarcopenia. A cause-and-effect relationship cannot be drawn by this crosssectional study but existing prospective studies support this hypothesis, showing that handgrip strength decreases as a consequence of a sedentary lifestyle and a reduced engagement in demanding household activities [17, 44]. Moreover, regular house work and strenuous activities in daily living, such as gardening, have been shown to be protective against dependence in ADL [44, 45]. As performance in ADL as well as muscle strength are modifiable and have the potential to prevent or delay excessive muscle weakness $[4,8]$, it would be useful to detect decline in muscle strength as soon as possible to ensure timely interventions.

\section{Limitations}

Some limitations of this cross-sectional study should be mentioned. Firstly, the sample included a representative group of 219 community-living people 75 years and over in German-speaking Switzerland. Generalizability of the results to the French-, Italian- 
and Romansh-speaking parts of Switzerland as well as to other countries is dependent on region-specific variation in handgrip strength. However, given that handgrip strength of adults 75 years and over in German-speaking Switzerland is similar to that of northern European countries, such as Denmark [26], the results of the current study are likely to be representative for older people from other northern and central European countries. Secondly, the subgroup of male participants was relatively small compared to the total population studied but is useful since published data from men $>80$ years are rare. Thirdly, determinants of handgrip strength were not exhaustive but limited to key characteristics consistently identified within the literature to explain the variance in handgrip strength. Fourthly, considering that handgrip strength has been shown to be related to body weight [27], categorization into probable sarcopeniagroups based on strength thresholds normalized to body weight might have changed the significance of our findings. A sub-analysis of our results, however, showed that weight did not differ between sarcopenia and ADL subgroups. Hence, normalization of grip strength would not have changed our results. Finally, the rigidity and weight of the Jamar-dynamometer has been suggested to afford difficulties in assessing handgrip strength in very old populations [46]. However, in our study, the weight of the device was supported by the examiner and the handle position was standardized and comfortable for all participants.

\section{Conclusions and implications}

The present study provided new insight into the prevalence of probable sarcopenia detected by low handgrip strength in community-living, non-hospitalized, oldest old women and men, and highlights the importance of detection of probable sarcopenia in clinical practice. With reference to the present data, one in every four communitydwelling people aged 75 years and over in German-speaking Switzerland could benefit from sarcopenia management to prevent negative consequences associated with the condition. Handgrip strength tests should be applied routinely in clinical assessments of older people to detect loss in muscle strength and to initiate timely intervention. 


\subsection{References}

1. Cruz-Jentoft AJ, Bahat G, Bauer J, Boirie Y, Bruyere O, Cederholm T, et al. Sarcopenia: revised European consensus on definition and diagnosis. Age Ageing. 2019.

2. Beaudart C, Zaaria M, Pasleau F, Reginster JY, Bruyere O. Health Outcomes of Sarcopenia: A Systematic Review and Meta-Analysis. PLoS One. 2017;12(1):e0169548.

3. Dodds RM, Syddall HE, Cooper R, Benzeval M, Deary IJ, Dennison EM, et al. Grip strength across the life course: normative data from twelve British studies. PLoS One. 2014;9(12):e113637.

4. Scott D, Blizzard L, Fell J, Jones G. The epidemiology of sarcopenia in community living older adults: what role does lifestyle play? J Cachexia Sarcopenia Muscle. 2011;2(3):125-34.

5. Ethgen O, Beaudart C, Buckinx F, Bruyere O, Reginster JY. The Future Prevalence of Sarcopenia in Europe: A Claim for Public Health Action. Calcif Tissue Int. 2017;100(3):229-34.

6. Cruz-Jentoft AJ, Baeyens JP, Bauer JM, Boirie Y, Cederholm T, Landi F, et al. Sarcopenia: European consensus on definition and diagnosis: Report of the European Working Group on Sarcopenia in Older People. Age Ageing. 2010;39(4):412-23.

7. Steffl M, Bohannon RW, Sontakova L, Tufano JJ, Shiells K, Holmerova I. Relationship between sarcopenia and physical activity in older people: a systematic review and meta-analysis. Clin Interv Aging. 2017;12:835-45.

8. Keller K. Sarcopenia. Wien Med Wochenschr. 2019;169(7-8):157-72.

9. Yoshimura $\mathrm{Y}$, Wakabayashi H, Bise T, Tanoue M. Prevalence of sarcopenia and its association with activities of daily living and dysphagia in convalescent rehabilitation ward inpatients. Clinical nutrition. 2018;37(6 Pt A):2022-8.

10. Sayer AA, Syddall HE, Martin HJ, Dennison EM, Roberts HC, Cooper C. Is grip strength associated with health-related quality of life? Findings from the Hertfordshire Cohort Study. Age Ageing. 2006;35(4):409-15.

11. Integrated Care for Older People: Guidelines on Community-Level Interventions to Manage Declines in Intrinsic Capacity. WHO Guidelines Approved by the Guidelines Review Committee. Geneva2017.

12. Al Snih S, Markides KS, Ottenbacher KJ, Raji MA. Hand grip strength and incident ADL disability in elderly Mexican Americans over a seven-year period. Aging Clin Exp Res. 2004;16(6):481-6.

13. Chan OY, van Houwelingen $\mathrm{AH}$, Gussekloo J, Blom JW, den Elzen WP. Comparison of quadriceps strength and handgrip strength in their association with health outcomes in older adults in primary care. Age. 2014;36(5):9714.

14. Ishizaki T, Watanabe S, Suzuki T, Shibata H, Haga $\mathrm{H}$. Predictors for functional decline among nondisabled older Japanese living in a community during a 3-year follow-up. J Am Geriatr Soc. 2000;48(11):1424-9.

15. Syddall $H$, Cooper $C$, Martin F, Briggs $R$, Aihie Sayer A. Is grip strength a useful single marker of frailty? Age Ageing. 2003;32(6):650-6. 
16. Alexandre Tda S, Corona LP, Nunes DP, Santos JL, Duarte YA, Lebrao ML. Gender differences in incidence and determinants of disability in activities of daily living among elderly individuals: SABE study. Arch Gerontol Geriatr. 2012;55(2):431-7.

17. Rantanen T, Volpato S, Ferrucci L, Heikkinen E, Fried LP, Guralnik JM. Handgrip strength and cause-specific and total mortality in older disabled women: exploring the mechanism. J Am Geriatr Soc. 2003;51(5):636-41.

18. Bae EJ, Park NJ, Sohn HS, Kim YH. Handgrip Strength and All-Cause Mortality in Middle-Aged and Older Koreans. Int J Environ Res Public Health. 2019;16(5).

19. Franzon K, Zethelius B, Cederholm T, Kilander L. The impact of muscle function, muscle mass and sarcopenia on independent ageing in very old Swedish men. BMC Geriatr. 2019;19(1):153.

20. Reiss J, Iglseder B, Alzner R, Mayr-Pirker B, Pirich C, Kassmann H, et al. Consequences of applying the new EWGSOP2 guideline instead of the former EWGSOP guideline for sarcopenia case finding in older patients. Age Ageing. 2019.

21. Su Y, Hirayama K, Han TF, Izutsu M, Yuki M. Sarcopenia Prevalence and Risk Factors among Japanese Community Dwelling Older Adults Living in a SnowCovered City According to EWGSOP2. J Clin Med. 2019;8(3).

22. Kim M, Won CW. Prevalence of sarcopenia in community-dwelling older adults using the definition of the European Working Group on Sarcopenia in Older People 2: findings from the Korean Frailty and Aging Cohort Study. Age Ageing. 2019.

23. von Elm E, Altman DG, Egger M, Pocock SJ, Gotzsche PC, Vandenbroucke JP, et al. The Strengthening the Reporting of Observational Studies in Epidemiology (STROBE) Statement: guidelines for reporting observational studies. Int J Surg. 2014;12(12):1495-9.

24. Shechtman O, Sindhu BS. Grip Strength. In: ASTH, editor. Clinical Assessment Recommendations, 3rd edition2013.

25. Wearing J, Konings $P$, Stokes $M$, de Bruin ED. Handgrip strength in old and oldest old Swiss adults - a cross-sectional study. BMC Geriatr. 2018;18(1):266.

26. Nevill AM, Holder RL. Modelling handgrip strength in the presence of confounding variables: results from the Allied Dunbar National Fitness Survey. Ergonomics. 2000;43(10):1547-58.

27. Taipale HT, Bell JS, Gnjidic D, Sulkava R, Hartikainen S. Muscle strength and sedative load in community-dwelling people aged 75 years and older: a population-based study. J Gerontol A Biol Sci Med Sci. 2011;66(12):1384-92.

28. Yang NP, Hsu NW, Lin CH, Chen HC, Tsao HM, Lo SS, et al. Relationship between muscle strength and fall episodes among the elderly: the Yilan study, Taiwan. BMC Geriatr. 2018;18(1):90.

29. Myers DB, Grennan DM, Palmer DG. Hand grip function in patients with rheumatoid arthritis. Arch Phys Med Rehabil. 1980;61(8):369-73.

30. Taekema DG, Gussekloo J, Maier AB, Westendorp RG, de Craen AJ. Handgrip strength as a predictor of functional, psychological and social health. A 
prospective population-based study among the oldest old. Age Ageing. 2010;39(3):331-7.

31. Folstein MF, Folstein SE, McHugh PR. "Mini-mental state". A practical method for grading the cognitive state of patients for the clinician. J Psychiatr Res. 1975;12(3):189-98.

32. Frey I, Berg A, Grathwohl D, Keul J. [Freiburg Questionnaire of physical activity-development, evaluation and application]. Soz Praventivmed. 1999;44(2):55-64.

33. Ainsworth BE, Haskell WL, Leon AS, Jacobs DR, Jr., Montoye HJ, Sallis JF, et al. Compendium of physical activities: classification of energy costs of human physical activities. Med Sci Sports Exerc. 1993;25(1):71-80.

34. Ainsworth BE, Haskell WL, Whitt MC, Irwin ML, Swartz AM, Strath SJ, et al. Compendium of physical activities: an update of activity codes and MET intensities. Med Sci Sports Exerc. 2000;32(9 Suppl):S498-504.

35. Matsui Y, Fujita R, Harada A, Sakurai T, Nemoto T, Noda N, et al. Association of grip strength and related indices with independence of activities of daily living in older adults, investigated by a newly-developed grip strength measuring device. Geriatr Gerontol Int. 2014;14 Suppl 2:77-86.

36. Mahoney FI, Barthel DW. Functional Evaluation: The Barthel Index. Md State Med J. 1965;14:61-5.

37. Gopinath B, Kifley A, Liew G, Mitchell P. Handgrip strength and its association with functional independence, depressive symptoms and quality of life in older adults. Maturitas. 2017;106:92-4.

38. Lawton MP, Brody EM. Assessment of older people: self-maintaining and instrumental activities of daily living. Gerontologist. 1969;9(3):179-86.

39. Anjum SN, Choudary P, Dimri R, Ankarath S. Comparative evaluation of grip and pinch strength in an Asian and European population. Hand Therapy. 2012;17(1):11-4.

40. Mijnarends DM, Luiking YC, Halfens RJG, Evers S, Lenaerts ELA, Verlaan S, et al. Muscle, Health and Costs: A Glance at their Relationship. The journal of nutrition, health \& aging. 2018;22(7):766-73.

41. Rantanen T, Era P, Heikkinen E. Physical activity and the changes in maximal isometric strength in men and women from the age of 75 to 80 years. J Am Geriatr Soc. 1997;45(12):1439-45.

42. Zhang YJ, H.; Li, A.; Liu, J.; Lia, H. Study on Prediction of Activities of Daily Living of the Aged People Based on Longitudinal Data. Procedia Computer Science 2016;91:470-7.

43. Neumann S, Kwisda S, Krettek C, Gaulke R. Comparison of the Grip Strength Using the Martin-Vigorimeter and the JAMAR-Dynamometer: Establishment of Normal Values. In Vivo. 2017;31(5):917-24. 


\section{Chapter 4}

\section{Feasibility and relevance of detection tests of probable sarcopenia in nursing-home residents}

This study was designed to address research aim 3 . The study evaluated the feasibility of two strength tests, commonly used to detect probable sarcopenia in communityliving people, in nursing-home residents, and the prevalence of probable sarcopenia, detected by each test. The study evaluated the indicative value of low strength, detected by each test, for overall strength, frailty and ADL performance.

The chapter has been reformatted from the published article:

Wearing J, Stokes M, de Bie R, de Bruin ED: Feasibility and relevance of detection tests of probable sarcopenia in nursing-home residents. Journal of Nursing Home Research 2020;6:93-99.

Contributions of co-authors:

M. Stokes contributed to study design, statistical analysis, data interpretation, and preparation critical revision of the manuscript.

$\mathrm{R}$. de Bie contributed to study conception and design, data interpretation, and preparation and critical revision of the manuscript.

E.D. de Bruin contributed to study conception and design, statistical analysis and interpretation, and preparation and critical revision of the manuscript. 


\subsection{Abstract}

Background: Handgrip strength and a chair-stand-test are often used to evaluate strength and function, and to detect probable sarcopenia in community-living, older adults. In institutionalized, frail older people, evaluation of muscle performance is of particular importance but it has received little attention.

Objectives: To evaluate the feasibility of handgrip strength and the chair stand test in nursing-home residents, and their relation to overall strength, daily functioning and frailty.

Methods: In a cross-sectional study 30 nursing-home residents, 23 women, age median (range) 86.5 (68-103) years were assessed for handgrip strength, the chair stand test, knee extensor and elbow flexor strength, gait speed, activities of daily living and frailty. The Mann-Whitney-U Test was used to compare sub-groups of sarcopenia (probable sarcopenia versus no probable sarcopenia) while Cohen's Kappa and Area under the Receiver Operating Characteristic curve examined relationships between tests.

Results: All participants were able to perform the handgrip strength test, while only 14 could complete the chair rise test. Probable sarcopenia was detected by handgrip strength in 22 and chair stand test in 24 (8 slow; 16 unable to complete) participants, with an overlap of 19 . Probable sarcopenia, detected by each of the tests, was significantly associated with low gait speed and severe frailty status, while low handgrip strength also indicated low elbow flexor and knee extensor strength, and high dependence in activities of daily living.

Conclusions: Handgrip strength test is superior to the chair stand test as a strength test to detect probable sarcopenia in nursing-home residents, as it could be completed by more frail people. Sarcopenia-specific cut off values in handgrip strength indicated overall strength, leg function, performance of daily activities and frailty, hence, the test could be used as a screening test for physical condition. Although further research is needed, given the importance of detecting muscle performance, handgrip strength testing is recommended in nursing-home residents. 


\subsection{Introduction}

Muscle strength is a very important prerequisite for healthy aging (1). It is a predictor of adverse health outcomes, such as dependence in activities of daily living (ADL) and mortality (2) in community-living older adults. Older people whose strength drops significantly due to chronic diseases or inactivity, and who lose independence in daily activities, receive support from home care or become institutionalised in long-term care (3). At admission to the institution, people are assessed for their need of care. However, standardized assessment of muscle status is typically not undertaken (4) even though nursing-home residents are at risk for further strength and functional decline $(3,5)$. Rather, residents are specifically evaluated for physical capacity only when negative consequences of functional decline, such as falls, occur. Since low muscle strength and function can be improved even in frail older people (6), strength testing is considered important in order to prescribe tailored interventions in a timely manner.

The two strength tests, handgrip strength (HGS) and chair stand test (CST), are quick and easy to perform and reportedly meaningful for health-related outcomes in community-dwelling older people (7). The European Working Group for Sarcopenia in Older People (EWGSOP2) advocates these two tests with distinct cut-off values to detect those likely to have sarcopenia (probable sarcopenia): the HGS of $<16 \mathrm{~kg}$ for women and $<27 \mathrm{~kg}$ for men, and a CST of $>15$ seconds (8). In case of probable sarcopenia detection, recommended interventions are initiated to improve strength even if the diagnosis of sarcopenia is not/not yet confirmed (8), as prevention of decline is vital. However, strength testing in long-term care has been little explored (5), despite the urgent need for specific information about muscle performance in this population. Feasibility of strength tests in older nursing-home residents to detect probable sarcopenia is questionable $(7,9)$. Moreover, the indicative value of probable sarcopenia detected by the EWGSOP2 guidelines for health-related outcomes, such as frailty and ADL dependence, in older nursing-home residents has not been explored to date. The objectives of this study, therefore, were to:

1. Evaluate the feasibility of HGS and CST in nursing-home residents

2. Evaluate the prevalence of probable sarcopenia detected by each test, according to cut off values defined by the EWGSOP2

3. Explore the differences between the sub-groups with/without probable sarcopenia in regard to strength, function, $A D L$ dependence, comorbidities and frailty 


\subsection{Methods}

Study design

An observational, cross-sectional study to assess muscle strength, physical function and frailty was undertaken in Swiss nursing-home residents between August and December 2017.

\section{Participants}

Older adults, aged 65 years and over, were screened for exclusion criteria by a certified nurse based on the RAI (Resident Assessment Instrument) which is routinely performed in nursing-home residents. Exclusion criteria were: a) severely impaired decision making (Cognitive performance scale $>4$ points); b) a history of acute lower limb pathology (fracture and/or surgery within the last 6 months); c) limb paralysis; and d) confinement to bed. Volunteers who were able to understand study content and signed informed consent, were included in the study. All study procedures complied with the principles of the Declaration of Helsinki for ethical research in humans and the study received approval from the local ethics committee (project-ID 2017-00839).

\section{Sample size}

Sample size $(n=30)$ was estimated a priori based on previously published data on prevalence of sarcopenia in nursing-home residents (10). The calculated number would be sufficient to detect a prevalence of $50 \%$ at a $90 \%$ confidence level and with $85 \%$ precision $(d=0.15)$.

\section{Data collection}

Strength measures, the CST, gait speed and the frailty assessment were examined by a physiotherapist trained and experienced in musculoskeletal assessments.

HGS was measured with a hydraulic hand dynamometer (Jamar ${ }^{\circledR}$, Lafayette, USA) according to the standardized protocol of the American Society of Hand Therapists (11). The maximal value of two trials was used to identify residents with and without probable sarcopenia according to a cut-off value of $16 \mathrm{~kg}$ for women and $27 \mathrm{~kg}$ for men, as defined by the EWGSOP2 (8).

CST was performed according to a standardized protocol, published by Guralnik (12). The test involves the completion of five chair rises from a full-seated position to upright stance in as short time as possible with the arms crossed over the chest. The time for completion of five chair stands was measured with a stop watch. Classification of "probable sarcopenia" or "no probable sarcopenia" was based on a cut off value of 15 seconds (8).

Participant demographics, medical history, cognitive performance and selfperformance in ADL were obtained using the RAI (Minimum Data Set Version 2.0). For evaluation of cognition and ADL, participants' performance was closely observed by trained nurses and then encoded with the standardized RAl-item coding system. 
a) Age was reported in years, height in meters and weight in $\mathrm{kg}$.

b) Medical history included chronic diseases of the metabolic, musculoskeletal, neurological, and respiratory system, psychiatric conditions, renal insufficiency, vertigo and cancer. Number and type of diseases were recorded.

c) Cognitive performance was classified on the Minimum Data Set Cognitive Performance Scale ranging from 0 (= intact cognition) to 6 (= severely limited cognition) points (13).

d) Basic ADL included 10 usual daily activities of nursing-home residents: bed mobility, transfer, dressing, eating/drinking, toilet use, personal hygiene, walking in a room and in a corridor, locomotion on and outside the ward. Each of the 10 activities was rated on a scale from 0 (independent) to 4 (fully dependent), with a full range of $0-40$, based on the performance of the last 7 days. Participants were categorized as a) independent in ADL when total score was 0 , and as dependent in ADL when total score was $\geq 1$, which reflected assistance or staff oversight in at least one activity.

Maximum voluntary isometric contraction strength of the knee extensor and elbow flexor muscles was measured using a hand-held dynamometer (Microfet2®, CompuFET, Hoggan Health Industries, Biometrics Europe). For measurement, the participant was seated with their back resting against a firm support, thighs fully supported. Knee and elbow were flexed at $90^{\circ}$ respectively while the participants were asked to push against the dynamometer as hard as possible. The highest value of two trials was recorded. Intraclass Correlation Coefficient (ICC) reported for repeated measures of hand-held dynamometry range between 0.90 and 0.98 in older adults (14).

Habitual gait speed $(\mathrm{m} / \mathrm{s})$ was evaluated over a 4-meter, level walkway at participant's preferred speed. Time was recorded to the nearest hundredth of a second with a stopwatch. Participants were permitted the use of a walking aid. Test-retest reliability of gait speed assessments recorded over comparable distances have been shown to be adequate (ICC of 0.715$)$ and related to measures of physical function $(r=0.554)$ in older individuals (15).

Physical frailty was evaluated according to Fried's frailty criteria (16), namely unintentional weight loss $<5 \mathrm{~kg}$ in the past year, weakness (low HGS), exhaustion (self-report), slowness (slow walking speed) and low physical activity. Participants were classified as "pre-frail" in case of 1-2 positive criteria and as "frail" in case of 3-5 positive criteria. 


\section{Statistical Analysis}

IBM SPSS Statistics, Version 23 was used for statistical analysis. The Mann-Whitney$U$ Test was used to compare the sub-groups, probable sarcopenia versus no probable sarcopenia, with respect to strength, physical function, ADL performance and frailty. Feasibility was based on the number of people that were able to complete the EWGSOP2 advocated screening tests for detection of probable sarcopenia. Cohen's Kappa and the area under the Receiver Operating Characteristic (ROC) curves (AUC) were applied for relationships between the two detection tests and accuracy of the tests to detect frailty status and gait speed. 


\subsection{Results}

Descriptive characteristics

Of a total of 30 nursing-home residents with median (range) age 86.5 (68-103) years, height 1.62 (1.49-1.72) $\mathrm{m}$ and weight 66.5 (35-95) kg, 23 were female. Prefrailty was detected in 13, frailty in 17 participants, and 29 had more than two chronic diseases. The cognitive performance, with 0 being cognitively intact, was median (range) 1 (03).

\section{Feasibility of test performance}

All participants could perform the HGS test, however only 14 participants (47\%) could successfully get up from a chair at all. Subsequently, participants who could not complete the CST $(n=16)$ and those who performed slower than the cut off value $(n=8)$ were combined as the slow/no CST group.

Prevalence of probable sarcopenia

Low HGS was prevalent in $78 \%(n=22)$ while the prevalence of probable sarcopenia detected by slow/no CST was $80 \%(n=24)$. Cohen's Kappa showed an overlap of $n=19$ between the people assessed by low HGS and those assessed by slow/no CST. The Kappa value of $0.259(95 \% \mathrm{Cl} 0.293-0.311)$ demonstrates a fair relationship between the two tests (17) (Table 1).

Table 1: Crosstabulation for prevalence and overlap of people with probable sarcopenia detected by low HGS and slow/no CST

\begin{tabular}{|c|c|c|c|c|}
\hline & \multicolumn{2}{|c|}{ Measure of HGS } & \multirow[t]{2}{*}{ Total } \\
\hline & & $\begin{array}{c}\text { Probable } \\
\text { sarcopenia }\end{array}$ & $\begin{array}{c}\text { No } \\
\text { probable } \\
\text { sarcopenia }\end{array}$ & \\
\hline Measure & Probable sarcopenia $(\mathrm{N})$ & 19 & 5 & 24 \\
\hline \multirow[t]{5}{*}{ of CST } & \% within probable sarcopenia by CST & 79.2 & 20.8 & 100 \\
\hline & \%within probable sarcopenia by HGS & 86.4 & 62.5 & 80 \\
\hline & No probable sarcopenia (N) & 3 & 3 & 6 \\
\hline & $\%$ within probable sarcopenia by CST & 50 & 50 & 100 \\
\hline & \%within probable sarcopenia by HGS & 13.6 & 37.5 & 20 \\
\hline \multirow[t]{3}{*}{ Total } & $(\mathrm{N})$ & 22 & 8 & 30 \\
\hline & $\%$ within probable sarcopenia by CST & 73 & 26.7 & 100 \\
\hline & \%within probable sarcopenia by HGS & 100 & 100 & 100 \\
\hline
\end{tabular}


Differences between the sub-groups with/without probable sarcopenia Participants with probable sarcopenia detected by low HGS also had lower elbow flexor and knee extensor strength, slower gait speed, were more often dependent in ADL and had more symptoms of frailty than people without $(p<.05)$. However, there was no significant difference in age, height, weight, comorbidities or the ability to perform the CST between sub-groups (Table 2).

Participants with probable sarcopenia detected by slow CST, had significantly slower gait speed and more frailty symptoms than those without. Age, height, weight, strength, ADL performance and comorbidities did not differ between sub-groups (Table 2). 
Table 2: Differences (median (min-max)) between participants with and without probable sarcopenia detected by low HGS and low/no CS

\begin{tabular}{|c|c|c|c|c|c|c|}
\hline & $\begin{array}{l}\text { HGS- } \\
\text { probable } \\
\text { sarcopenia }\end{array}$ & $\begin{array}{l}\text { HGS- } \\
\text { no probable } \\
\text { sarcopenia }\end{array}$ & $\begin{array}{l}\mathrm{p}- \\
\text { values }\end{array}$ & $\begin{array}{l}\text { CST- } \\
\text { probable } \\
\text { sarcopenia }\end{array}$ & $\begin{array}{l}\text { CST- } \\
\text { no probable } \\
\text { sarcopenia }\end{array}$ & $\begin{array}{l}p- \\
\text { values }\end{array}$ \\
\hline \multicolumn{7}{|l|}{ Demographics } \\
\hline $\mathrm{N}$ & 22 & 8 & & 24 & 6 & \\
\hline Age (years) & $\begin{array}{l}86.5 \\
(68-103)\end{array}$ & $\begin{array}{l}86.5 \\
(78-89)\end{array}$ & .540 & $\begin{array}{l}87.0 \\
(69-98)\end{array}$ & $\begin{array}{l}83.0 \\
(68-103)\end{array}$ & .265 \\
\hline Height (m) & $\begin{array}{l}1.61 \\
(1.49-1.72)\end{array}$ & $\begin{array}{l}1.63 \\
(1.49-1.67)\end{array}$ & .827 & $\begin{array}{l}1.63 \\
(1.49-1.72)\end{array}$ & $\begin{array}{l}1.57 \\
(1.49-1.67)\end{array}$ & .234 \\
\hline Weight (kg) & $\begin{array}{l}67.6 \\
(44-95)\end{array}$ & $\begin{array}{l}65.5 \\
(35-83)\end{array}$ & .362 & $\begin{array}{l}67.6 \\
(35-95)\end{array}$ & $\begin{array}{l}59.0 \\
(39.5-74)\end{array}$ & .245 \\
\hline Strength & & & & & & \\
\hline Quadriceps (kg) & $\begin{array}{l}10.5 \\
(6.8-15.8)\end{array}$ & $\begin{array}{l}13.2 \\
(11.8-17.5)\end{array}$ & $.007^{*}$ & $\begin{array}{l}12.3 \\
(6.8-17.5)\end{array}$ & $\begin{array}{l}11.2 \\
(7.5-15.5)\end{array}$ & .503 \\
\hline Elbow flexor $(\mathrm{kg})$ & $\begin{array}{l}8.2 \\
(4.9-14.4)\end{array}$ & $\begin{array}{l}11.0 \\
(8.9-14.5)\end{array}$ & $.012^{*}$ & $\begin{array}{l}9.2 \\
(4.9-14.4)\end{array}$ & $\begin{array}{l}9.2 \\
(5.8-14.5)\end{array}$ & .756 \\
\hline
\end{tabular}

\section{Function}

\begin{tabular}{|c|c|c|c|c|c|c|}
\hline $\begin{array}{l}\text { Gait speed } \\
(n=28)\end{array}$ & $\begin{array}{l}0.55 \\
(0.19-0.85)\end{array}$ & $\begin{array}{l}0.75 \\
(0.43-1.09)\end{array}$ & $.028^{*}$ & $\begin{array}{l}0.55 \\
(0.19-0.87)\end{array}$ & $\begin{array}{l}0.77 \\
(0.55-1.09)\end{array}$ & $.032^{*}$ \\
\hline $\begin{array}{l}\text { Chair stand test } \\
\text { yes/no }(n=30)\end{array}$ & $41 / 59$ & $63 / 37$ & .417 & & & \\
\hline $\begin{array}{l}\text { Chair stand test } \\
\sec (n=14)\end{array}$ & $\begin{array}{l}19 \\
(12.0-41.0)\end{array}$ & $\begin{array}{l}15 \\
(9.5-48.3)\end{array}$ & .346 & & & \\
\hline \multicolumn{7}{|l|}{ ADL disability } \\
\hline $\begin{array}{l}\text { ADL category } \\
\text { (indep/dep) }\end{array}$ & $41 / 59$ & $88 / 12$ & $.039^{*}$ & $54 / 46$ & $50 / 50$ & .100 \\
\hline
\end{tabular}

\begin{tabular}{|c|c|c|c|c|c|c|}
\hline Comorbidities & & & & & & \\
\hline Number & $3(2-5)$ & $3.5(0-7)$ & .848 & $3(2-7)$ & $3(0-5)$ & .675 \\
\hline Frailty & & & & & & \\
\hline $\begin{array}{l}\text { Number of } \\
\text { symptoms (max 5) }\end{array}$ & $3(2-5)$ & $2(1-3)$ & $.007^{*}$ & $3(1-5)$ & $2(1-2)$ & $.002^{*}$ \\
\hline $\begin{array}{l}\text { Frailty category }{ }^{\#} \\
\text { (prefrail/frail) }\end{array}$ & $32 / 68$ & $75 / 25$ & $.049^{*}$ & $29 / 71$ & $100 / 0$ & $.003^{*}$ \\
\hline
\end{tabular}

Continuous variables are documented as median (min-max), p-values with exact significance, 2-tailed; categorical variables\# are presented as percentages 
The AUC showed that probable sarcopenia detected by HGS distinguished between frailty statuses to $72 \%$ and gait speed to $77 \%$. The CST distinguished between frailty statuses to $85 \%$ and gait speed to $79 \%$ (Fig. 1 and 2).

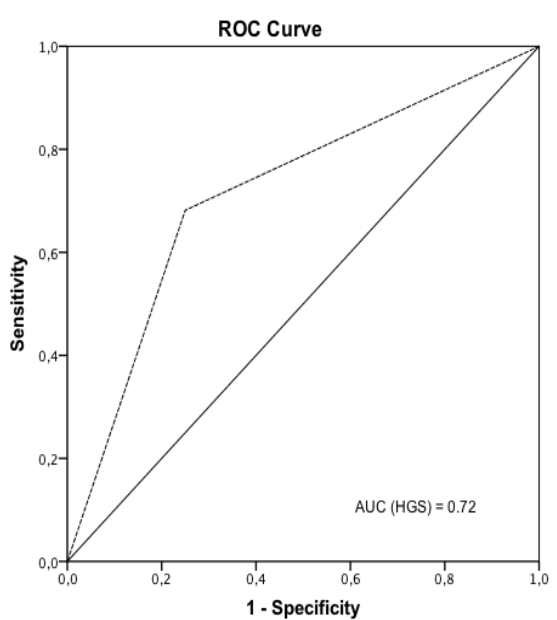

Fig.1a

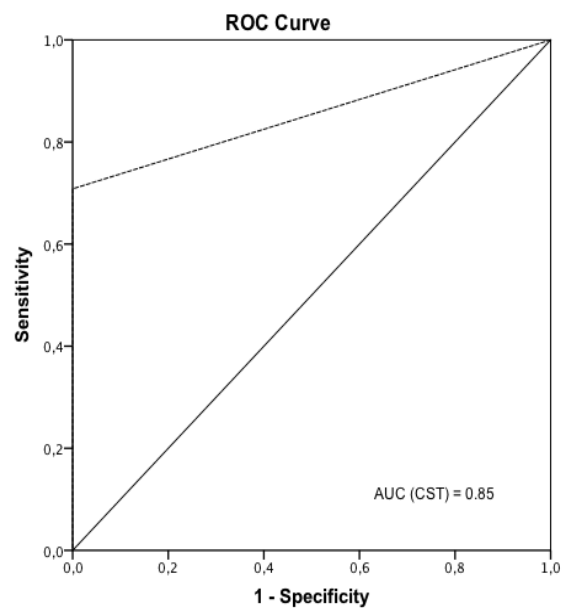

Fig.1b

Fig.1 ROC curve and AUC: handgrip strength (1a) and chair stand test (1b) accuracy in discriminating frailty status

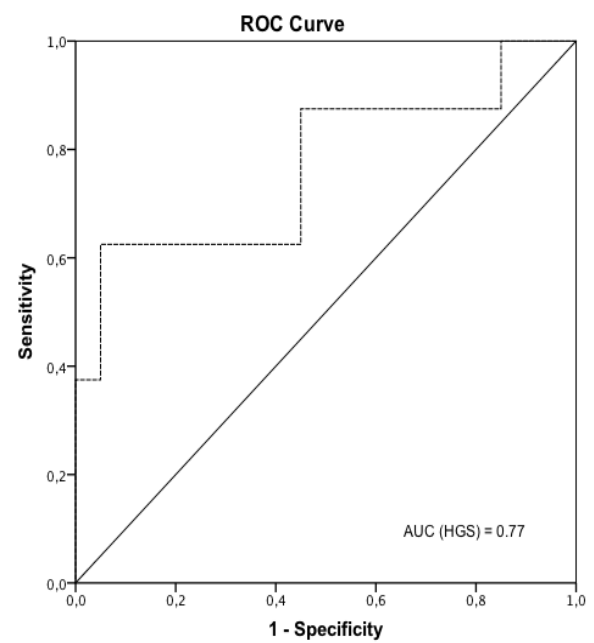

Fig.2a

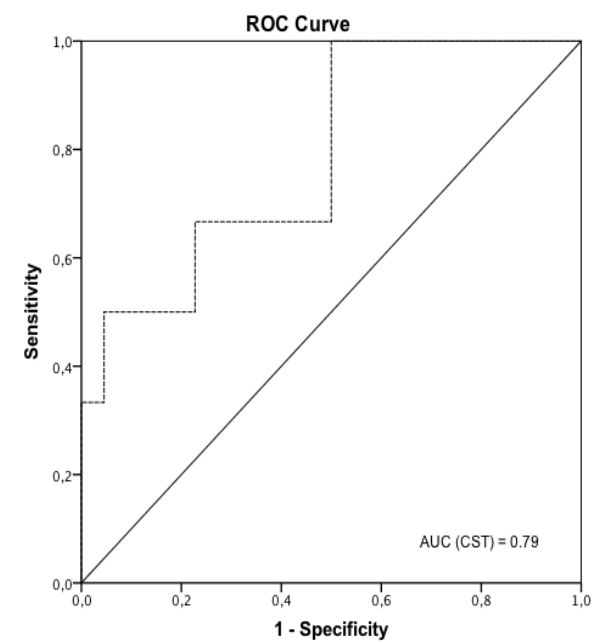

Fig.2b

Fig. 2 ROC curve and AUC: handgrip strength (Fig.2a) and chair stand test (Fig.2b) accuracy in determining gait speed 


\subsection{Discussion}

This group of 30 nursing-home residents was heterogeneous in their health and frailty status. However, the participants are representative of institutionalized, older people in regard to muscle strength and physical function (18).

The feasibility of performing the two EWGSOP2 advocated tests differed significantly in this group of nursing-home residents. While all participants could perform the HGS test, more than half of the residents could not stand up from a seated position without the use of their upper limbs. Oldest-old nursing-home residents often experience an excessive loss in muscle strength which might drop below the necessary threshold needed for standing up (19). Hence, the floor effect of the CST observed in this study might limit its usefulness in this population even if participants who have not been able to perform the test were also classified as having probable sarcopenia, as were participants who had results below the threshold. Modifications of the proposed CST performance (8) that are recommended to avoid floor effects in older people suggest to use the 30s CST (7) or the fastest of two chair stands at comfortable speed (20). However, even if the original test was modified to just one repetition, this floor effect would remain as none of the participants in this study who were unable to perform the CST including five repetitions, were able to complete even a single chair stand. The test might be sufficiently meaningful if test results are dichotomized in the subgroups slow/no CST and normal CST.

Moreover, the two tests detected different sub-groups as having probable sarcopenia. The EWGSOP2 advocates that both tests can be used interchangeably as estimates of strength (8). However, they may identify different determinants of muscle strength. HGS may be reflective of overall isometric strength (21) while the CST does not only measure pure muscle strength but also reflects other neuro-muscular properties such as power and balance $[25,26]$. Arguably, power and balance are not normally required in nursing-home residents as the chair stand is typically performed slowly with use of arms/hands as additional support [27].

The prevalence of probable sarcopenia was almost threefold higher in this group of nursing-home residents than in community-living older people of similar age (22), and $20 \%$ higher than in nursing-home residents who were 10 years younger (23). Nursinghome residents are at particular risk of strength decline (3) due to physical inactivity and malnutrition (1). Given the negative associations of muscle weakness, such as mobility limitations and high risk of falls (1), the high prevalence of probable sarcopenia highlights the need for feasible strength assessment in these individuals to initiate adequate interventions and to avoid further decline.

Overall, both detection tests had an indicative value for gait speed and frailty, while HGS was also suggestive of overall strength and ADL performance in this study of elderly nursing-home residents. 
The participants with probable sarcopenia had lower isometric elbow flexor and knee extensor strength than those without, but only when detected by low HGS. This may reflect that HGS is an indicator of general neuromuscular capacity $(2,21)$ whereas CST covers task-specific capabilities such as leg power (see previous section) (24, 25). Further research is needed to evaluate the relationship between HGS, the CST and different aspects of strength as well as feasible modifications of the CST for the very old population.

The sub-groups differed in gait speed, independent of test for detection by $0.2 \mathrm{~m} / \mathrm{s}$. Both tests were almost equally accurate in distinguishing gait speed. An increase of $0.1 \mathrm{~m} / \mathrm{s}$ has been reported to be a substantial change (26) that significantly improves survival after one year (27). Previous literature evaluating physical function in nursinghome residents reported a significant correlation between HGS and gait speed $(r=$ $0.24, p<.001)(23)$. The present results, applying sarcopenia-specific cut off values for HGS (8), contribute the knowledge that people with low HGS and CST are likely to have gait speed indicating particular risk for falls and hospitalization (28). Hence, detection of probable sarcopenia as an indicator of walking speed, can be used to initiate individual gait assessment.

Regarding ADL, only low HGS could detect differences, not the CST. More people with probable sarcopenia were dependent in ADL than those without, which is consistent with findings reported in community-living older adults (22), and in people across different health care settings (5). Independence in ADL is of particular importance in older people due to its relation to quality of life and health care costs (29). Therefore, HGS had an additional value over CST in this population as it could potentially be used for frequent screening of ADL performance.

Number of comorbidities were not different between sub-groups, independent of the detection test. These findings correspond with previous literature that evaluated the relationship between HGS and the occurrence of comorbidity ( $\geq 3$ chronic diseases) in community-living older adults (30). Hence, low HGS and CST have indicative value for physical function in older nursing-home residents independent of chronic diseases. Both detection tests of probable sarcopenia might also be useful as screening tests for frailty status with the CST being superior to HGS, since it was more accurate in distinguishing between prefrail and frail nursing-home residents. Even though frailty symptoms occurred in all 30 participants, reflecting a very vulnerable population, the status of frailty is meaningful for adverse outcomes and mortality (16).

\section{Limitations of the study}

A limitation of this study is the small number of participants which led to small subgroups. The findings could therefore be under/overestimated. However, since information about muscle status in nursing-home residents is rare, the findings may still provide indicative evidence for future research. Secondly, participants were only recruited from one nursing-home in Switzerland. However, important health parameters are similar across residents of nursing-homes in Europe, such as functional decline and severity of disability (3). Therefore, the results could be considered generizable to nursing-homes in this continent. 


\section{Conclusions}

Muscle strength testing is crucial in older people who are at risk for strength decline, as well as for those already experiencing consequences of muscle weakness, such as functional limitations and ADL dependence. The present results provide novel, clinically relevant data about the feasibility of strength tests for nursing-home residents that can be used for detection of probable sarcopenia but also as screening tests for health outcomes. Low HGS as well as slow/no CST demonstrate high prevalence of probable sarcopenia in nursing-home residents, indicating low level of physical function and frailty. However, the CST may not be an implementable measure of strength in clinical practice of nursing-homes, hence, HGS is recommended as a routine test for detection of probable sarcopenia. 


\subsection{References}

1. McLeod M, Breen L, Hamilton DL, Philp A. Live strong and prosper: the importance of skeletal muscle strength for healthy ageing. Biogerontology. 2016;17(3):497-510.

2. Bohannon RW. Grip Strength: An Indispensable Biomarker For Older Adults. Clin Interv Aging. 2019; 14:1681-91.

3. Laffon de Mazieres C, Morley JE, Levy C, et al. Prevention of Functional Decline by Reframing the Role of Nursing Homes? J Am Med Dir Assoc. 2017;18(2):10510.

4. Onder G, Carpenter I, Finne-Soveri H, et al. Assessment of nursing home residents in Europe: the Services and Health for Elderly in Long TERm care (SHELTER) study. BMC Health Serv Res. 2012; 12:5.

5. Roberts HC, Syddall HE, Sparkes J, et al. Grip strength and its determinants among older people in different healthcare settings. Age Ageing. 2014;43(2):241-6.

6. Clegg A, Young J, Iliffe S, Rikkert MO, Rockwood K. Frailty in elderly people. Lancet. 2013;381(9868):752-62.

7. Beaudart C, Rolland $\mathrm{Y}$, Cruz-Jentoft AJ, et al. Assessment of Muscle Function and Physical Performance in Daily Clinical Practice: A position paper endorsed by the European Society for Clinical and Economic Aspects of Osteoporosis, Osteoarthritis and Musculoskeletal Diseases (ESCEO). Calcif Tissue Int. 2019;105(1):1-14.

8. Cruz-Jentoft AJ, Bahat G, Bauer J, et al. Sarcopenia: revised European consensus on definition and diagnosis. Age Ageing. 2019.

9. Neumann S, Kwisda S, Krettek C, Gaulke R. Comparison of the Grip Strength Using the Martin-Vigorimeter and the JAMAR-Dynamometer: Establishment of Normal Values. In Vivo. 2017;31(5):917-24.

10. Shen Y, Chen J, Chen X, Hou L, Lin X, Yang M. Prevalence and Associated Factors of Sarcopenia in Nursing Home Residents: A Systematic Review and Meta-analysis. J Am Med Dir Assoc. 2019;20(1):5-13.

11. Shechtman O, Sindhu BS. Grip Strength. In: ASTH, editor. Clinical Assessment Recommendations, 3rd edition2013.

12. Guralnik JM, Simonsick EM, Ferrucci L, et al. A short physical performance battery assessing lower extremity function: association with self-reported disability and prediction of mortality and nursing home admission. J Gerontol. 1994;49(2):M85-94.

13. Morris JN, Fries BE, Mehr DR, et al. MDS Cognitive Performance Scale. J Gerontol. 1994;49(4):M174-82.

14. Arnold CM, Warkentin KD, Chilibeck PD, Magnus CR. The reliability and validity of handheld dynamometry for the measurement of lower-extremity muscle strength in older adults. Journal of strength and conditioning research / National Strength \& Conditioning Association. 2010;24(3):815-24. 
15. Kim HJ, Park I, Lee HJ, Lee $\mathrm{O}$. The reliability and validity of gait speed with different walking pace and distances against general health, physical function, and chronic disease in aged adults. J Exerc Nutrition Biochem. 2016;20(3):4650.

16. Fried LP, Tangen CM, Walston J, et al. Frailty in older adults: evidence for a phenotype. J Gerontol A Biol Sci Med Sci. 2001;56(3):M146-56.

17. Landis JR, Koch GG. The measurement of observer agreement for categorical data. Biometrics. 1977;33(1):159-74.

18. Casas-Herrero A, Cadore EL, Zambom-Ferraresi F, et al. Functional capacity, muscle fat infiltration, power output, and cognitive impairment in institutionalized frail oldest old. Rejuvenation Res. 2013;16(5):396-403.

19. Eriksrud O, Bohannon RW. Relationship of knee extension force to independence in sit-to-stand performance in patients receiving acute rehabilitation. Physical therapy. 2003;83(6):544-51.

20. Mehmet $\mathrm{H}$, Yang AWH, Robinson SR. What is the optimal chair stand test protocol for older adults? A systematic review. Disabil Rehabil. 2019:1-8.

21. McGrath RP, Kraemer WJ, Snih SA, Peterson MD. Handgrip Strength and Health in Aging Adults. Sports Med. 2018;48(9):1993-2000.

22. Franzon $\mathrm{K}$, Zethelius $\mathrm{B}$, Cederholm $\mathrm{T}$, Kilander $\mathrm{L}$. The impact of muscle function, muscle mass and sarcopenia on independent ageing in very old Swedish men. BMC Geriatr. 2019;19(1):153.

23. Wisniowska-Szurlej A, Cwirlej-Sozanska A, Woloszyn N, Sozanski B, Wilmowska-Pietruszynska A. Association between Handgrip Strength, Mobility, Leg Strength, Flexibility, and Postural Balance in Older Adults under Long-Term Care Facilities. Biomed Res Int. 2019; 2019:1042834.

24. Alcazar J, Losa-Reyna J, Rodriguez-Lopez C, et al. The sit-to-stand muscle power test: An easy, inexpensive and portable procedure to assess muscle power in older people. Experimental gerontology. 2018; 112:38-43.

25. Lord SR, Murray SM, Chapman K, Munro B, Tiedemann A. Sit-to-stand performance depends on sensation, speed, balance, and psychological status in addition to strength in older people. J Gerontol A Biol Sci Med Sci. 2002;57(8):M539-43.

26. Perera S, Mody SH, Woodman RC, Studenski SA. Meaningful change and responsiveness in common physical performance measures in older adults. $\mathrm{J}$ Am Geriatr Soc. 2006;54(5):743-9.

27. Hardy SE, Perera S, Roumani YF, Chandler JM, Studenski SA. Improvement in usual gait speed predicts better survival in older adults. J Am Geriatr Soc. 2007;55(11):1727-34.

28. Middleton A, Fritz SL, Lusardi M. Walking speed: the functional vital sign. J Aging Phys Act. 2015;23(2):314-22.

29. Mlinac ME, Feng MC. Assessment of Activities of Daily Living, Self-Care, and Independence. Arch Clin Neuropsychol. 2016;31(6):506-16. 
30. Cesari M, Onder G, Russo A, et al. Comorbidity and physical function: results from the aging and longevity study in the Sirente geographic area (iISIRENTE study). Gerontology. 2006;52(1):24-32. 


\section{Chapter 5}

\section{Quadriceps muscle strength is a discriminant predictor of dependence in daily activities in nursing home residents}

This study was designed to address research aim 4 and evaluated the relationship between muscle characteristics of knee extensor and elbow flexor muscles, physical function and ADL performance in nursing-home residents.

The chapter has been reformatted from the published article:

Wearing J, Stokes M, de Bruin ED: Quadriceps muscle strength is a discriminant predictor of dependence in daily activities in nursing home residents. PLoS ONE (2019) 14(9)

Contributions of co-authors:

M. Stokes contributed to study design, statistical analysis, data interpretation, and preparation critical revision of the manuscript.

E.D. de Bruin contributed to study conception and design, statistical analysis and interpretation, and preparation and critical revision of the manuscript. 


\subsection{Abstract}

Objective: This study aimed to explore the relationship between dependence in Activities of Daily Living and muscle strength, muscle morphology and physical function in older nursing home residents, taking possible confounders into consideration.

Methods: A total of 30 nursing home residents (age, 85.6 \pm 7.1 years) were included in this observational cross-sectional study. Performance of basic Activities of Daily Living (ADL) was assessed with the Resident Assessment Instrument and categorized as either independent or dependent. Isometric grip, quadriceps and elbow-flexor strength were determined by hand-dynamometry, muscle thickness and echo intensity by Bmode ultrasonography, a sit-to-stand task by using a stop watch and physical activity by the German-Physical-Activity Questionnaire. Degree of frailty was evaluated according to Fried's frailty criteria, whereas cognition, depression, incontinence, pain and falls were part of the Resident Assessment Instrument.

Results: Dependence in Activities of Daily Living was negatively correlated with physical activity $\left(r_{s}=-0.44, p=.015\right)$, handgrip $\left(r_{s}=-0.38, p=.038\right)$, elbow-flexor $\left(r_{s}=-0.42\right.$, $p=.032)$ and quadriceps strength $\left(r_{s}=-0.67, p<.001\right)$, analysed by Spearman's correlation. Chronic diseases $\left(r_{s}=-0.41, p=.027\right)$ and incontinence $\left(r_{s}=-0.39, p=.037\right)$ were positively correlated with $A D L$ while the other variables were not related. Only quadriceps strength remained significant with logistic regression (Wald (1) $=4.7, p=.03$ ), when chronic diseases, quadriceps and handgrip strength were considered $\left(R^{2} .79\right)$. $11 \mathrm{~kg}$ was the best fitting value in this sample to predict performance in Activities of Daily Living, evaluated with Receiver-Operating Characteristic analysis, with a sensitivity of $100 \%$ and a specificity of $79 \%$.

Conclusion and implication: Quadriceps strength had a positive independent relationship with performance in ADL in the nursing home residents studied. Although a large prospective study is needed to verify the results, maintaining quadriceps strength above $11 \mathrm{~kg}$ may be helpful in retaining independence in this cohort. 


\subsection{Introduction}

In $2017,15.7 \%$ of the Swiss population aged 80 years and over were institutionalized [1]. The demand for long-term care is expected to expand [2] since life expectancy will continue to increase in industrialized countries [3], with an expected rise of the old-old population by $300 \%$ in 2050 [4]. Admission of older persons to nursing homes is dependent on cognitive and/or functional impairment in combination with a lack of assistance in daily home life, which often leads to dependence in activities of daily living (ADL) [5]. In 30-50\% of these people, dependence actually increases within the first 18 months of institutionalization due to further functional decline [6, 7], which adversely affects quality of life [8] and health care costs [7]. Prevention of physical decline in nursing home residents is, therefore, essential to maintain a certain amount of independence, with beneficial effects for the individual as well as for the health care system.

The ability of nursing home residents to perform ADL independently is associated with multiple factors, both modifiable and non-modifiable, but is mainly dependent on age, chronic disease and disability, with the latter factor being the most discriminant predictor [9]. Physical disability in old age is highly associated with low muscle strength, which decreases progressively due to an age-related decline in muscle mass and quality [10]. Muscle strength is reduced by up to $50 \%$ in people aged 80 years and over [11], with highest rates of loss in physically inactive individuals [12, 13] that are institutionalized in nursing homes [14].

Previous studies involving community dwelling older people have shown the relevance of quadriceps strength for e.g. independent performance of sit-to-stand tasks $[15,16]$ and the effortless execution of ADL [15, 17]. In older people in need of long-term care, only a few studies investigated whether quadriceps strength relates to the level of required care and findings were inconclusive [18-20]. A positive association between quadriceps strength and ADL performance was confirmed by intervention studies that have shown training to be effective in improving physical function even in non-healthy, non-robust, ADL-dependent older adults suffering from disuse-related muscle weakness [21-26]. However, the optimal program remains unclear [23]. Therefore, specifying the underlying physical determinants of dependence in basic ADL of institutionalized older adults would help to determine the most important component of a specific training program.

In the present study, we aimed to investigate whether muscle structure, strength, function or physical activity were predictive variables of dependence in ADL in nursing home residents, when accounting for cognition, depression, falls, incontinence, chronic disease, sedative medication and pain. 


\subsection{Methods}

\section{Study Design}

A cross-sectional study of muscle characteristics and physical function of nursing home residents was undertaken in a long-term care institution in Switzerland between August and December 2017. Recruitment targeted older adults, aged 65 years and over. Exclusion criteria were a) an inability to understand study content and provide sign informed consent; b) severely impaired decision making (Cognitive performance scale > 4 points) [27]; c) a history of acute lower limb pathology (fracture and/or surgery within the last 6 months); d) skin disorders involving the anterior thigh and/or arm; e) limb paralysis; and f) confinement to bed.

Nursing home residents were screened by the senior nurse for exclusion criteria based on the last RAl assessment. Only participants who were deemed competent to consent and voluntarily agreed to participate were considered for study inclusion. All study procedures complied with the principles of the Declaration of Helsinki for ethical research in humans and the study received approval from the local ethics committee (project-ID 2017-00839).

Details are presented in the following report, which adheres to the reporting guidelines for cross-sectional studies [28].

\section{Sample size}

Sample size was calculated a priori using published data for quadriceps strength in nursing home residents [20]. A total sample size of 19 participants was required to ensure sufficient statistical power $(\beta=0.2)$ to detect a $25 \%$ difference in strength between ADL independent and dependent groups $(\alpha=.05)$. It has been previously shown that disabled older adults, as defined by self-reported independence in basic and instrumental ADL, exhibit up to $50 \%$ lower muscle strength than non-disabled individuals [17].

\section{Data collection \\ Participant demographics}

Participant demographics, medications history, medical history and independence in ADL were obtained using of the Long-Term Care Facility Resident Assessment Instrument (RAI; Minimum Data Set Version 2.0). For assessment of ADL, urinary incontinence, cognitive performance and depressive symptoms, observations were judged and encoded by one of four nurses who were experienced RAl-item coders. All nurses had received the same training on the use of the tool in its application. Detailed RAl items are shown in Table 1. 
Table 1: Items of the Resident Assessment Instrument obtained from the study participants

\begin{tabular}{|c|c|}
\hline RAl items & Units and classification \\
\hline age & years \\
\hline height & meters \\
\hline weight & kilogram \\
\hline urinary continence & $\begin{array}{l}\text { 4-point-scale from } 0 \text { (= continent) to } 4 \text { (= always } \\
\text { incontinent, no bladder control) }\end{array}$ \\
\hline pain intensity & $\begin{array}{l}\text { Numeric Analog Scale from } 0 \text { (= no pain) to } 10 \text { (=worst } \\
\text { pain) }\end{array}$ \\
\hline falls & frequency within last three months \\
\hline cognitive performance & $\begin{array}{l}\text { Minimum Data Set Cognitive Performance Scale (scale } \\
\text { ranging from } 0 \text { (= intact cognition) to } 6 \text { (= severely } \\
\text { limited cognition) }\end{array}$ \\
\hline $\begin{array}{l}\text { frequency of depressive } \\
\text { symptoms }\end{array}$ & $\begin{array}{l}\text { scale from } 0 \text { (symptoms weren't shown) to } 2 \text { (symptoms } \\
\text { shown on } 6 / 7 \text { days/week) }\end{array}$ \\
\hline $\begin{array}{l}\text { amount and type of } \\
\text { chronic diseases }\end{array}$ & $\begin{array}{l}\text { metabolic, musculoskeletal, neurological, psychiatric, } \\
\text { respiratory disease, renal insufficiency, vertigo and } \\
\text { cancer }\end{array}$ \\
\hline $\begin{array}{l}\text { regular intake of } \\
\text { medication }\end{array}$ & antidepressants, sedatives and muscle relaxants \\
\hline $\begin{array}{l}\text { self-performance in } \\
\text { activities of daily living } \\
\text { (ADL) }\end{array}$ & $\begin{array}{l}\text { bed mobility, transfer, walking in a room, walking in a } \\
\text { corridor, locomotion on the ward, locomotion outside the } \\
\text { ward, dressing, eating/drinking, toilet use and personal } \\
\text { hygiene over the past } 7 \text { days, } \\
\text { each rated on a scale from } 0 \text { (independent) to } 4 \text { (fully } \\
\text { dependent), full range of possible outcome } 0-40 \text {. } \\
\text { Categorization as independent in ADL when total score } \\
=0 \text {, which reflected no need for assistance or staff } \\
\text { oversight. Categorization as dependent when total } \\
\text { score } \geq 1 \text {, which reflected a need for assistance or staff } \\
\text { oversight in at least one activity }\end{array}$ \\
\hline
\end{tabular}

One investigator, a physiotherapist, trained and experienced in musculoskeletal assessments and ultrasonography, completed the following test series for all participants. 


\section{Muscle strength}

Maximal isometric quadriceps and elbow-flexor muscle strength, as the highest of two trials, was evaluated using a hand-held dynamometer (Microfet2 ${ }^{\circledR}$, CompuFET, Hoggan Health Industries, Biometrics Europe). For measurement of elbow-flexor strength, the participant was seated on a chair, elbow flexed at $90^{\circ}$ and forearm supinated. For measurement of quadriceps strength, the participant was seated on a plinth, with their back resting against a firm support, thighs fully supported, knees flexed to $90^{\circ}$ and the lower legs hanging freely. The curved transducer pad of a handheld dynamometer was positioned at $80 \%$ of the forearm and tibial length respectively, to resist maximal isometric force of the elbow flexors and quadriceps. The participants were asked to push against the dynamometer as hard as possible for 3 seconds. Strength was measured in Newtons $(N)$, and converted into Kilograms (kg) by dividing $\mathrm{N}$ by 9.81 . Torque was calculated in Newtonmeters $(\mathrm{Nm})$ by multiplying force by the lever arm length of the forearm and tibia respectively. Hand-held dynamometry has been shown to be a valid and reliable technique to assess isometric strength in older adults [29, 30]. Test-retest reliability of hand-held dynamometry is high when assessed by a trained examiner using a standardized protocol [31]; with intra-rater reliability Intraclass Correlation Coefficient (ICC) ranging between 0.90 and 0.98 [29].

Handgrip strength was measured with a hand dynamometer (Jamar®, Lafayette, USA) according to the standardized protocol recommended by the American Society of hand therapists [32].

\section{Muscle morphology}

Real-time, B-mode ultrasonography (Nemio MX Type SSA-590A, Toshiba, Japan) with a $12 \mathrm{MHz}$ linear transducer array (45 mm footprint) was used to obtain transverse images of the dominant extremities. Images of the rectus femoris/vastus intermedius as well as the biceps brachii/brachialis were taken using a previously published protocol for community-dwelling older adults [33, 34], and post-processed using semiautomated MATLAB code (MathWorks ${ }^{\circledR}$, Massachusetts, USA). Muscle thickness and primary muscle echotexture statistics were subsequently calculated, with the mean of two images taken for further analysis.

The thickness of the muscles was defined as the distance between the inner border of the fascial layer that distinguishes muscles from superficial fat and bone. Ultrasoundbased measures of thigh tissue thickness are highly correlated with the gold standard of Magnetic Resonance Imaging ( $r=0.99)$ [35] and have a reported intra-rater reliability of ICC 0.88-0.99 in older people [33, 36].

For grayscale analysis, settings of the ultrasound scanner (gain, time gain control, dynamic range value, focus and power) were adjusted to assure good quality of the images and kept constant for all participants; depth was readjusted to individual muscle thickness. Echogenicity of rectus femoris and biceps brachii was defined as the average grayscale within a rectangular region of interest and recorded as unspecified units (UU) 0-255. The analysis method has been previously shown to have high intrarater reliability, with a reported ICC of 0.97-0.99 [37]. High muscle echo intensity is 
associated with low tissue density in CT scans [38] and high adipose tissue content in muscle biopsies [39].

\section{Functional mobility}

Functional mobility was estimated using the sit-to-stand task repeated 5 times [40]. A chair with a straight backrest, $40 \mathrm{~cm}$ seat height and without armrests was placed against a solid support. Participants were instructed to complete 5 sit-to-stand maneuvers as fast as possible without the use of their arms. The time taken for completion was recorded. Times in excess of 13.6 seconds are associated with increased disability [41].

\section{Physical activity}

The German physical activity 50+ questionnaire was used to calculate energy expenditure (kcal/week) [42]. The questionnaire has a test-retest reliability of $r=0.52-$ 0.6 [42] and is widely used in German speaking countries to evaluate physical activity in older people.

\section{Frailty}

Physical frailty was evaluated according to Fried's frailty criteria [43]. Participants were characterized as "not frail", "pre-frail" or "frail" according to the number of positive criteria identified (0, 1-2 and $\geq 3$, respectively).

\section{Statistical Analysis}

The Statistical Package for the Social Sciences (SPSS Statistics, Version 23.0. IBM Corporation, Armonk, NY) was used for analysis. Shapiro-Wilk test was used to test for normality. Dependent on data distribution, descriptive statistics are presented as mean \pm standard deviation or median (range); differences between the ADL groups were analyzed using independent t-tests and Mann-Whitney-U-test. Relationships of ADL performance with independent variables were identified by Spearman's correlation coefficients and binary logistic regression analysis. Receiver-Operating Characteristic (ROC) curve was utilized for sensitivity/specificity analysis of predictors of ADL performance. 


\subsection{Results}

\section{Characteristics of study population}

Of 177 nursing home residents who were screened, 30 fulfilled the eligibility criteria and were included in the study (mean age (SD) 85.7 (7.1) years, 76.7\% female). 43\% of the study sample were categorized as pre-frail, $57 \%$ as frail, $97 \%$ had $\geq$ two chronic diseases, $30 \%$ experienced depressive symptoms, $20 \%$ took sedative medication, $62 \%$ were cognitively impaired, while $70 \%$ were diagnosed with dementia, $23 \%$ had fallen, $34 \%$ experienced pain and $28 \%$ were incontinent. Four participants were excluded from strength measurements due to concerns associated with the risk of osteoporotic fracture and 14 were incapable of rising from a chair without using their arms. Given that only half of the participants could rise from a chair 5 times without using their arms, functional mobility was dichotomized into the categories "able to complete 5STS" and "unable to complete 5STS" for further analysis.

Of the 30 participants, 16 were categorized as independent and 14 as dependent in ADL based on items of the RAI. There were no statistically significant differences between groups in terms of age, weight, height, number of years institutionalized, medication history, as well as for muscle morphology, functional mobility and physical activity. The group dependent in ADL experienced a significantly higher number of chronic diseases and more severe incontinence, lower handgrip, elbow-flexor and quadriceps strength. Quadriceps strength of participants independent in ADL was greater by a median of $4.3 \mathrm{~kg}$ than those dependent in ADL (Fig 1).

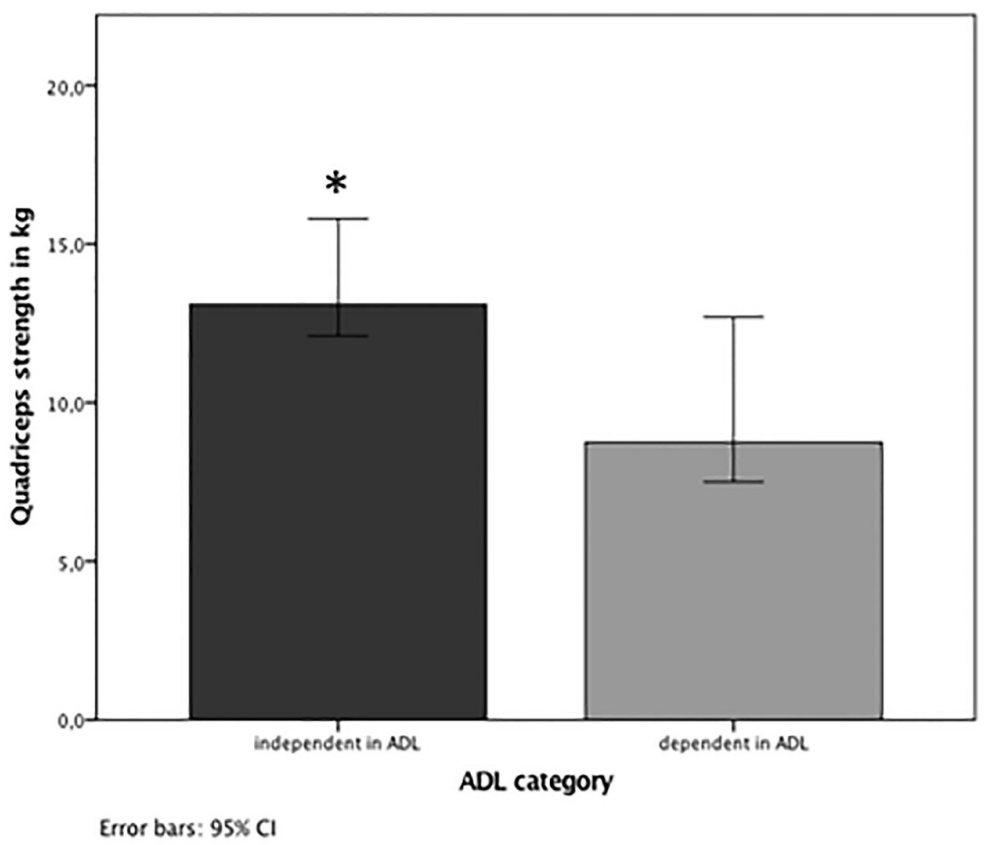

*significant difference between groups

Fig 1: Quadriceps strength in people independent and dependent in ADL

Characteristics of participants are presented in Table 2. 
Table 2: Participants' characteristics of the ADL dependent and independent group

\begin{tabular}{|c|c|c|c|c|}
\hline \multirow[t]{3}{*}{$\begin{array}{l}\text { Characteristic } \\
\text { (unit) }\end{array}$} & \multirow{3}{*}{$\begin{array}{l}\text { ADL } \\
\text { independent } \\
\text { Mean (SD)/ } \\
\text { Median (range) }\end{array}$} & \multirow{3}{*}{$\begin{array}{l}\text { ADL } \\
\text { dependent } \\
\text { Mean (SD)/ } \\
\text { Median (range) }\end{array}$} & \multicolumn{2}{|c|}{$\begin{array}{l}\text { equality of means/ } \\
\text { medians }\end{array}$} \\
\hline & & & \multirow[t]{2}{*}{$t / U$} & \multirow[t]{2}{*}{$\mathrm{p}$} \\
\hline & & & & \\
\hline \multicolumn{5}{|l|}{ Demographics } \\
\hline Age $^{\dagger}$ (years) & $87.0(15)$ & $86.0(35)$ & $U=100.5$ & .64 \\
\hline Weight $^{\dagger}(\mathrm{kg})$ & $66.5(52.2)$ & $68.0(51)$ & $U=98.0$ & .58 \\
\hline Height $^{\dagger}(m)$ & $1.64(0.23)$ & $1.59(0.21)$ & $U=80.5$ & .19 \\
\hline Incontinence (0-4 points) & $0(1)$ & $0(4)$ & $U=68$ & $.038^{*}$ \\
\hline Pain intensity (0-10) & $0.53(0.74)$ & $0.64(1.60)$ & $\mathrm{t}(18.1)=-.234$ & .82 \\
\hline Falls (number) & $0.63(1.63)$ & $0.29(0.47)$ & $\mathrm{t}(17.8)=.797$ & .44 \\
\hline Cognitive performance (0-6) & $1.0(3)$ & $2.0(3)$ & $U=79$ & .24 \\
\hline Depressive symptoms (0-32) & $1.62(3.95)$ & $0.71(1.27)$ & $t(25)=0.815$ & .42 \\
\hline Chronic diseases (number) & $2.75(1.24)$ & $3.86(1.29)$ & $t(27.1)=-2.387$ & $.024^{*}$ \\
\hline Medication (number) & $0.81(0.40)$ & $0.79(0.43)$ & $\mathrm{t}(27.0)=.176$ & .86 \\
\hline Institutionalization (years) & $2.9(2.2)$ & $3.4(1.8)$ & $\mathrm{t}(27.8)=-.572$ & .57 \\
\hline \multicolumn{5}{|l|}{ Muscle strength } \\
\hline Handgrip strength ${ }^{\dagger}(\mathrm{kg})$ & $16.0(22)$ & $13.3(13)$ & $U=63.0$ & $.043^{*}$ \\
\hline Quadriceps strength ${ }^{\dagger}(\mathrm{kg})$ & $13.1(5.7)$ & $8.8(6.9)$ & $U=18.5$ & $<.001^{*}$ \\
\hline Quadriceps strength ${ }^{\dagger}(N)$ & $128.2(56.4)$ & $85.4(63.3)$ & $U=18.5$ & $<.001^{*}$ \\
\hline Strength/body weight (N/kg) & $2.1(0.7)$ & $1.4(0.4)$ & $\mathrm{t}(16.7)=2.797$ & $.013^{*}$ \\
\hline Quadriceps torque ${ }^{\dagger}(\mathrm{Nm})$ & $39.1(18.8)$ & $26.8(20.3)$ & $U=20$ & $.001^{*}$ \\
\hline Torque/body weight $(\mathrm{Nm} / \mathrm{kg})$ & $0.6(0.2)$ & $0.4(0.1)$ & $t(16.9)=2.763$ & $.013^{*}$ \\
\hline Elbow-flexor strength ${ }^{\dagger}(\mathrm{kg})$ & $9.7(7.3)$ & $7.0(9.5)$ & $U=43.0$ & $.036^{*}$ \\
\hline \multicolumn{5}{|l|}{ Muscle morphology } \\
\hline Quadriceps thickness (mm) & $17.7(4.7)$ & $18.7(6.7)$ & $t(28)=-.465$ & .65 \\
\hline Rectus femoris grayscale ${ }^{\dagger}(U U)$ & $117.2(78)$ & $115.5(101)$ & $U=109.0$ & .92 \\
\hline Elbow-flexor thickness ${ }^{\dagger}(\mathrm{mm})$ & $24.8(18)$ & $26.5(16)$ & $U=111$ & .98 \\
\hline Biceps brachii grayscale $^{\dagger}(U U)$ & $132(81)$ & $133(86)$ & $U=111$ & .98 \\
\hline \multicolumn{5}{|l|}{ Functional mobility } \\
\hline 5 sit-to-stand (sec) & $20.3(11.6)$ & $20.6(12.3)$ & $\mathrm{t}(8.0)=-.051$ & .96 \\
\hline Physical activity (kcal/week) & $842(879)$ & $508(1347)$ & $\mathrm{t}(21.9)=.792$ & .44 \\
\hline
\end{tabular}

${ }^{*}$ significant difference, ${ }^{\dagger}$ data not normally distributed, differences determined with the Mann-Whitney$U$ test, $p$ equates exact significance 
Quadriceps strength, in the present study, was not related to body weight. Therefore, actual strength values in $\mathrm{kg}$ were used for analysis. To aid comparison with previous research, quadriceps strength was also expressed as a ratio of strength $[(\mathrm{N}) / \mathrm{body}$ weight $(\mathrm{kg})]$.

Of the group that was independent in ADL $(n=16), 9$ participants could complete the 5STS, while 7 could not. Of the group that was dependent in ADL ( $n=14), 5$ participants could complete the 5STS, while 9 were not able to complete the 5STS.

\section{Correlations of ADL category with demographics, medical and medications history}

The level of ADL dependence significantly correlated with a higher number of comorbidities $\left(r_{s}=.41, p=.027\right)$ and incontinence $\left(r_{s}=.39, p=.037\right)$, but was not associated with sex, age, falls, cognitive performance, sedative medication, depressive mood, pain or physical frailty at the univariate level (S1 Appendix).

\section{Correlations of ADL category with muscle strength, muscle morphology, functional mobility and physical activity}

Dependence in ADL was weakly associated with lower handgrip strength $\left(r_{s}=-0.38\right.$, $p=.038)$, lower elbow-flexor strength $\left(r_{s}=-0.42, p=.032\right)$ and lower physical activity $\left(r_{s}=-\right.$ $0.44, p=.015)$ but moderately correlated with lower quadriceps strength $\left(r_{s}=-0.67\right.$, $p<.001)$. There was no correlation of ADL dependence with muscle morphology and functional mobility/the ability to rise from a chair 5 times (S2 Appendix).

\section{Regression and ROC analysis}

To determine factors that were predictive of ADL performance, binary logistic regression was undertaken iteratively using different combinations of covariates, including the factor with the highest correlation with ADL (quadriceps strength) and factors that were moderately correlated with ADL (handgrip strength, elbow-flexor strength, urinary incontinence and number of chronic diseases) at the univariate level (S1 and S2 Appendix).

The combination of variables that best explained the variance in ADL performance included quadriceps strength, chronic diseases and handgrip strength (S3 Appendix). Approximately $79 \%$ of the variance was explained by these three factors (Nagelkerke's $\mathrm{R}^{2}=0.786$ ). However, quadriceps strength was the only independent predictor of dependence with an Odds Ratio (OR) of $0.353(95 \% \mathrm{Cl} 0.138-0.905, p=.030)$, indicating a $65 \%$ lower risk of being dependent when quadriceps strength increased by $1 \mathrm{~kg}$ (Table 3$)$. 
Table 3

Binary logistic regression with inclusion analysis of the variables quadriceps strength, chronic diseases and physical activity

\begin{tabular}{lllllll}
\hline predictor & $\begin{array}{l}\text { Regression } \\
\text { coefficient }(B)\end{array}$ & $\begin{array}{l}\text { Significance } \\
\text { level }(\mathrm{p})\end{array}$ & $\begin{array}{l}\operatorname{Exp}(\mathrm{B})=\mathrm{O} \\
\mathrm{R}\end{array}$ & & $\begin{array}{l}95 \% \\
\text { Exp(B) }\end{array}$ & $\mathrm{Cl}$ for \\
\cline { 3 - 6 } & & & & & & \\
\hline quadriceps strength & -1.040 & .030 & 0.353 & 0.138 & 0.905 \\
chronic diseases & 1.325 & .074 & 3.763 & 0.877 & 16.139 \\
handgrip strength & -.213 & .390 & 0.809 & 0.498 & 1.313 \\
constant & 10.863 & .067 & 52183.975 & & \\
\hline
\end{tabular}

The ROC curve for analysis of sensitivity and specificity of quadriceps strength to identify people independent and dependent in ADL showed an area under the curve of 0.89 . Strength of $11.25 \mathrm{~kg}$ was the best fitting value with a sensitivity of $100 \%$ and a specificity of $79 \%$. Sensitivity and specificity of quadriceps strength values are shown in Table 4. 
Table 4

Coordinates of ROC curve analysis for accuracy of quadriceps strength in detecting residents of nursing homes dependent in ADL

\begin{tabular}{|c|c|c|}
\hline $\begin{array}{l}\text { Quadriceps strength }(\mathrm{kg}) \\
\text { greater than or equal to }\end{array}$ & Sensitivity & 1-specificity \\
\hline 5.800 & 1.000 & 1.000 \\
\hline 7.000 & 1.000 & .929 \\
\hline 7.350 & 1.000 & .857 \\
\hline 7.550 & 1.000 & .786 \\
\hline 7.900 & 1.000 & .643 \\
\hline 8.450 & 1.000 & .571 \\
\hline 8.750 & 1.000 & .500 \\
\hline 9.300 & 1.000 & .429 \\
\hline 10.150 & 1.000 & .357 \\
\hline 10.600 & 1.000 & .286 \\
\hline$\ddagger_{11} .250$ & 1.000 & .214 \\
\hline 11.950 & .833 & .214 \\
\hline 12.150 & .750 & .214 \\
\hline 12.300 & .667 & .214 \\
\hline 12.550 & .583 & .214 \\
\hline 12.850 & .583 & .143 \\
\hline 13.100 & .500 & .071 \\
\hline 13.350 & .417 & .071 \\
\hline 13.600 & .333 & .071 \\
\hline 13.900 & .333 & 0.000 \\
\hline 14.950 & .250 & 0.000 \\
\hline 16.650 & .083 & 0.000 \\
\hline 18.500 & 0.000 & 0.000 \\
\hline
\end{tabular}

${ }^{\ddagger}$ Best fitting quadriceps strength value to detect dependent/independent performance of ADL 


\subsection{Discussion}

This study aimed to evaluate potential muscle-related predictors of dependence in ADL in nursing homes residents, taking cognitive function, depression, pain, urinary incontinence, chronic diseases, medication and falls into consideration.

Of the investigated parameters, greater handgrip-strength, elbow-flexor strength, quadriceps strength and physical activity, as well as less incontinence and chronic diseases, were positively associated with the ability to independently perform basic ADL whereas quadriceps strength was the only independent predictor.

The positive relationship observed between quadriceps strength and ADL performance is consistent with a previous study in which functional performance was evaluated in older people with dementia in need of long-term care [20]. ADL-independent participants in their study had $40-45 \%$ higher strength than ADL-dependent, while ours differed by about $33 \%$. Suzuki and colleagues specifically included people diagnosed with dementia, whereas the present study also included participants without dementia and of different cognitive performance levels. Interestingly, neither quadriceps strength nor ADL dependence was related to cognitive performance in our population. This is opposed to previously reported findings [44] and might be due to the small size of our sample.

The present findings do not correspond with other studies in which the level of care was observed to be independent of quadriceps strength in old, physically disabled people $[18,19]$. These earlier studies differed in regard to the assessment instrument (care time [19], respectively a non-specified instrument [18] versus RAI), included ADL (basic and instrumental ADL [19] respectively non-specified assessment [18] versus basic $A D L)$ and categorization of $A D L$ performance (3-point scale [18, 19] versus dichotomous classification). However, the main difference is potentially the type of ADL on which the categorization is based. In contrast to most basic activities, many instrumental $A D L$, such as the regulation of finances and telephone use, do not require appreciable quadriceps strength. Hence, it could be expected that when ADL dependence is categorized on the basis of instrumental activities, it is unlikely to be correlated with quadriceps strength.

Consequently, the present study adds the following new information to previous findings: 1. the relationship between low quadriceps strength and $A D L$ dependence may be valid for residents in nursing homes independent of cognitive performance; 2 . quadriceps strength not only has a significant relation to dependence in basic ADL but also has a strong independent association with $A D L$ dependence regardless of muscle structure, muscle function, physical activity and important confounding factors of demographics, medical and medication history.

It is an interesting outcome that low quadriceps strength but not low muscle thickness or high echo intensity was associated with $\mathrm{ADL}$ dependence. One possible explanation for this finding could be that a decline in motor cortical properties rather than changes in muscle morphology accounted for low voluntary strength in our population. Muscle weakness associated with aging has diverse underlying mechanisms and is not solely explained by atrophy of muscle [45]. The nervous system's overall ability to maximally activate a muscle, including descending drive from the motor cortex, also declines with 
age and significantly contributes to decreased voluntary contraction of available musculature [46]. Particularly in older-old individuals, voluntary activation, defined as "the level of voluntary drive during an effort" [47, 48] is diminished [49-51] and may account for up to one third of the loss in force production [52].

Furthermore, it seems contradictory that an older person may have adequate quadriceps strength to rise from a chair independently but is not able to complete the repeated sit-to-stand exercise (5STS). However, while poor performance on the STS test (>10-13 seconds) has been shown to predict incidence of disability in older community-living older adults $[40,53]$, its sensitivity is limited $(50 \%)$ and its clinical use could be largely restricted to high functioning, community-living older people [54]. Quadriceps strength is one important underlying precondition of the ability to stand up from a chair [55], however, it is not the only determinant. In most elderly nursing home residents the ability to rise from a standard-height chair is also dependent on the use of arms and arm rests [56] and, when not constrained by artificially imposed time limits, may still be performed independently. Completion of the 5STS test, in comparison, requires more complex abilities, as it is performed without the use of arms and is timed. Hence, the 5STS test needs coordinated contraction and high contraction speed (power) of multiple lower extremity muscles, including the gluteal and ankle dorsi flexor muscles [57-59]. Secondly, successful completion of 5STS also requires balance, proprioception and tactile sensation [58], all of which also decrease with age and disease. Thirdly, voluntary functional strength in older people might be mainly explained by reduced voluntary activation due to changes in central and peripheral nervous systems [46]. The functional mobility task of 5STS with its physical requirements, therefore, may not reflect the abilities necessary to live an ADL independent, nursing home life. Rather, quadriceps strength would appear to be a better predictor of ADL disability than the 5STS test in this population of lesser functioning older people.

An isometric quadriceps strength of $>11 \mathrm{~kg}$ predicted ADL-independence by $100 \%$ and ADL-dependence by $79 \%$ in this study sample. The findings show that quadriceps strength was of high importance for explaining the variance in ADL performance; an improvement of $1 \mathrm{~kg}$ lowers the risk of becoming dependent by $65 \%$. Interventional studies have shown that exercise programs of 8-12 weeks, including resistance exercises 2-3 times weekly, were effective in increasing quadriceps strength in older, nursing home residents by a minimum of $3 \mathrm{~kg}[\underline{18}, \underline{22}]$. Thus, nursing home residents with physical disability may be able to improve ADL independence through quadriceps strengthening. This finding supports the call for preventive measures to avoid functional decline in nursing home dwellers [7].

Previous research has established that quadriceps strength differs significantly in community living older people independent in ADL (3.5-3.8 N/kg) from those partially dependent (2.2-2.9 N/kg) [15], when independence is considered as being able to e.g. walk $50 \mathrm{~m}$ without any personal or device support and without loss of normal speed and safety. In comparison, the present study showed that frail, disabled, nursing home residents of the same age were only half as strong, with the independent group having a median strength of $2.1 \mathrm{~N} / \mathrm{kg}$, compared to the ADL dependent group with median 
strength of $1.4 \mathrm{~N} / \mathrm{kg}$. However, approximately half of the participants could still perform usual nursing-home ADL, such as walking a few meters with a walker and rising from a chair with the use of arm rests, without supervision or assistance of another person. Some limitations of this cross-sectional study should be mentioned. Firstly, observations by nursing staff of behavior and emotions by nursing staff entailed the risk that some actions of the participants could have been unrecognized and therefore not recorded adequately. However, the observation period included seven days in which residents were closely observed by a trained nurse attentive to precise assessment. Therefore, the risk of information bias was likely to be small. Even though RAl data were obtained by different assessors, data can still be assumed sufficiently reliable since inter-rater reliability of the RAI items has been shown to be $0.63-0.92$ (weighted Kappa) [60]. Secondly, physical activity measures were based on self-report and behavioral observations of nursing staff. Although previous studies have questioned the accuracy of self-reported measures of physical activity in older populations [61], participants were closely monitored during the study so that any discrepancy between reported and actual activity was likely to be small. Thirdly, the number of participants who could complete the timed sit-to-stand task was rather small. Findings with regard to this variable could therefore be underpowered. However, even when the participants were categorized into two groups depending on their ability to complete the task, results did not change. Therefore, the results were assumed to be valid for this cohort. Fourthly, a causal relationship between ADL performance and quadriceps strength cannot be made due to the nature of the cross-sectional study design. However, the results indicate a strong association between ADL dependence and low quadriceps strength and longitudinal studies have demonstrated beneficial effects of quadriceps' strength training on physical function [21-26]. Fifthly, the study sample only included participants from one nursing home. Therefore, the results of the sample might not be generalizable to a wider population of older, frail nursing home residents. The study did, however, include a wide variety of participants with regard to ADL performance. Therefore, the participants could be considered representative of the target population.

\section{Conclusions}

This study has shown that strength, physical activity and incontinence were potentially modifiable factors associated with ADL dependence in nursing home residents, with quadriceps strength being the only independent predictor of dependence in ADL, independent of age, frailty status, co-morbidities and cognitive function.

Although further research is required, interventions aimed at increasing these physical abilities with a specific focus on enhancing leg muscle strength beyond target threshold values may be a useful strategy for reducing dependence in ADL of nursing home dwellers. 


\subsection{References}

1. bfs. Gesundheit im Alter

https://www.bfs.admin.ch/bfs/de/home/statistiken/gesundheit/gesundheitszustan d/alter.html: Bundesamt für Statistik; 2017 [cited 2019 January 21].

2. Crimmins EM. Lifespan and Healthspan: Past, Present, and Promise. Gerontologist. 2015;55(6):901-11. doi: 10.1093/geront/gnv130. PubMed PMID: 26561272; PubMed Central PMCID: PMCPMC4861644.

3. Kontis V, Bennett JE, Mathers CD, Li G, Foreman K, Ezzati M. Future life expectancy in 35 industrialised countries: projections with a Bayesian model ensemble. Lancet. 2017;389(10076):1323-35. doi: 10.1016/S01406736(16)32381-9. PubMed PMID: 28236464; PubMed Central PMCID: PMCPMC5387671.

4. United Nations DoEaSA. World Population Ageing2017 January 21, 2019:[2-42 pp.].

5. Luppa M, Luck T, Weyerer S, Konig HH, Brahler E, Riedel-Heller SG. Prediction of institutionalization in the elderly. A systematic review. Age Ageing. 2010;39(1):31-8. doi: 10.1093/ageing/afp202. PubMed PMID: 19934075.

6. Jerez-Roig J, de Brito Macedo Ferreira LM, Torres de Araujo JR, Costa Lima K. Functional decline in nursing home residents: A prognostic study. PLoS One. 2017;12(5):e0177353 (1-14). doi: 10.1371/journal.pone.0177353. PubMed PMID: 28493946; PubMed Central PMCID: PMCPMC5426763.

7. Laffon de Mazieres C, Morley JE, Levy C, Agenes F, Barbagallo M, Cesari M, et al. Prevention of Functional Decline by Reframing the Role of Nursing Homes? J Am Med Dir Assoc. 2017;18(2):105-10. doi: 10.1016/j.jamda.2016.11.019. PubMed PMID: 28126135.

8. Luleci E, Hey W, Subasi F. Assessing selected quality of life factors of nursing home residents in Turkey. Arch Gerontol Geriatr. 2008;46(1):57-66. doi: 10.1016/j.archger.2007.02.007. PubMed PMID: 17433462.

9. Lane NE, Wodchis WP, Boyd CM, Stukel TA. Disability in long-term care residents explained by prevalent geriatric syndromes, not long-term care home characteristics: a cross-sectional study. BMC Geriatr. 2017;17(1):49. doi: 10.1186/s12877-017-0444-1. PubMed PMID: 28183274; PubMed Central PMCID: PMCPMC5301427.

10. Manini TM, Clark BC. Dynapenia and aging: an update. J Gerontol A Biol Sci Med Sci. 2012;67(1):28-40. Epub 2011/03/30. doi: 10.1093/gerona/glr010. PubMed PMID: 21444359; PubMed Central PMCID: PMC3260480.

11. Akima $\mathrm{H}$, Kano $\mathrm{Y}$, Enomoto $\mathrm{Y}$, Ishizu $\mathrm{M}$, Okada $\mathrm{M}$, Oishi $\mathrm{Y}$, et al. Muscle function in 164 men and women aged 20--84 yr. Med Sci Sports Exerc. 2001;33(2):2206. PubMed PMID: 11224809.

12. Bamman MM, Clarke MS, Feeback DL, Talmadge RJ, Stevens BR, Lieberman $\mathrm{SA}$, et al. Impact of resistance exercise during bed rest on skeletal muscle sarcopenia and myosin isoform distribution. Journal of applied physiology. 1998;84(1):157-63. doi: 10.1152/jappl.1998.84.1.157. PubMed PMID: 9451630.

13. Volkers KM, de Kieviet JF, Wittingen HP, Scherder EJ. Lower limb muscle strength (LLMS): why sedentary life should never start? A review. Arch Gerontol 
Geriatr. 2012;54(3):399-414. doi: 10.1016/j.archger.2011.04.018. PubMed PMID: 21601928.

14. Shen Y, Chen J, Chen X, Hou L, Lin X, Yang M. Prevalence and Associated Factors of Sarcopenia in Nursing Home Residents: A Systematic Review and Meta-analysis. J Am Med Dir Assoc. 2019;20(1):5-13. doi: 10.1016/j.jamda.2018.09.012. PubMed PMID: 30409494.

15. Azegami M, Ohira M, Miyoshi K, Kobayashi C, Hongo M, Yanagihashi R, et al. Effect of single and multi-joint lower extremity muscle strength on the functional capacity and ADL/IADL status in Japanese community-dwelling older adults. Nurs Health Sci. 2007;9(3):168-76. doi: 10.1111/j.1442-2018.2007.00317.x. PubMed PMID: 17688474.

16. Ploutz-Snyder LL, Manini T, Ploutz-Snyder RJ, Wolf DA. Functionally relevant thresholds of quadriceps femoris strength. J Gerontol A Biol Sci Med Sci. 2002;57(4):B144-52. PubMed PMID: 11909879.

17. Hairi NN, Cumming RG, Naganathan V, Handelsman DJ, Le Couteur DG, Creasey $\mathrm{H}$, et al. Loss of muscle strength, mass (sarcopenia), and quality (specific force) and its relationship with functional limitation and physical disability: the Concord Health and Ageing in Men Project. J Am Geriatr Soc. 2010;58(11):2055-62. doi: 10.1111/j.1532-5415.2010.03145.x. PubMed PMID: 21054284.

18. Fiatarone MA, Marks EC, Ryan ND, Meredith CN, Lipsitz LA, Evans WJ. Highintensity strength training in nonagenarians. Effects on skeletal muscle. Jama. 1990;263(22):3029-34. PubMed PMID: 2342214.

19. Ota A, Ohta M, Nakamura Y, Fukunaga T, Muraoka I. Strength and Thickness of Knee Extensor Muscles in Frail Elderly People at Different Levels of Certified Care Need. International Journal of Sport and Health Science. 2008;6:91-7. doi: 10.5432/ijshs.6.91.

20. Suzuki M, Kirimoto H, Inamura A, Yagi M, Omori Y, Yamada S. The relationship between knee extension strength and lower extremity functions in nursing home residents with dementia. Disabil Rehabil. 2012;34(3):202-9. doi: 10.3109/09638288.2011.593678. PubMed PMID: 21962209.

21. Aguirre LE, Villareal DT. Physical Exercise as Therapy for Frailty. Nestle Nutr Inst Workshop Ser. 2015;83:83-92. doi: 10.1159/000382065. PubMed PMID: 26524568; PubMed Central PMCID: PMCPMC4712448.

22. Cadore EL, Casas-Herrero A, Zambom-Ferraresi F, Idoate F, Millor N, Gomez M, et al. Multicomponent exercises including muscle power training enhance muscle mass, power output, and functional outcomes in institutionalized frail nonagenarians. Age. 2014;36(2):773-85. doi: 10.1007/s11357-013-9586-z. PubMed PMID: 24030238; PubMed Central PMCID: PMCPMC4039263.

23. de Labra C, Guimaraes-Pinheiro C, Maseda A, Lorenzo T, Millan-Calenti JC. Effects of physical exercise interventions in frail older adults: a systematic review of randomized controlled trials. BMC Geriatr. 2015;15:154 doi: 10.1186/s12877015-0155-4. PubMed PMID: 26626157; PubMed Central PMCID: PMCPMC4667405.

24. Krist L, Dimeo F, Keil T. Can progressive resistance training twice a week improve mobility, muscle strength, and quality of life in very elderly nursing-home 
residents with impaired mobility? A pilot study. Clin Interv Aging. 2013;8:443-8. doi: 10.2147/CIA.S42136. PubMed PMID: 23637524; PubMed Central PMCID: PMCPMC3639017.

25. Arrieta H, Rezola-Pardo C, Gil SM, Irazusta J, Rodriguez-Larrad A. Physical training maintains or improves gait ability in long-term nursing home residents: A systematic review of randomized controlled trials. Maturitas. 2018;109:45-52. doi: 10.1016/j.maturitas.2017.12.003. PubMed PMID: 29452781.

26. Arrieta H, Rezola-Pardo C, Gil SM, Virgala J, Iturburu M, Anton I, et al. Effects of Multicomponent Exercise on Frailty in Long-Term Nursing Homes: A Randomized Controlled Trial. J Am Geriatr Soc. 2019;67(6):1145-51. doi: 10.1111/jgs.15824. PubMed PMID: 30891748.

27. Morris JN, Fries BE, Mehr DR, Hawes C, Phillips C, Mor V, et al. MDS Cognitive Performance Scale. J Gerontol. 1994;49(4):M174-82. PubMed PMID: 8014392.

28. von Elm E, Altman DG, Egger M, Pocock SJ, Gotzsche PC, Vandenbroucke JP, et al. The Strengthening the Reporting of Observational Studies in Epidemiology (STROBE) Statement: guidelines for reporting observational studies. Int J Surg. 2014;12(12):1495-9. doi: 10.1016/j.jjsu.2014.07.013. PubMed PMID: 25046131.

29. Arnold CM, Warkentin KD, Chilibeck PD, Magnus CR. The reliability and validity of handheld dynamometry for the measurement of lower-extremity muscle strength in older adults. Journal of strength and conditioning research / National Strength \& Conditioning Association. 2010;24(3):815-24. doi: 10.1519/JSC.0b013e3181aa36b8. PubMed PMID: 19661831.

30. Stark T, Walker B, Phillips JK, Fejer R, Beck R. Hand-held dynamometry correlation with the gold standard isokinetic dynamometry: a systematic review. PM R. 2011;3(5):472-9. doi: 10.1016/j.pmrj.2010.10.025. PubMed PMID: 21570036.

31. Bohannon RW. Test-retest reliability of hand-held dynamometry during a single session of strength assessment. Physical therapy. 1986;66(2):206-9. doi: 10.1093/ptj/66.2.206. PubMed PMID: 3945674.

32. Shechtman O, Sindhu BS. Grip Strength. In: ASTH, editor. Clinical Assessment Recommendations, 3rd edition2013.

33. Agyapong-Badu S, Warner M, Samuel D, Narici M, Cooper C, Stokes M. Anterior thigh composition measured using ultrasound imaging to quantify relative thickness of muscle and non-contractile tissue: a potential biomarker for musculoskeletal health. Physiological measurement. 2014;35(10):2165-76. doi: 10.1088/0967-3334/35/10/2165. PubMed PMID: 25243984.

34. Delaney S, Worsley P, Warner M, Taylor M, Stokes M. Assessing contractile ability of the quadriceps muscle using ultrasound imaging. Muscle Nerve. 2010;42(4):530-8. doi: 10.1002/mus.21725. PubMed PMID: 20665511.

35. Mechelli F, Arendt-Nielsen L, Stokes M, Agyapong-Badu S. Validity of Ultrasound Imaging Versus Magnetic Resonance Imaging for Measuring Anterior Thigh Muscle, Subcutaneous Fat, and Fascia Thickness. Methods Protoc. 2019;2(3). doi: 10.3390/mps2030058. PubMed PMID: 31295936.

36. Mayans D, Cartwright MS, Walker FO. Neuromuscular ultrasonography: quantifying muscle and nerve measurements. Phys Med Rehabil Clin N Am. 
2012;23(1):133-48, xii. doi: 10.1016/j.pmr.2011.11.009. PubMed PMID: 22239880; PubMed Central PMCID: PMCPMC3321511.

37. Harris-Love MO, Seamon BA, Teixeira C, Ismail C. Ultrasound estimates of muscle quality in older adults: reliability and comparison of Photoshop and Image J for the grayscale analysis of muscle echogenicity. PeerJ. 2016;4:e1721. doi: 10.7717/peerj.1721. PubMed PMID: 26925339; PubMed Central PMCID: PMCPMC4768702.

38. Sipila S, Suominen $\mathrm{H}$. Muscle ultrasonography and computed tomography in elderly trained and untrained women. Muscle Nerve. 1993;16(3):294-300. doi: 10.1002/mus.880160309. PubMed PMID: 8446128.

39. Reimers K, Reimers CD, Wagner S, Paetzke I, Pongratz DE. Skeletal muscle sonography: a correlative study of echogenicity and morphology. J Ultrasound Med. 1993;12(2):73-7. PubMed PMID: 8468739.

40. Guralnik JM, Simonsick EM, Ferrucci L, Glynn RJ, Berkman LF, Blazer DG, et al. A short physical performance battery assessing lower extremity function: association with self-reported disability and prediction of mortality and nursing home admission. J Gerontol. 1994;49(2):M85-94. PubMed PMID: 8126356.

41. Guralnik JM, Ferrucci L, Pieper CF, Leveille SG, Markides KS, Ostir GV, et al. Lower extremity function and subsequent disability: consistency across studies, predictive models, and value of gait speed alone compared with the short physical performance battery. J Gerontol A Biol Sci Med Sci. 2000;55(4):M221-31. PubMed PMID: 10811152.

42. Huy $C$, Schneider $S$. [Instrument for the assessment of middle-aged and older adults' physical activity: design, eliability and application of the German-PAQ50+]. Z Gerontol Geriatr. 2008;41(3):208-16. doi: 10.1007/s00391-007-0474-y. PubMed PMID: 18327696.

43. Fried LP, Tangen CM, Walston J, Newman AB, Hirsch C, Gottdiener J, et al. Frailty in older adults: evidence for a phenotype. J Gerontol A Biol Sci Med Sci. 2001;56(3):M146-56. Epub 2001/03/17. PubMed PMID: 11253156.

44. Chen WL, Peng TC, Sun YS, Yang HF, Liaw FY, Wu LW, et al. Examining the Association Between Quadriceps Strength and Cognitive Performance in the Elderly. Medicine (Baltimore). 2015;94(32):e1335. doi: 10.1097/MD.0000000000001335. PubMed PMID: 26266380; PubMed Central PMCID: PMCPMC4616681.

45. Tieland M, Trouwborst I, Clark BC. Skeletal muscle performance and ageing. J Cachexia Sarcopenia Muscle. 2018;9(1):3-19. doi: 10.1002/jcsm.12238. PubMed PMID: 29151281; PubMed Central PMCID: PMCPMC5803609.

46. Manini TM, Hong SL, Clark BC. Aging and muscle: a neuron's perspective. Curr Opin Clin Nutr Metab Care. 2013;16(1):21-6. doi: 10.1097/MCO.0b013e32835b5880. PubMed PMID: 23222705; PubMed Central PMCID: PMCPMC3868452.

47. Gandevia SC. Spinal and supraspinal factors in human muscle fatigue. Physiol Rev. 2001;81(4):1725-89. doi: 10.1152/physrev.2001.81.4.1725. PubMed PMID: 11581501.

48. Taylor JL. Point: the interpolated twitch does/does not provide a valid measure of the voluntary activation of muscle. Journal of applied physiology. 
2009;107(1):354-5. doi: 10.1152/japplphysiol.91220.2008. PubMed PMID: 18801954.

49. Clark BC, Taylor JL. Age-related changes in motor cortical properties and voluntary activation of skeletal muscle. Curr Aging Sci. 2011;4(3):192-9. PubMed PMID: 21529329; PubMed Central PMCID: PMCPMC3184350.

50. Harridge SD, Kryger A, Stensgaard A. Knee extensor strength, activation, and size in very elderly people following strength training. Muscle Nerve. 1999;22(7):831-9. PubMed PMID: 10398199.

51. Stevens JE, Stackhouse SK, Binder-Macleod SA, Snyder-Mackler L. Are voluntary muscle activation deficits in older adults meaningful? Muscle Nerve. 2003;27(1):99-101. doi: 10.1002/mus.10279. PubMed PMID: 12508301.

52. Clark DJ, Fielding RA. Neuromuscular contributions to age-related weakness. J Gerontol A Biol Sci Med Sci. 2012;67(1):41-7. doi: 10.1093/gerona/glr041. PubMed PMID: 21415261; PubMed Central PMCID: PMCPMC3260482.

53. Makizako H, Shimada H, Doi T, Tsutsumimoto K, Nakakubo S, Hotta R, et al. Predictive Cutoff Values of the Five-Times Sit-to-Stand Test and the Timed "Up \& Go" Test for Disability Incidence in Older People Dwelling in the Community. Physical therapy. 2017;97(4):417-24. doi: 10.2522/ptj.20150665. PubMed PMID: 28371914.

54. Bohannon RW. Five-repetition sit-to-stand test: usefulness for older patients in a home-care setting. Percept Mot Skills. 2011;112(3):803-6. doi: 10.2466/15.26.PMS.112.3.803-806. PubMed PMID: 21853769.

55. Eriksrud O, Bohannon RW. Relationship of knee extension force to independence in sit-to-stand performance in patients receiving acute rehabilitation. Physical therapy. 2003;83(6):544-51. PubMed PMID: 12775200.

56. Alexander NB, Galecki AT, Nyquist LV, Hofmeyer MR, Grunawalt JC, Grenier $\mathrm{ML}$, et al. Chair and bed rise performance in ADL-impaired congregate housing residents. J Am Geriatr Soc. 2000;48(5):526-33. doi: 10.1111/j.15325415.2000.tb04999.x. PubMed PMID: 10811546.

57. Van der Heijden MM, Meijer K, Willems PJ, Savelberg HH. Muscles limiting the sit-to-stand movement: an experimental simulation of muscle weakness. Gait Posture. 2009;30(1):110-4. doi: 10.1016/j.gaitpost.2009.04.002. PubMed PMID: 19419871.

58. Lord SR, Murray SM, Chapman K, Munro B, Tiedemann A. Sit-to-stand performance depends on sensation, speed, balance, and psychological status in addition to strength in older people. J Gerontol A Biol Sci Med Sci. 2002;57(8):M539-43. PubMed PMID: 12145369.

59. Zech A, Steib S, Sportwiss D, Freiberger E, Pfeifer K. Functional muscle power testing in young, middle-aged, and community-dwelling nonfrail and prefrail older adults. Arch Phys Med Rehabil. 2011;92(6):967-71. doi: 10.1016/j.apmr.2010.12.031. PubMed PMID: 21514567.

60. Mor V, Angelelli J, Jones R, Roy J, Moore T, Morris J. Inter-rater reliability of nursing home quality indicators in the U.S. BMC Health Serv Res. 2003;3(1):20. doi: 10.1186/1472-6963-3-20. PubMed PMID: 14596684; PubMed Central PMCID: PMCPMC280691. 
61. Colbert LH, Matthews CE, Havighurst TC, Kim K, Schoeller DA. Comparative validity of physical activity measures in older adults. Med Sci Sports Exerc. 2011;43(5):867-76. doi: 10.1249/MSS.0b013e3181fc7162. PubMed PMID: 20881882; PubMed Central PMCID: PMCPMC3303696. 
5.7 Supporting information

S1 Appendix. Correlations of ADL category with demographics

S2 Appendix. Correlations of ADL category with muscle-related parameter

S3 Appendix. Binary logistic regression

S1 Appendix: Correlations of ADL category with demographics

\begin{tabular}{lll}
\hline variable & $\begin{array}{l}\text { Correlation } \\
\text { coefficient }\left(r_{\mathrm{s}}\right)\end{array}$ & Significance $(\mathrm{p})$ \\
\hline demographics & & \\
age & -.09 & .639 \\
sex & -.12 & .542 \\
height & -.24 & .194 \\
weight & .11 & .570 \\
urinary incontinence & .39 & $.037^{*}$ \\
pain intensity & -.12 & .543 \\
falls & .07 & .701 \\
cognitive performance & .23 & .238 \\
frequency of depressive symptoms & .09 & .660 \\
symptoms of physical frailty & .22 & .234 \\
amount of chronic diseases & .41 & $.027^{\star}$ \\
regular intake of medication & -.03 & .861 \\
\hline
\end{tabular}

*significant difference

S2 Appendix: Correlations of ADL category with muscle-related parameter

\begin{tabular}{lll}
\hline variable & $\begin{array}{l}\text { Correlation } \\
\text { coefficient }\left(r_{\mathrm{s}}\right)\end{array}$ & Significance $(\mathrm{p})$ \\
\hline muscle strength & & \\
$\quad$ handgrip strength & -0.38 & $=.038^{*}$ \\
elbow flexor strength & -0.42 & $=.032^{*}$ \\
$\begin{array}{l}\text { quadriceps strength } \\
\text { muscle morphology }\end{array}$ & -0.67 & $<.001^{*}$ \\
quadriceps thickness & & \\
rectus femoris grayscale & .01 & $=.968$ \\
elbow-flexor thickness & -.02 & $=.903$ \\
$\quad$ biceps brachii grayscale & -.01 & $=.968$ \\
functional mobility/ 5 sit-to-stand category & .01 & $=.968$ \\
physical activity & -.21 & $=.276$ \\
\hline
\end{tabular}

*significant difference 
S3 Appendix: Binary logistic regression

\begin{tabular}{llllll}
\hline predictor & Regression & Significance & Exp(B)=OR & \multicolumn{2}{l}{$95 \%$ Cl for Exp(B) } \\
& coefficient $(B)$ & level $(p)$ & & lower & upper \\
\hline $\begin{array}{l}\text { Quadriceps } \\
\text { strength } \\
\text { constant }\end{array}$ & -.992 & .014 & 0.371 & 0.167 & 0.821 \\
\hline
\end{tabular}

Nagelkerke's $R^{2}=0.65$

\begin{tabular}{|c|c|c|c|c|c|}
\hline \multirow[t]{2}{*}{ predictor } & \multirow{2}{*}{$\begin{array}{l}\text { Regression } \\
\text { coefficient (B) }\end{array}$} & \multirow{2}{*}{$\begin{array}{l}\text { Significanc } \\
\text { e level (p) }\end{array}$} & \multirow[t]{2}{*}{$\operatorname{Exp}(B)=O R$} & \multicolumn{2}{|c|}{$95 \% \mathrm{Cl}$ for $\operatorname{Exp}(\mathrm{B})$} \\
\hline & & & & lower & upper \\
\hline $\begin{array}{l}\text { Quadriceps } \\
\text { strength }\end{array}$ & -1.166 & .031 & 0.312 & 0.108 & 0.901 \\
\hline $\begin{array}{l}\text { Incontinence } \\
\text { category }\end{array}$ & 1.957 & .174 & 7.078 & 0.422 & 118.848 \\
\hline constant & 13.251 & .038 & 568610.962 & & \\
\hline
\end{tabular}

Nagelkerke's $R^{2}=0.69$

\begin{tabular}{lllllc}
\hline predictor & Regression & Significance & Exp(B)=O & \multicolumn{2}{c}{$95 \%$ Cl for Exp(B) } \\
& coefficient $(B)$ & level $(p)$ & $R$ & lower & upper \\
\hline Quadriceps & -1.128 & .018 & 0.324 & 0.127 & 0.825 \\
strength & & & & & \\
Chronic diseases & 1.092 & .091 & 2.979 & 0.839 & 10.579 \\
constant & 9.575 & .083 & 14403.725 & & \\
\hline
\end{tabular}

Nagelkerke's $R^{2}=0.77$

\begin{tabular}{|c|c|c|c|c|c|}
\hline \multirow[t]{2}{*}{ predictor } & \multirow{2}{*}{$\begin{array}{l}\text { Regression } \\
\text { coefficient (B) }\end{array}$} & \multirow{2}{*}{$\begin{array}{l}\text { Significance } \\
\text { level }(p)\end{array}$} & \multirow[t]{2}{*}{$\operatorname{Exp}(B)=O R$} & \multicolumn{2}{|c|}{$95 \% \mathrm{Cl}$ for $\operatorname{Exp}(\mathrm{B})$} \\
\hline & & & & lower & upper \\
\hline $\begin{array}{l}\text { Quadriceps } \\
\text { strength }\end{array}$ & -.992 & .053 & 0.317 & 0.136 & 1.012 \\
\hline Chronic diseases & 1.091 & .090 & 2.979 & 0.845 & 10.504 \\
\hline $\begin{array}{l}\text { Elbow-flexor } \\
\text { strength }\end{array}$ & -.205 & .591 & 0.815 & 0.387 & 1.717 \\
\hline constant & 10.483 & .087 & 19426.475 & & \\
\hline
\end{tabular}

Nagelkerke's $\mathrm{R}^{2}=0.78$ 


\begin{tabular}{lllllc}
\hline predictor & $\begin{array}{l}\text { Regression } \\
\text { coefficient }(B)\end{array}$ & $\begin{array}{l}\text { Significance } \\
\text { level }(p)\end{array}$ & Exp(B)=OR & \multicolumn{2}{c}{$95 \%$ Cl for Exp(B) } \\
& -1.127 & .019 & 0.324 & 0.126 & 0.832 \\
\hline $\begin{array}{l}\text { Quadriceps } \\
\text { strength }\end{array}$ & & & & & \\
$\begin{array}{l}\text { Chronic diseases } \\
\text { Incontinence }\end{array}$ & .998 & .149 & 2.712 & 0.699 & 10.528 \\
$\begin{array}{l}\text { category } \\
\text { constant }\end{array}$ & .709 & .607 & 2.203 & 0.108 & 44.774 \\
\hline
\end{tabular}

Nagelkerke's $\mathrm{R}^{2}=0.76$

\begin{tabular}{llllll}
\hline predictor & Regression & Significance & Exp(B)=OR & \multicolumn{2}{c}{$95 \% \mathrm{Cl}$ for Exp(B) } \\
& coefficient $(\mathrm{B})$ & level $(\mathrm{p})$ & & lower & upper \\
\hline $\begin{array}{l}\text { Quadriceps } \\
\text { strength }\end{array}$ & -1.149 & .019 & 0.317 & 0.121 & 0.828 \\
Chronic diseases & .976 & .126 & 2.655 & 0.761 & 9.262 \\
$\begin{array}{l}\text { Physical activity } \\
\text { constant }\end{array}$ & .000 & .572 & 1.000 & 0.998 & 1.001 \\
\hline
\end{tabular}

Nagelkerke's $R^{2}=0$ 


\section{Chapter 6}

\section{Relationship between sonographic index of muscle quality and quadriceps muscle strength in nursing-home residents - a proof-of-concept study}

This study was designed to address research aim 5 and evaluated the relationship between muscle strength of the knee extensor muscles and sonographic measures of muscle thickness and muscle quality, gait speed and physical activity in nursing-home residents.

The chapter has been reformatted from the published article:

Wearing J, Stokes M, de Bie R, de Bruin ED: Relationship between sonographic index of muscle quality and quadriceps muscle strength in nursing-home residents. Journal of Nursing Home Residents 2020;6

Contributions of co-authors:

M. Stokes contributed to study design, data interpretation, and preparation critical revision of the manuscript.

R. de Bie contributed to study conception and design, data interpretation, and preparation and critical revision of the manuscript.

E.D. de Bruin contributed to study conception and design, statistical analysis and interpretation, and preparation and critical revision of the manuscript. 


\subsection{Abstract}

Background: Age-related neurological and muscular changes lead to low strength and function in older people. The proportional contribution of these changes to strength decline alters with increasing age. However, it is not clear how the muscle changes in the older people which have excessive loss of strength due to multimorbidity and inactivity. Unlike community-living older adults, intramuscular alterations are rarely evaluated in nursing-home residents despite their potential importance for specific sarcopenia assessment and guiding interventions to improve strength.

Objectives: To explore potential relationships between muscle strength, muscle quantity, contractile quality and physical activity in older nursing-home residents.

Design: A cross-sectional proof-of-concept study.

Setting: A nursing-home in Switzerland.

Participants: 24 nursing-home residents, median age (range) 86.5 (68-103) years.

Measurements: Sonographic measures of muscle thickness and echotexture were used as surrogate measures of muscle quantity and contractile quality of the quadriceps muscle. The relationship between sonographic measures and isometric strength of the knee extensors, gait speed and physical activity was evaluated using Pearson's and Spearman's correlation coefficients. A subgroup analysis of low $(n=12)$ and normal $(n=12)$ physical activity, based on energy expenditure cut off values of 383 $\mathrm{kcal} /$ week for men and 270 for women, was also undertaken.

Results: In nursing home residents with normal physical activity, muscle quality positively correlated with knee extensor strength $(r=0.727, p=.007)$ and gait speed $(r=0.588, p=.044)$ while muscle thickness was not ( $p=0.966$ and $p=.564$ respectively). There was no correlation among variables for $n=24$ or the subgroup with low physical activity.

Conclusions: The results provide proof of concept that poor muscle quality is associated with low strength in older nursing-home residents that are physically active. Ultrasound derived muscle quality assessment has potential to detect activity-related muscle differences in old age, associated with sarcopenia, and may be more appropriate than muscle thickness measures.

Keywords: knee extensor strength, muscle quality, heterogeneity, nursing-home residents, physical activity 


\subsection{Introduction}

Age-related neurological and muscular changes lead to low strength in older people with an increased risk of functional decline [1]. Residents of nursing homes, in particular, often have excessive muscle weakness [2] due to multiple chronic diseases, inactivity and malnutrition [1]. To prevent adverse health outcomes, assessment of muscle disorders, and preservation or improvement in muscle strength are essential [3].

For several decades, the age-related muscle disorder sarcopenia has been mainly attributed to a reduction in muscle mass [1]. Recently, however, it has been shown that the relationship between strength and muscle mass is inconsistent in older people and that strength decreases to a higher extent than mass with aging [4]. Explanatory models have now highlighted the potential role of muscle quality and neural function, in addition to muscle mass, as key determinants of muscle strength [4]. Muscle quality has been shown to decrease with age but is suspected to change more due to muscle disuse, which often accompanies aging [5]. In the clinical context of strength, muscle quality refers to contractile characteristics of muscle fibres [5] and can be determined e.g. by the ratio of muscle strength per body mass or muscle imaging techniques [6]. The quality of muscular contraction is thought to be diminished by multiple factors [5], including the accumulation of intramuscular connective and adipose (non-contractile) tissue [7], muscle fibre necrosis and inflammation that change the density and heterogeneity of the muscle structure [8].

Evaluation of intramuscular non-contractile tissue has been recently applied in research that focuses on age-related changes in muscle as well as in patients with muscle impairments such as muscular dystrophy [5, 9]. While Magnetic Resonance Imaging has been widely used to quantify morphologic abnormalities in muscles, Bmode ultrasound imaging has been shown to be a reliable alternative in clinical settings, complementing functional measures of muscles and demonstrating disease progression by changes in thickness and echo intensity [9]. Clinical trials evaluating healthy older, community-living people have shown that strength consistently declines along with altered muscle quality, however its relation to muscle quantity is controversial [10-12]. Moreover, muscle quality has been shown to be positively related to gait performance $[12,13]$. Despite the high informative value of ultrasound measures in detecting muscle changes in healthy elderly, there is a lack of studies using ultrasound in older ( $\geq 65$ years), particularly in oldest-old ( $\geq 85$ years), comorbid people [14].

Only a few studies to date have evaluated muscle characteristics in nursing-home residents. As muscle strength decreases with age, particularly rapidly after the age of 80 years [15], the proportional contribution of muscular and neurological changes leading to strength decline also changes $[4,15]$. Particularly in people with a very low muscle condition such as in nursing-home residents $[1,2,16]$, the muscle might show a specific pattern of biological changes. Moreover, as the evaluation of muscle function by assessments typically used in older adults is limited in people with very low muscle condition due to physical restrictions [17], evaluation of ultrasound-derived muscle 
changes might be a valuable alternative for this cohort. Therefore, morphologic changes in muscle, and relationships between strength, function and physical activity in this population merit separate attention to improve clinical assessment of sarcopenia in this population. So far, it has been shown in computer-tomographical scans that cross-sectional area of the quadriceps femoris was related to knee extensor strength and gait speed in frail, older nursing-home residents [18]. However, whether there is a relationship between ultrasound measures of muscle morphology and strength of the lower extremities in nursing-home residents has not been explored to date [7].

The objectives of this study were 1. To explore potential relationships between sonographic measures of muscle quantity, quality and strength of the knee extensors in older nursing-home residents, specifically including oldest-old people, and 2. To examine the relationships of knee extensor characteristics and gait speed within subgroups based on physical activity level. 


\subsection{Methods}

Study design

An observational, cross-sectional proof-of-concept [19] study design was used to explore the potential relationships between muscle strength, sonographically measured thickness, indices of quality, and physical function in a convenience sample of older, comorbid residents of a nursing-home in Switzerland, including oldest-old people ( $\geq 85$ years).

Participants recruitment

Residents were included if they were able to walk, with or without the aid of a walking device, and cognitively able to understand study content. Exclusion criteria were a) severe impairment in decision making (Cognitive performance scale $>4$ points) [20], b) acute illness, c) a history of acute lower limb pathology within the last 6 months (fracture and/or surgery) and d) skin disorders involving the anterior thigh.

All participants provided informed consent following a verbal and written explanation of the study procedures, which complied with the principles of the Declaration of Helsinki for ethical research in humans. The study received approval from the local ethics committee (Ethikkommission Nordwest- und Zentralschweiz (EKNZ), project-ID 2017-00839).

Data collection

Participants demographics

Age, height and body mass of the participants and number of chronic diseases that may affect muscle characteristics (metabolic, musculoskeletal, neurological, psychiatric, respiratory disease, renal insufficiency and cancer) were extracted from nursing assessments and medical history.

Muscle strength, muscle morphology, physical function and physical activity were examined by a physiotherapist trained and experienced in musculoskeletal assessments.

Muscle strength

Maximal isometric strength of the knee extensor was measured with a hand-held dynamometer (Microfet ${ }^{\circledR}$, CompuFET, Hoggan Health Industries, Biometrics Europe). For measurements, participants were seated on a plinth, with their back and thighs fully supported, knee positioned at $90^{\circ}$ and lower leg hanging freely. The curved transducer pad of the dynamometer was positioned at $80 \%$ of the length of the tibia. Participants were requested to push against the dynamometer as hard as possible for 3 seconds.

The peak force measured during two trials was recorded in $\mathrm{kg}$. Relative strength was calculated by normalizing peak force to body mass. Isometric muscle strength determined by hand-held dynamometry in older adults has been shown to be 
comparable to strength values measured with the gold standard method of isokinetic strength testing [21] with a high test-retest reliability (ICC 0.90-0.98) [22].

\section{Muscle morphology}

Real-time, B-mode ultrasonography (Nemio MX Type SSA-590A, Toshiba, Japan) with a 12-MHz linear transducer array (45 $\mathrm{mm}$ footprint) was used to obtain two transverse scans of the rectus femoris and vastus intermedius muscles at a site two-thirds of the distance between the antero-superior iliac spine and the superior pole of the patella. Standardized sonographic settings were used for all participants and images were acquired using a uniform protocol developed for older adults [23]. Ultrasound images were post-processed using a MATLAB code (MathWorks ${ }^{\circledR}$, Massachusetts, USA). Muscle thickness was calculated as the distance between the fascial layers that distinguish muscles from the subcutaneous fat layer, and muscles from bone. Thickness values were expressed as a percentage of total thigh thickness to account for individual body composition [23]. Sonographic measures of quadriceps thickness have been previously shown to be highly correlated $(r=0.98)$ with gold standard measures obtained from Magnetic Resonance Imaging [14], and have a reported intrarater reliability of ICC 0.88-.099 in older people [8, 23].

Muscle echotexture was characterized by echo intensity and heterogeneity, determined over a rectangular region of interest. Echo intensity was estimated by calculating the mean grayscale value in unspecified units (UU), ranging between 0 255. High values reflected hyperechoic tissue which reportedly reflects the accumulation of non-contractile tissue [9], muscle fibre necrosis and inflammation [8]. Tissue heterogeneity was estimated by calculating the standard deviation (SD) of grayscale value [24]. Low SD reflected low heterogeneity which indicates homogenous tissue structure and evenly distributed non-contractile tissue within muscle [24]. Homogeneous muscle tissue patterns have been shown to be positively associated with muscle disorders [24], and age-related strength differences [25]. Quantification of tissue heterogeneity has been demonstrated to be sensitive in detecting neuromuscular disorders including myopathy and muscle dystrophy [26].

\section{Physical function}

Preferred gait speed was evaluated over a $4 \mathrm{~m}$ distance. This method is commonly used for evaluation of functional performance in older adults and shows excellent testretest reliability in older people with comorbidities [17].

\section{Physical activity}

Physical activity was evaluated using the German Physical Activity 50+ questionnaire [27], which measures the duration of various household and leisure time activities and allows for estimation of energy expenditure based on the Compendium for Physical Activities [28]. Its performance characteristics have been reported elsewhere [27]. Energy expenditure was reported in kcal/week and dichotomized into low- and normal physical activity based on cut off values of 383 and $270 \mathrm{kcal} /$ week for men and women, respectively [29]. For evaluation of physical activity, participants as well as nurses 
responsible for their care, who closely observe the nursing-home residents $24 \mathrm{~h} / 7 \mathrm{~d}$ were interviewed, to increase precision of the responses.

Statistical analysis

Normal distribution of the data was evaluated using the Shapiro-Wilk test. Normally distributed data have been reported as mean (SD), not normally distributed data as median (range). For normally distributed data, Pearson's correlation coefficient was used to evaluate correlations between measures of muscle strength, muscle morphology, physical performance and physical activity, and to analyze relationships between knee extensor characteristics within the physical activity subgroups. For not normally distributed data, Spearman's correlation coefficient was used accordingly. 


\subsection{Results}

Descriptive Analysis

The study sample included $n=24$ participants (18 women), median age (range) 86.5 (68-103) years, with $n=12$ participants in each physical activity-subgroup (Table 1).

Table 1: Descriptive characteristics of the participants

\begin{tabular}{|c|c|c|c|}
\hline & $\begin{array}{l}\text { Normal physical } \\
\text { activity } \\
\text { Mean (SD)/ } \\
\text { median (range) }\end{array}$ & $\begin{array}{l}\text { Low physical } \\
\text { activity } \\
\text { Mean (SD)/ } \\
\text { median (range) }\end{array}$ & $\begin{array}{l}\text { Total group } \\
\text { Mean (SD)/ } \\
\text { median (range) }\end{array}$ \\
\hline \multicolumn{4}{|l|}{ Demographics } \\
\hline $\mathrm{n}$ & 12 & 12 & 24 \\
\hline $\operatorname{Sex}^{\dagger}($ female, $n)$ & 9 & 9 & 18 \\
\hline $\mathrm{Age}^{\dagger}$ (years) & $88(69-103)$ & $86(68-98)$ & $86.5(68-103)$ \\
\hline Height $^{\dagger}(m)$ & $1.6(1.49-1.70)$ & $1.6(1.49-1.72)$ & $1.6(1.49-1.72)$ \\
\hline Body mass $^{\dagger}(\mathrm{kg})$ & $67.6(39.5-86.0)$ & $73.0(44.0-87.2)$ & $69.6(39.5-87.2)$ \\
\hline Number of chronic diseases (n) & $2.7(1.2)$ & $3.9(1.4)$ & $3.3(1.4)$ \\
\hline \multicolumn{4}{|l|}{ Leg characteristics } \\
\hline $\begin{array}{l}\text { Knee extensor strength/ body } \\
\text { mass }(\mathrm{kg} / \mathrm{kg})\end{array}$ & $0.2(0.08)$ & $0.16(0.03)$ & $0.18(0.06)$ \\
\hline $\begin{array}{l}\text { Quadriceps thickness in } \\
\text { percentage of total thickness }{ }^{\dagger} \\
(\%)\end{array}$ & $50(43-73)$ & $48(35-73)$ & $50(35-73)$ \\
\hline Rectus femoris grayscale $^{\dagger}$ (UU) & $113(82-173)$ & $116(72-127)$ & $113(72-173)$ \\
\hline $\begin{array}{l}\text { Rectus femoris grayscale } \mathrm{SD}^{\dagger} \\
(\mathrm{UU})\end{array}$ & 32 (24-39) & $34(18-43)$ & $32(18-43)$ \\
\hline \multicolumn{4}{|l|}{$\begin{array}{l}\text { Physical function and physical } \\
\text { activity }\end{array}$} \\
\hline $\begin{array}{l}\text { Gait speed over } 4 \text { meters }^{\dagger} \\
(\mathrm{m} / \mathrm{s})\end{array}$ & $0.60(0.38-1.09)$ & $0.55(0.19-0.85)$ & $0.56(0.19-1.09)$ \\
\hline Physical activity (kcal/week) & $1297(1445)$ & $77(100)$ & $682(1182)$ \\
\hline
\end{tabular}

${ }^{\dagger}$ data not normally distributed

Correlation analysis $(n=24)$

Knee extensor strength normalized to body mass was not significantly correlated to sex or measures of muscle morphology, physical function or physical activity (Table 2). 
Table 2: Correlations among demographic parameters, quadriceps muscle strength and morphology, physical function and physical activity $(n=24)$

\begin{tabular}{|c|c|c|c|c|c|c|c|c|c|c|}
\hline & & Age & Height & $C D$ & KES & QT & $R G$ & RGSD & GS & PA \\
\hline Sex & $\begin{array}{l}r \\
P\end{array}$ & $\begin{array}{c}0.021^{\dagger} \\
.923\end{array}$ & $\begin{array}{c}-0.105^{\dagger} \\
.627\end{array}$ & $\begin{array}{c}-0.189^{\dagger} \\
.378\end{array}$ & $\begin{array}{c}0.097^{\dagger} \\
.651\end{array}$ & $\begin{array}{c}-0.445^{\dagger *} \\
.029\end{array}$ & $\begin{array}{c}0.083^{\dagger} \\
.698\end{array}$ & $\begin{array}{c}-0.042^{\dagger} \\
.847\end{array}$ & $\begin{array}{c}-0.174^{\dagger} \\
.417\end{array}$ & $\begin{array}{c}-0.042^{\dagger} \\
.845\end{array}$ \\
\hline Age & r & & $-0.013^{\dagger}$ & $0.176^{\dagger}$ & $-0.084^{\dagger}$ & $-0.078^{\dagger}$ & $0.263^{\dagger}$ & $-0.284^{\dagger}$ & $-.480^{\dagger *}$ & $-0.042^{\dagger}$ \\
\hline Height & $\begin{array}{l}P \\
r \\
P\end{array}$ & & .953 & $\begin{array}{c}.411 \\
-0.314^{\dagger} \\
135\end{array}$ & $\begin{array}{c}.697 \\
0.027^{\dagger} \\
902\end{array}$ & $\begin{array}{c}.716 \\
-0.034^{\dagger} \\
875\end{array}$ & $\begin{array}{c}.214 \\
-0.012^{\dagger} \\
955\end{array}$ & $\begin{array}{c}.179 \\
-0.200^{\dagger} \\
348\end{array}$ & $\begin{array}{c}.017 \\
0.258^{\dagger} \\
224\end{array}$ & $\begin{array}{c}.847 \\
0.148^{\dagger} \\
489\end{array}$ \\
\hline CD & r & & & & $\begin{array}{c}-0.401 \\
.052\end{array}$ & $\begin{array}{c}0.138^{\dagger} \\
.519\end{array}$ & $\begin{array}{c}-0.117^{\dagger} \\
.585\end{array}$ & $\begin{array}{c}-0.173^{\dagger} \\
.419\end{array}$ & $\begin{array}{c}-0.403^{\dagger} \\
.051\end{array}$ & $\begin{array}{c}-0.201 \\
.347\end{array}$ \\
\hline KES & $\begin{array}{l}r \\
P\end{array}$ & & & & & $\begin{array}{c}0.031^{\dagger} \\
.885\end{array}$ & $\begin{array}{c}0.262^{\dagger} \\
.217\end{array}$ & $\begin{array}{c}0.237^{\dagger} \\
.264\end{array}$ & $\begin{array}{c}0.364^{\dagger} \\
.081\end{array}$ & $\begin{array}{c}-0.014 \\
.948\end{array}$ \\
\hline QT & r & & & & & & $-0.037^{\dagger}$ & $-0.099^{\dagger}$ & $-0.023^{\dagger}$ & $0.049^{\dagger}$ \\
\hline RG & r & & & & & & & $\begin{array}{c}0.181^{\dagger} \\
398\end{array}$ & $\begin{array}{c}-0.120^{\dagger} \\
575\end{array}$ & $\begin{array}{c}-0.141^{\dagger} \\
512\end{array}$ \\
\hline RGSD & $\begin{array}{l}r \\
P\end{array}$ & & & & & & & & $0.024^{\dagger}$ & $-0.148^{\dagger}$ \\
\hline GS & $\begin{array}{l}r \\
P\end{array}$ & & & & & & & & & $\begin{array}{c}0.272^{\dagger} \\
.199\end{array}$ \\
\hline
\end{tabular}

$\mathrm{CD}=$ number of chronic diseases, $\mathrm{KES}=$ knee extensor strength normalized to body mass, $\mathrm{QT}=$ quadriceps thickness in relation to total thickness, $R G=$ Rectus grayscale, RGSD = rectus grayscale standard deviation, GS = gait speed, PA = physical activity, Significance $p<.05$ ${ }^{\dagger}$ correlations determined by Spearman's Correlation Coefficient Body mass was excluded from the correlation analysis as muscle strength has been normalized to mass.

Correlations within physical activity subgroups ( $n=12$ each)

To determine if a higher activity level, mainly achieved by walks in the garden and outside the nursing-home, is important to determine relationships of morphological measures and strength of the quadriceps, the sample was divided into two subgroups categorized by the physical activity cut-off value of $270 \mathrm{kcal}$ for women and $383 \mathrm{kcal}$ for men. The cut off value determines whether a person is at risk for frailty [39]. Both subgroups included $n=12$ participants with an energy expenditure of mean (SD) 68 $\mathrm{kcal} /$ week (100) in the slow group and $1297 \mathrm{kcal} /$ week (1445) in the group with normal physical activity.

Within the subgroup with normal physical activity, knee extensor strength was positively correlated with tissue heterogeneity $(r=0.727, p=.007)$ but not with muscle thickness $(r=0.014, p=.966)$. Similarly, muscle tissue heterogeneity was positively correlated with gait speed $(r=0.588, p=.044)$. However, within the subgroup of people with low physical activity, there were no significant correlations among knee extensor strength normalised to body mass, comorbidities, muscle thickness and muscle echo intensity and heterogeneity, or gait speed, as shown in Table 3. 
Table 3: Correlation analysis between muscle characteristics of the knee extensor and gait speed within subgroups of physical activity

\begin{tabular}{|c|c|c|c|c|c|c|c|}
\hline & & KES & $C D$ & QT & RG & RGSD & GS \\
\hline \multicolumn{8}{|c|}{ Normal physical activity } \\
\hline sex & $\begin{array}{l}r \\
P\end{array}$ & $\begin{array}{c}0.139^{\dagger} \\
.666\end{array}$ & $\begin{array}{c}-0.148^{\dagger} \\
.647\end{array}$ & $\begin{array}{c}-0.139^{\dagger} \\
.666\end{array}$ & $\begin{array}{c}-0.307^{\dagger} \\
.332\end{array}$ & $\begin{array}{c}0.028^{\dagger} \\
.931\end{array}$ & $\begin{array}{c}-0.168^{\dagger} \\
.603\end{array}$ \\
\hline \multirow[t]{2}{*}{ KES } & $r$ & & -0.472 & $0.014^{\dagger}$ & $0.371^{\dagger}$ & $0.727^{\dagger *}$ & $0.228^{\dagger}$ \\
\hline & $\mathrm{P}$ & & .121 & .966 & .236 & .007 & .477 \\
\hline$C D$ & $\begin{array}{l}r \\
P\end{array}$ & & & $\begin{array}{c}0.100^{\dagger} \\
.757\end{array}$ & $\begin{array}{c}0.030^{\dagger} \\
.927\end{array}$ & $\begin{array}{c}-0.289^{\dagger} \\
.363\end{array}$ & $\begin{array}{c}-0.694^{\dagger *} \\
.012\end{array}$ \\
\hline QT & $\begin{array}{l}r \\
P\end{array}$ & & & & $\begin{array}{c}-0.084^{\dagger} \\
.795\end{array}$ & $\begin{array}{c}0.077^{\dagger} \\
.812\end{array}$ & $\begin{array}{c}0.186^{\dagger} \\
.564\end{array}$ \\
\hline$R G$ & $\begin{array}{l}r \\
P\end{array}$ & & & & & $\begin{array}{c}0.056^{\dagger} \\
.863\end{array}$ & $\begin{array}{c}-0.245^{\dagger} \\
.442\end{array}$ \\
\hline RGSD & $\begin{array}{l}r \\
P\end{array}$ & & & & & & $\begin{array}{c}0.588^{\dagger *} \\
.044\end{array}$ \\
\hline \multicolumn{8}{|c|}{ Low physical activity } \\
\hline sex & $\begin{array}{l}r \\
P\end{array}$ & $\begin{array}{c}-0.028^{\dagger} \\
.931\end{array}$ & $\begin{array}{c}-0.291^{\dagger} \\
.359\end{array}$ & $\begin{array}{c}-0.697^{\dagger *} \\
.012\end{array}$ & $\begin{array}{c}0.474^{\dagger} \\
.120\end{array}$ & $\begin{array}{c}-0.084^{\dagger} \\
.796\end{array}$ & $\begin{array}{c}-0.139^{\dagger} \\
.666\end{array}$ \\
\hline KES & $\begin{array}{l}r \\
P\end{array}$ & & $\begin{array}{c}0.062 \\
.848\end{array}$ & $\begin{array}{c}0.042^{\dagger} \\
.897\end{array}$ & $\begin{array}{c}0.126^{\dagger} \\
.697\end{array}$ & $\begin{array}{c}0.056^{\dagger} \\
.863\end{array}$ & $\begin{array}{c}0.427^{\dagger} \\
.167\end{array}$ \\
\hline$C D$ & $\begin{array}{l}r \\
P\end{array}$ & & & $\begin{array}{c}0.241^{\dagger} \\
.451\end{array}$ & $\begin{array}{c}-0.339^{\dagger} \\
.281\end{array}$ & $\begin{array}{c}-0.237^{\dagger} \\
.458\end{array}$ & $\begin{array}{c}0.007^{\dagger} \\
.982\end{array}$ \\
\hline QT & $\begin{array}{l}r \\
P\end{array}$ & & & & $\begin{array}{c}-0.182^{\dagger} \\
.572\end{array}$ & $\begin{array}{c}-.112^{\dagger} \\
.729\end{array}$ & $\begin{array}{l}0.203^{\dagger} \\
.527\end{array}$ \\
\hline RG & $\begin{array}{l}r \\
P\end{array}$ & & & & & $\begin{array}{c}0.322^{\dagger} \\
.308\end{array}$ & $\begin{array}{c}0.007^{\dagger} \\
.983\end{array}$ \\
\hline RGSD & $\begin{array}{l}r \\
P\end{array}$ & & & & & & $\begin{array}{c}-0.350^{\dagger} \\
.265\end{array}$ \\
\hline
\end{tabular}

$\mathrm{CD}=$ number of chronic diseases, $\mathrm{KES}=$ knee extensor strength normalized to body mass, $\mathrm{QT}=$ quadriceps thickness in relation to total thickness, $R G=$ Rectus grayscale, RGSD = rectus grayscale standard deviation, $\mathrm{GS}$ = gait speed, PA = physical activity

†correlations determined by the Spearman's correlation coefficient

*significance $p<.05$

Correlations of rectus femoris tissue heterogeneity with knee extensor strength, in those with normal and low physical activity are shown in Figure 1. Figure 2 presents two ultrasound images with different muscle tissue heterogeneity. 
Figure 1: Correlations between rectus femoris tissue heterogeneity and knee extensor strength

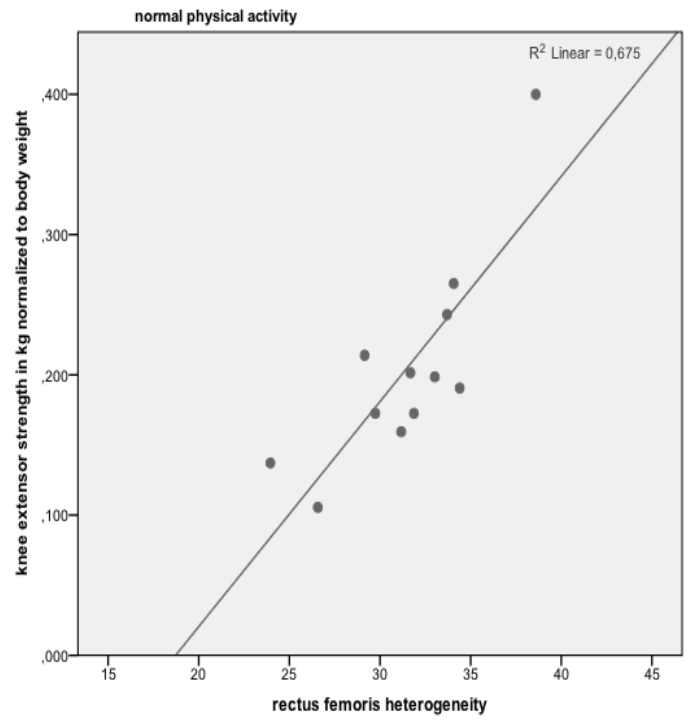

(A)

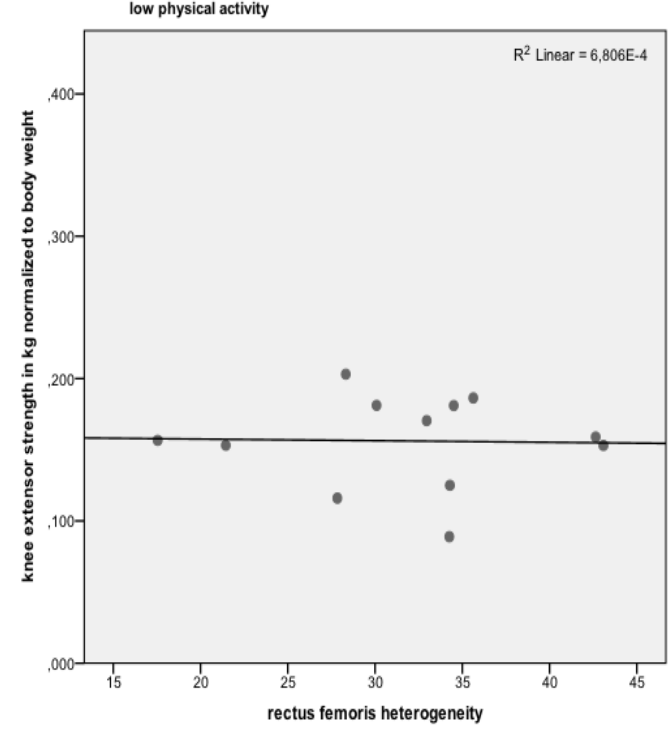

(B)

Scatterplot of rectus femoris tissue heterogeneity and knee extensor strength normalized to body mass in those with normal physical activity (A) and low physical activity (B).

Figure 2: Comparison of two ultrasound images different in grayscale standard deviation

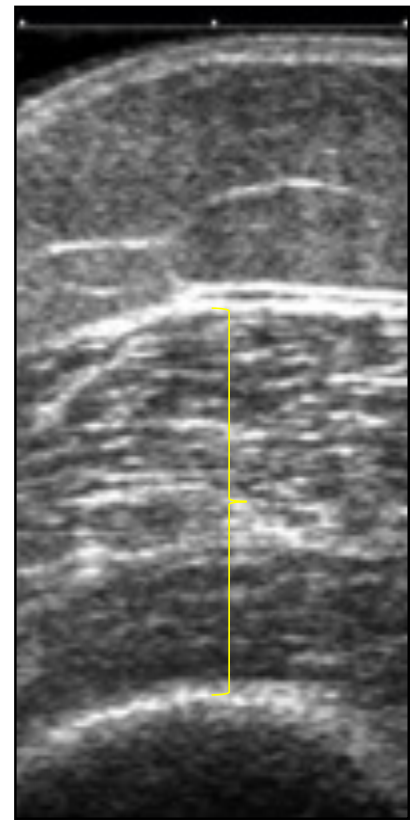

(A)

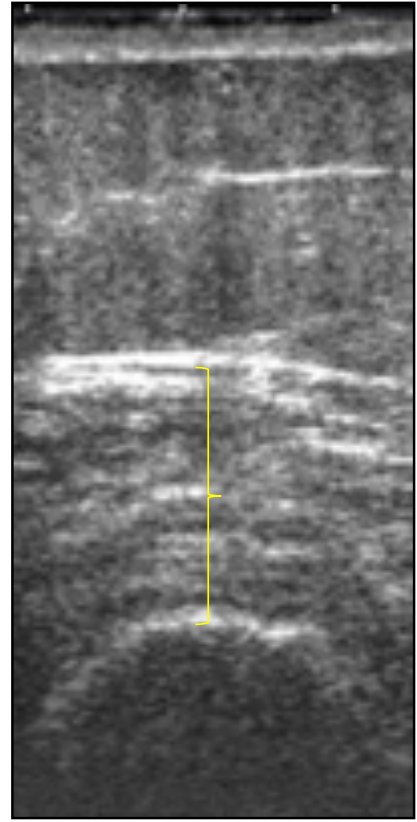

(B)

Two ultrasound images with similar grayscale value of muscle tissue (region indicated by yellow line) but different in grayscale standard deviation (SD): (A) higher grayscale SD (heterogeneous tissue) of a participant with normal physical activity level, (B) lower grayscale SD (homogenous tissue) of a participant with low physical activity level; the length of the yellow arrow defines the muscle thickness between subcutaneous tissue above it and bone below. 


\subsection{Discussion}

This study explored potential relationships among ultrasound derived indices of muscle quality characteristics, muscle function (gait speed) and physical activity in older, multimorbid nursing-home residents. This proof-of-concept study targeting muscle aging mechanisms showed that ultrasound assessments explored the relationship between muscle quality, strength of the knee extensors and gait speed in older nursing-home residents with normal physical activity. Ultrasound imaging seems to be a useful measure for detecting physical-activity-related muscle differences in this cohort, contributing to comprehensive sarcopenia assessment. It can be useful to detect differences in muscle quality associated with limitations in muscle function in people not capable of performing functional measures of strength.

While knee extensor strength values in the current study are comparable to strength values reported for nursing-home residents of other European countries [18], strength and muscle morphology were not related to age. Although muscle characteristics change over the lifespan, differences within a group of older, comorbid people might be more related to disuse than to age per se [1]. The relationship between knee extensor strength, muscle thickness and muscle morphology differed depending on the physical activity level in this sample of participants. The cut-off value for low- and normal-physical activity (279/383 kcal per week) in the current study is equivalent to the energy expended by a $50-\mathrm{kg}$ body mass woman whose only activity is to walk at a comfortable speed for 20 minutes a day, 5 times a week. Physical activity at this level reflects very little activity even for nursing home residents and is considered to be indicative of high disability [16].

In elderly residents with normal physical activity, tissue heterogeneity, a measure of muscle quality $[6,25]$, correlated with knee extensor strength but not thickness. This finding is consistent with previous literature in community-living elderly [10-13]. Muscle quality might, therefore, be a more appropriate indicator of age-related changes in muscle strength than muscle thickness. In the present study, muscle heterogeneity was not only related to strength in the subgroup with normal physical activity but also to gait speed, an important measure of functional status [1]. Even if a causal relationship cannot be established by these data, they indicate mutual impact between these factors. It is possible that minimizing the accumulation of non-contractile tissue in muscle through physical activity interventions [5] could also effectively improve noncontractile tissue dispersion and positively affect gait. Further research evaluating the impact of physical activity on muscle heterogeneity could verify this suggestion.

Within the low physical activity subgroup, no significant relationships were observed between knee extensor strength and common sonographic measures of muscle morphology (muscle thickness and echo intensity). This finding cannot be compared to the literature as, to our knowledge, this is the first study to evaluate those relationships in nursing-home residents concerning physical activity. One potential reason for the present results might be that once muscle strength drops below a certain threshold, morphological interactions are less apparent. Alternatively, it is possible that the sonographic approach in the present study is not sufficiently sensitive to detect 
physical activity-related differences in muscle of highly reduced condition. The detection of catabolic biomarkers in blood samples could potentially give more detailed information about muscular changes [5]. Another reason might be that neurological components of strength were not considered in this study as an explanatory factor for low strength. However, echotexture analysis of ultrasound images provides important information in the context of age-related muscle disorder even in older, comorbid nursing-home residents.

The present findings are indicative of the following hypotheses: 1 . Muscle quality contributes to age-related decrease in strength in nursing-home residents. Further research is needed to verify this hypothesis and should also focus on the neurological determinant of muscle strength. 2. Grayscale SD evaluated by echo intensity of ultrasound images could be used to detect differences in age-related muscle quality. The accordance of different methods detecting heterogeneity in muscle structure would have to be evaluated.

\section{Limitations}

One potential limitation of this study is that tissue heterogeneity is likely to vary within a given muscle and may be dependent on subcutaneous tissue thickness [25]. While this study adopted a standardized region of interest for estimating tissue heterogeneity, it should be recognized that calculation of parameters at the midpoint of the muscle, without taking subcutaneous tissue into consideration, may not be reflective of the whole muscle unit. The findings are, however, consistent with other studies in which tissue heterogeneity has been shown to be altered in neuromuscular disease and agerelated muscle wasting $[24,25]$. Secondly, we cannot be certain that the isometric strength measurements involved maximal effort of the participants. Discrepancies between voluntary muscle contraction und maximal possible contraction could have been detected by electrical muscle stimulation using the interpolated twitch technique [30] but this is not feasible outside of laboratory settings. Therefore, the assessment of maximal isometric voluntary contraction is an appropriate alternative as it has been shown to be reliable in strength detection of older adults in clinical settings [22]. Although further studies are needed to verify the results, the findings of the present study provide new insights into muscle characteristics in older, including oldest-old, institutionalized people.

\section{Conclusions}

The present results provide proof-of-concept that muscle tissue heterogeneity, a sonographically measured index of muscle quality, is positively related to knee extensor strength and gait speed, in older nursing-home residents with normal physical activity level. The findings indicate that the assessment of muscle quality from ultrasound images might be a more appropriate method to detect age-related differences in muscle than the evaluation of muscle thickness, at least in older people with normal physical activity. Given the sample size of the current study ( $n=24)$, assessment of ultrasound-derived muscle morphology in a larger population sample is 
warranted. Inclusion of these assessments may be recommended as part of a comprehensive assessment of sarcopenia and for monitoring the outcome of preventative interventions designed to improve muscle strength and function in older individuals. 


\subsection{References}

1. Cruz-Jentoft, A.J. and A.A. Sayer, Sarcopenia. Lancet, 2019. 393(10191): p. 2636-2646.

2. Shen, Y., et al., Prevalence and Associated Factors of Sarcopenia in Nursing Home Residents: A Systematic Review and Meta-analysis. J Am Med Dir Assoc, 2019. 20(1): p. 5-13.

3. Fragala, M.S., et al., Resistance Training for Older Adults: Position Statement From the National Strength and Conditioning Association. J Strength Cond Res, 2019. 33(8): p. 2019-2052.

4. Manini, T.M. and B.C. Clark, Dynapenia and aging: an update. J Gerontol A Biol Sci Med Sci, 2012. 67(1): p. 28-40.

5. Fragala, M.S., A.M. Kenny, and G.A. Kuchel, Muscle quality in aging: a multidimensional approach to muscle functioning with applications for treatment. Sports Med, 2015. 45(5): p. 641-58.

6. Correa-de-Araujo, R., et al., The Need for Standardized Assessment of Muscle Quality in Skeletal Muscle Function Deficit and Other Aging-Related Muscle Dysfunctions: A Symposium Report. Front Physiol, 2017. 8: p. 87.

7. Addison, O., et al., Intermuscular fat: a review of the consequences and causes. Int J Endocrinol, 2014. 2014: p. 309570.

8. Mayans, D., M.S. Cartwright, and F.O. Walker, Neuromuscular ultrasonography: quantifying muscle and nerve measurements. Phys Med Rehabil Clin N Am, 2012. 23(1): p. 133-48, xii.

9. Simon, N.G., Y.I. Noto, and C.M. Zaidman, Skeletal muscle imaging in neuromuscular disease. J Clin Neurosci, 2016. 33: p. 1-10.

10. Fukumoto, Y., et al., Skeletal muscle quality assessed from echo intensity is associated with muscle strength of middle-aged and elderly persons. Eur J Appl Physiol, 2012. 112(4): p. 1519-25.

11. Watanabe, Y., et al., Echo intensity obtained from ultrasonography images reflecting muscle strength in elderly men. Clin Interv Aging, 2013. 8: p. 993-8.

12. Rech, A., et al., Echo intensity is negatively associated with functional capacity in older women. Age (Dordr), 2014. 36(5): p. 9708.

13. Akazawa, N., et al., Relationships between intramuscular fat, muscle strength and gait independence in older women: A cross-sectional study. Geriatr Gerontol Int, 2017. 17(10): p. 1683-1688.

14. Ticinesi, A., et al., Muscle Ultrasound and Sarcopenia in Older Individuals: A Clinical Perspective. J Am Med Dir Assoc, 2017. 18(4): p. 290-300.

15. Hunter, S.K., H.M. Pereira, and K.G. Keenan, The aging neuromuscular system and motor performance. J Appl Physiol (1985), 2016. 121(4): p. 982-995.

16. Buckinx, F., et al., Relationship between ambulatory physical activity assessed by activity trackers and physical frailty among nursing home residents. Gait Posture, 2017. 54: p. 56-61.

17. Beaudart, C., et al., Assessment of Muscle Function and Physical Performance in Daily Clinical Practice : A position paper endorsed by the European Society for 
Clinical and Economic Aspects of Osteoporosis, Osteoarthritis and Musculoskeletal Diseases (ESCEO). Calcif Tissue Int, 2019. 105(1): p. 1-14.

18. Casas-Herrero, A., et al., Functional capacity, muscle fat infiltration, power output, and cognitive impairment in institutionalized frail oldest old. Rejuvenation Res, 2013. 16(5): p. 396-403.

19. Justice, J., et al., Frameworks for Proof-of-Concept Clinical Trials of Interventions That Target Fundamental Aging Processes. J Gerontol A Biol Sci Med Sci, 2016. 71(11): p. 1415-1423.

20. Morris, J.N., et al., MDS Cognitive Performance Scale. J Gerontol, 1994. 49(4): p. M174-82.

21. Stark, T., et al., Hand-held dynamometry correlation with the gold standard isokinetic dynamometry: a systematic review. PM R, 2011. 3(5): p. 472-9.

22. Arnold, C.M., et al., The reliability and validity of handheld dynamometry for the measurement of lower-extremity muscle strength in older adults. J Strength Cond Res, 2010. 24(3): p. 815-24.

23. Agyapong-Badu, S., et al., Anterior thigh composition measured using ultrasound imaging to quantify relative thickness of muscle and non-contractile tissue: a potential biomarker for musculoskeletal health. Physiol Meas, 2014. 35(10): p. 2165-76.

24. Cartwright, M.S., et al., Quantitative neuromuscular ultrasound in the intensive care unit. Muscle Nerve, 2013. 47(2): p. 255-9.

25. Harris-Love, M.O., et al., Association Between Muscle Strength and Modeling Estimates of Muscle Tissue Heterogeneity in Young and Old Adults. J Ultrasound Med, 2019. 38(7): p. 1757-1768.

26. Maurits, N.M., et al., Muscle ultrasound analysis: normal values and differentiation between myopathies and neuropathies. Ultrasound Med Biol, 2003. 29(2): p. 215-25.

27. Huy, C. and S. Schneider, [Instrument for the assessment of middle-aged and older adults' physical activity: design, eliability and application of the GermanPAQ-50+]. Z Gerontol Geriatr, 2008. 41(3): p. 208-16.

28. Ainsworth, B.E., et al., Compendium of physical activities: an update of activity codes and MET intensities. Medicine and Science in Sports and Exercise, 2000. 32(9 Suppl): p. S498-504.

29. Fried, L.P., et al., Frailty in older adults: evidence for a phenotype. J Gerontol A Biol Sci Med Sci, 2001. 56(3): p. M146-56.

30. McPhee, J.S., et al., Knee extensor fatigue resistance of young and older men and women performing sustained and brief intermittent isometric contractions. Muscle Nerve, 2014. 50(3): p. 393-400. 


\section{Chapter 7}

\section{General Discussion}

In this thesis, an insight into muscle strength in people aged 75 years and over was gained on the basis of strength assessments for overall health monitoring, prevalence of probable sarcopenia, and the functional impairment and neuromuscular changes associated with low muscle strength in oldest-old people (over 85 years).

Previous research evaluating physical health in the elderly has focussed on the socalled "young old" age group, those aged 65-74 years, and contributed to an increased health condition over the last 20 years [1]. With increasing life expectancy in the next decades, there will be a disproportionate increase in the older-old (75-84 years) and oldest-old age groups (85 years and above) [2] in the community along with an expected high prevalence of age-related muscle disorder [3] accompanied by a further decline in physical health [4].

Collectively, this research had three aims; 1 . To provide reference values of strength measures of the older-old and oldest-old people for clinical use 2. to provide data for public health monitoring, 3 . to provide initial evidence of neuromuscular changes in a population not previously studied for further investigations.

This chapter summarizes the main findings, and discusses how they support and add to the existing literature. Finally, clinical implications and future research possibilities building upon this research are reported. 


\subsection{Main findings and clinical implications}

\subsubsection{Handgrip strength in oldest-old adults}

From the perspective of overall physical health, the oldest-old age group is at increased risk for multi-morbidity, poly-medication, complex geriatric syndromes such as frailty, and associated functional limitations [5, 6]. Comprehensive geriatric assessments are necessary to evaluate all determinants of health decline in this population. However, handgrip strength is recommended as a conclusive stand-alone measurement to monitor older people for risk of poor health [7]. Sex, age and locationspecific reference values of handgrip strength demonstrate the range of values that are accountable for health-related factors such as chronic diseases, physical activity level and nutritional intake [8-13]. To date, these specific reference values for men and women of the highest age groups are available for the following European regions: the Netherlands (up to 95 years) [14], Denmark, Southern France and Southern Italy (up to $>100$ years) [9]. In Switzerland, normative data of age- and gender-specific handgrip strength have been evaluated for older people up to the age of 84 years [15]. The present cross-sectional data of the Swiss population (aged 75-100 years), outlined in

Chapter 2, demonstrated identical strength values for the age group 75-84 years to the previously published Swiss sample and therewith, confirmed previous findings. In addition, the findings expanded existing data of men by the age-group 85-99 years and data of women by the age-groups 85-89 and 90-99 years. In men, handgrip strength of the oldest-old people (maximum \pm SD $29.3 \pm 7.3$ ) did not differ from the age-group 80-84 years but was significantly lower than in people aged 75-79 years. In women, the oldest-old age groups (85-89 and 90-99 years) were not significantly different from each other (maximum \pm SD $19.0 \pm 3.8$ and $16.5 \pm 4.7$ respectively). However, handgrip strength in both groups was significantly lower than in the younger age-groups (75-84 years). Collectively with previously published handgrip strength data of the Swiss population [15], the present results provide stable reference values for men and women aged 75-99 years, as reference values were based on samples of $n=57-102$ per age-group. The age- and gender- distribution of the study sample, as well as the percentage of people dependent in daily activities, were comparable with the Swiss population of the same geographic region [16]. Hence, the reference values can be considered generalizable to the population of German-speaking Switzerland.

\section{Clinical implications}

The reference values of handgrip strength are of direct use for clinical measures as part of a) the routine geriatric assessments in practices of general practitioners, b) the entry examination and subsequent checks in nursing-homes, c) the screening of strength for initiating interventions by physical therapists in Switzerland. Indirectly, the availability of full range of reference values could increase the use of handgrip strength measures to screen for overall strength and physical health. Moreover, it can increase the awareness of people for strength as an important source of current and future health. 
7.1.2. Prevalence of probable sarcopenia in community-living older people

From the perspective of specific risk assessment for age-related muscle wasting, (pre) sarcopenia, people are assessed for handgrip strength and categorized based on cutoff values according to the newest guidelines for diagnosing sarcopenia [17]. Previously, the primary indicator of sarcopenia was low muscle mass [18]. The evaluation of lean body mass with the gold standard of Dual Energy X-Ray Absorptiometry led to an estimated prevalence of pre-sarcopenia of about $30 \%$ and $50 \%$ in old-old and oldest-old men and women [19]. Interventions aiming to improve sarcopenia were focused on increasing muscle mass. In 2019 the guidelines were changed [17]. Taking research results about age-related changes of muscle characteristics and their implication for functional decline into account, strength has found to be superior as the primary indicator of sarcopenia. The application of the new guidelines is important for health monitoring of the population. The detection of low handgrip strength rather than low muscle mass may provide prevalence updates, relevant for predictions of future disease occurrences and strategies to prevent sarcopenia [20]. However, point prevalence data of low handgrip strength have not yet been evaluated for the Swiss population. So far, prevalence of low strength has been reported for older Asian people (mean age 70-80 years) and ranged between $10 \%$ and $17 \%$ [21, 22]. In older Northern/Central Europeans (mean age 80-90 years), the prevalence in community-living men [23], and in male and female inpatients [20] was higher $(28 \%, 33 \%$, and $28 \%$, respectively). The present study, outlined in Chapter 3 , evaluated prevalence data of low handgrip strength in a representative sample of the older-old and oldest-old German-Swiss population. Results confirmed previous data of non-hospitalized Northern European men as prevalence of probable sarcopenia (28\%) was commensurate with community-living men from Sweden. The findings added data of community-living, non-hospitalized women (prevalence of probable sarcopenia: $26.3 \%$ ) which have not been evaluated before. Collectively with data from Northern/central European countries, they might provide references for the northern part of Europe.

It is well researched that decreased handgrip strength is a strong risk factor for functional decline [7]. As for the specific predictive value of low handgrip strength, identified by sarcopenia-specific cut-off of $16 \mathrm{~kg}$ for women and $27 \mathrm{~kg}$ for men, it has been shown previously that low handgrip strength is associated with independent aging (defined by "absence of diagnosed dementia and Mini Mental State Examination $\geq 25$ points, community-dwelling, independence in personal ADL and ability to walk outdoors alone") [23]. The present results contributed new knowledge that people with probable sarcopenia had an increased risk of 2.8 to be dependent in ADL compared to people with normal strength. Moreover, ADL performance seemed to be an independent predictor of probable sarcopenia. Even though a cause-effect relationship cannot be derived from these cross-sectional data, existing prospective studies support this hypothesis $[24,25]$. They have shown that handgrip strength decreases as a consequence of reduced engagement in demanding activities in daily living [24, 25]. It is likely that muscle strength and ADL performance have mutual influence, so 
that strength training as well as using as much strength as possible in every-day tasks could prevent ADL dependence.

Overall, the prevalence of people with probable sarcopenia, indicating the risk for sarcopenia, dropped by up to $22 \%$ when the new definition with low strength as the initial characteristic was applied. The focus on strength rather than muscle mass in detecting probable sarcopenia identified a different subgroup of people with agerelated muscle disorder [20]. However, the comparison of findings across age-groups and continents and between healthy, community-living people and inpatients demonstrated that population specificity in prevalence studies of probable sarcopenia in regard to age, ethnic groups and institutionalization is important for exact health data.

Clinical implications

Prevalence data of probable sarcopenia help to monitor an important aspect of health status. Detecting a pre-stage of sarcopenia allows timely initiation strategies and interventions to be put in place that aim to prevent further decline. When further muscle wasting can be stopped or delayed, physical health of the individual as well as health care costs would benefit immensely [17]. Moreover, health care costs represented by higher rates of hospitalization, nursing home admissions and community healthcare expenditure in sarcopenic patients compared to non-sarcopenic patients, as well as sarcopenia-related comorbidities, could be reduced substantially [26, 27]. The detection of the prevalence of probable sarcopenia, identified by handgrip strength, confirms the need of routine strength assessment, as outlined in the previous paragraph. By applying cut-off values to classify people as having probable sarcopenia, a population with distinct risk of potential future health problems has been investigated. Therefore, the present study reported in Chapter 3 provides data that are clinically relevant to monitor the health condition of the Swiss population, which is important for effective health management. The results about prevalence of probable sarcopenia and factors associated with low strength could inform health insurance companies about the importance of effective strategies to reverse muscle weakness.

\subsubsection{Feasibility and relevance of strength tests in nursing-home residents}

The prevalence of probable sarcopenia in oldest-old nursing-home residents is proposed to be much higher than in community-dwelling elderly but objective evaluation is challenging. The handgrip strength test and the chair stand test are currently the recommended strength tests for detection of probable sarcopenia [17]. Both tests have been shown to be valid and reliable in detecting different aspects of strength [28], and predictive of functional decline. They are also widely used by research studies evaluating adverse health outcomes, and have been shown to be feasible for evaluating the strength of well-functioning, community-living elderly [7, 29]. However, in oldest-old nursing-home residents, research as to the feasibility of these tests has shown conflicting results [28, 30]. Moreover, associations of probable sarcopenia, detected by handgrip strength $<27 \mathrm{~kg}$ for men and $<16 \mathrm{~kg}$ for women, or 
by the chair stand test $>15$ seconds, with adverse health outcomes have not been explored, as outlined in the introduction of Chapter 3.

Handgrip strength assessment using the customary JAMAR ${ }^{\circledR}$ hand-dynamometer was suggested to cause difficulties in oldest-old populations due to the rigidity and weight of the device [30]. However, previous studies using the $\mathrm{JAMAR}^{\circledR}$ in oldest-old people without hand pain or stiffness did not report on any problems with performing the test procedure or using the device [31-33]. In the present study, people with hand pain or stiffness were excluded from participation, and the examiner supported the base of the dynamometer for testing, following the guidelines of the standard procedure [34]. All participants included in the study were able to perform the handgrip strength test using the $\mathrm{JAMAR}^{\circledR}$ hand-dynamometer; none of them expressed any difficulties.

Therefore, the cross-sectional data, outlined in Chapter 4, confirmed the good applicability of the handgrip strength test in oldest-old nursing-home residents even if alternative testing equipment with softer handles might be more comfortable [30]. Nonetheless, by means of the test performance, it is uncertain if participants achieved their maximal possible strength, as limitations due to decreased neural drive were not evaluated. A future reliability study could verify intra-tester and inter-tester reliability of the handgrip strength assessment with different test devices. Including electrical nerve or muscle stimulation with twitch interpolation would also objectify neural aspects on voluntary grip strength [35] but would only be practical in a laboratory environment. Inconsistency of repeated efforts can indicate lack of maximal effort, so is a useful clue in situations when it is not possible to verify that effort is maximal.

As for the chair stand test, the health condition seemed to play a crucial role for test performance. In previous studies it has been shown that particularly frail and acutely ill older adults could not complete 5 repetitions [28, 32, 36, 37] as defined in the original test procedure [38]. The present results confirm those findings as only about $50 \%$ of the participants could complete the chair rise test. The findings added the knowledge that even one repetition is impossible for some oldest-old, multi-morbid, frail people. Therefore, the original version of the chair stand test is suggested to be modified for oldest-old and vulnerable people. Based on the results of Chapter 4, the point prevalence of probable sarcopenia in nursing home residents $(80 \%)$ was much higher than that in non- institutionalized people of the same age (26-28\%, Chapter 3$)$.

Muscle strength as well as the ability to rise from a chair without using the arms for support have been shown to be related to functional performance, ADL independence and frailty in people in need of care [39]. As for specific risk indication of probable sarcopenia for functional limitations, low handgrip strength has been shown to detect oldest-old, long-term care residents with very low gait speed [32], indicating great limitations in community ambulation [40]. The present results confirmed previous findings as probable sarcopenia detected participants who were significantly slower in walking than people without probable sarcopenia. Findings of Chapter 4 added the knowledge that both low handgrip strength ( $<27 \mathrm{~kg}$ for men and $<16 \mathrm{~kg}$ for women) and slow chair stand test (> 15 seconds or participant not able to perform test), predicted low gait speed to $77 \%$ and $79 \%$ respectively. Moreover, probable sarcopenia, evaluated by low handgrip strength, detected frailty to $72 \%$ while no/slow 
chair stand test detected it by $85 \%$. Low HGS was probably superior to the CST in expressing functional limitations as it also indicated low overall strength and dependence in basic ADL. The findings of Chapter 4 showed for the first time that probable sarcopenia had a high indicative value for functional capacity in nursing-home residents.

\section{Clinical implications}

To date, standardized assessment of strength, physical function and frailty is typically not undertaken in nursing-homes [41]. The research findings about feasibility and relevance of detecting probable sarcopenia in this group of the oldest-old people may contribute to clinical implementation of strength testing in the long term. Based on the present and previous findings, HGS is recommended in nursing-homes as part of the entry assessment and sheds light on the ease of performance of this test. The indication of adverse outcomes by low HGS, verified in larger, longitudinal studies, may highlight HGS as a screening test not only for overall strength but also for function, ADL performance and frailty. Screening tests could help recognize and counteract further decline in a timely manner.

\subsubsection{Relationship between quadriceps muscle strength and dependence in daily activities in nursing home residents}

While handgrip strength is an estimate of whole body strength, specific lower extremity muscle characteristics could explain ADL performance in more detail to advance exercise programs to improve independence in daily activities. Whether residents are dependent or independent in basic ADL mainly depends on their ability to turn in bed, to get up from bed, a chair and the toilet with/without using their hands, to do self-care, to walk short distances within and outside their living room with/without a walking aid. Quadriceps strength has been shown to be a key component for remaining independent in these activities [42, 43]. Community-dwelling people aged 83 years admitted to primary care were shown to have quadriceps strength of $25 \mathrm{~kg}(\approx 2.7$ $\mathrm{Nm} / \mathrm{kg}$ peak torque normalized to body mass) [44] while peak isometric torque of 3-3.5 $\mathrm{Nm} / \mathrm{kg}$ body mass is necessary for getting up from a sitting position and for walking without using the hand/arms [42]. In nursing-home residents, this threshold is supposed to be lower due to the use of arm and hands in almost all activities. In the present study quadriceps strength of (pre)frail, nursing-home residents was moderately correlated to ADL dependence $\left(r_{s}=0.67, p<.001\right)$, with mean strength values of $11.4 \mathrm{~kg}$, respectively $0.52 \mathrm{Nm} / \mathrm{kg}$ when torque was calculated and normalized to body mass. These results were in accordance with previous research evaluating quadriceps strength in frail, oldest-old, institutionalized people $(12.9 \mathrm{~kg})[45,46]$. In Chapter 5 we provided the first evidence that an isometric quadriceps strength of $>$ $11 \mathrm{~kg}$ (quadriceps torque of $0.52 \mathrm{Nm}$ per kg body mass) is $100 \%$ sensitive and $79 \%$ specific in predicting ADL-independence in this population. When quadriceps torque was calculated, and normalized to body weight, people independent in ADL had 0.6 $\mathrm{Nm} / \mathrm{kg}$ compared to people dependent in ADL with $0.4 \mathrm{Nm} / \mathrm{kg}$. Although the results 
have to be verified in prospective studies, the findings from Chapter 5 indicated that quadriceps strength is an independent predictor of ADL dependence taking handgrip strength, elbow-flexor strength, urinary incontinence and number of chronic diseases into account.

\section{Clinical implications}

Based on these findings, quadriceps strength measure can be recommended as a specific screening test for ADL performance in nursing-home residents with values $\leq$ $11 \mathrm{~kg}$ predicting high risk of ADL dependence. In addition, the results might help existing exercise recommendations to specify the program and target strength of 11 $\mathrm{kg}$ for improvement of ADL independence.

\subsubsection{Muscle quality in muscles of oldest-old, institutionalized people}

Exercise programs aiming at increasing quadriceps strength along with physical function have been shown to be successful even in co-morbid people with frailty [4750] However, their overall efficacy in improving ADL performance is small [51] and the variability of motor performance increases in oldest-old people [52].

Assuming that neuromuscular plasticity is maintained even in oldest age groups [53], it should be possible to enhance the effect of exercise. One possibility is to increase protein synthesis e.g. through complementary supplementation of protein in malnourished people [54]. Another possibility might be to improve tissue modification in response to exercises that specifically addresses strength-related neurological and muscular components [52]. As muscle strength and rate of force development decreases with age, the decline accelerates from the age of 80 years on [52]. This rapid decline has been shown to be related to a reduction in muscle mass [53, 55]; however, the change in strength exceeds the change in mass [56]. Contraction quality of the muscle, affected by intramuscular adipose tissue accumulation and reduced capacity to voluntarily activate the muscles through decreased neural activation, appears to explain strength decline in oldest-old people to a great extent $[52,55,56]$. Of these muscular and neural components, contraction quality of a muscle is part of the algorithm for detection of sarcopenia [17].

In specialized clinical investigations, diminished muscle quality is commonly detected by increased echo intensity (expressed as higher grayscale values) of muscle ultrasound images [57]. Higher grayscale values have been shown to be related to isometric quadriceps strength in community-living, healthy, active elderly [58-60]. The results presented in Chapter $\mathbf{6}$ added proof of concept that the relationship between ultrasound-derived index of muscle quality and strength also exists in oldest-old, comorbid, frail nursing-home residents. This relationship seemed to be dependent on physical activity as it was only apparent in people who expended more than 270/383 kcal of energy per week. Assuming that people with physical activity levels below this threshold can be considered very vulnerable and at risk for no return to improve strength, the results might be important for detecting people who would respond to exercise. This hypothesis was based on cross-sectional data collected from a small 
sample and needs to be verified in a larger cohort study. However, improving physical activity in nursing-home residents has previously been shown to be crucial to prevent disability but also, that it might not be effective in reversing functional capacity in people with muscle decline below a certain level [61].

In studies evaluating muscle quality by ultrasonography, grayscale values are typically used to express changes in echo intensity [58-60,62] reflecting age-related alterations in muscle composition. The results of Chapter 6 demonstrated that the ultrasound grayscale standard deviation, which reflects the heterogeneity in the composition of muscle tissue, was also indicative for age-related intramuscular changes. Therewith, the present data were in accordance with previous findings in intensive care unit patients [63] and might provide an additional muscle quality index with potential to evaluate age-related intramuscular changes. As demonstrated by the present findings in Chapter 4, some measures of muscle characteristics that are typically used in healthy, young-old community living people are not feasible in oldest-old nursing-home residents, such as the chair stand test. Ultrasound imaging of muscle might be a valuable alternative to evaluate age-related changes in this cohort [64].

\section{Clinical implications}

The findings about the relationship between the index of muscle quality and muscle strength indicate the usefulness of ultrasound imaging in clinical sarcopenia assessment in nursing-home residents. They provide information about muscle characteristics in oldest-old people and might contribute to advancing specific interventions aiming to improve strength in this cohort. The results shed light on the importance of physical activity for preventing strength loss in nursing-home residents, as already recommended [61]. 


\subsection{Methodological considerations and limitations}

1. The findings reported in this thesis are based on two cross-sectional studies. The research design allowed for the rapid and cost-effective collection of normative strength data in representative cohorts and identification of factors that are associated with low strength. The design did not provide insight into temporal relationships or causation. Nonetheless, the results identified key factors as a basis for future prospective studies.

2. The intra-tester reliability of the measures used in this thesis to evaluate strength (hand-held dynamometry) and ultrasound-derived muscle characteristics (muscle thickness and echogenicity) in nursing-home residents was shown previously to be high in healthy, older adults (ICC 0.88-0.99) [6568]. However, reliability has not explicitly been tested in older-old and oldestold multimorbid people above the age of 75 years. As motor performance and clarity of ultrasound images may vary more in the oldest age groups compared to young-old people, reliability studies need to be conducted to verify the variability of repeated measures. Retrospectively, it was acceptable to evaluate the relationship between ultrasound-derived muscle quality and strength of the quadriceps in oldest-old nursing-home residents prior to reliability testing, as the positive results demonstrated proof of concept, indicating that investing in comprehensive reliability studies will be worthwhile.

3. The results are premised on sample sizes of a) $n>200$ for reference values of handgrip strength for the older-old and oldest-old Swiss population and point prevalence data of probable sarcopenia in community-living elderly; and b) $n>$ 20 for evaluations in nursing-home residents. Oldest-old adults and particularly nursing-home residents are underrepresented in health-related research [69, 70]. The lack of enrollment of this cohort in research studies is related to concerns of researchers as well as of potential participants [69]. The barriers for researchers are the great heterogeneity of the cohort in many health aspects, safety risks in study procedures due to physical impairment and recruitment difficulties due to cognitive limitations [69, 70]. The cohort's reluctance to participate is explained by e.g. a lack of understanding the study protocol and procedure, distrust of research and complicated access of the study site [69]. The experience of undertaking the studies of this thesis tends to confirm the barriers to research identified in the literature [69, 70]. For instance, recruitment of participants was difficult, as many were very reluctant to volunteer. Anecdotally, the reluctance of community-dwelling older people to participate in this research was related to their perception of the benefits of participation relative to the time-consuming nature of the study procedures. Some people questioned whether their participation in the research would generate tangible benefits for older populations. Nursing-home residents were often reticent to volunteer due to the intimidating nature of the obligatory 6-page 
study protocol required for informed consent and because of a fear of potential over-exertion imposed by the study procedures. To meet the concerns, they were raised and discussed with potential participants in the presence of family members or representatives in personal information meetings, either via phone or in face-to-face visits. Trust, communication and practical translation of research findings were, therefore, critical for the engagement of elderly people in this research. Although number of participants was still restricted and might limit generalizability to the whole population, the samples were representative of oldest-old people in Switzerland in important aspects of physical function and ADL performance and can be considered sufficient to provide insight into this cohort. Results in community-living people and nursing-home residents are consistent with findings of other authors measuring handgrip strength in Switzerland, the Netherlands and Denmark [9, 14, 15], as outlined in the discussion of Chapter 2; limitation section of Chapter 3; discussion of Chapter 6. The results could therefore be considered valid for the oldest-old Swiss and potentially also for people from Northern/Central Europe.

Evaluations in nursing-home residents in the present research, reporting relationships of strength with health-related components and neuromuscular changes, were based on univariate analysis due to small sample sizes. Therefore, the relative influence of the predictor variables on the dependent variable and probable confounding between variables could not be determined. Correlations need to be replicated in larger cohorts applying multivariate analysis. The present findings were novel in this area of research and provide sufficient preliminary evidence as the basis for further research.

4. Some analyses in this thesis did not consider a comprehensive range of variables (Chapter 3-5). Low handgrip strength in Chapter 3, for example, was used to detect probable sarcopenia. However, it could not be ruled out that some of the people identified had true sarcopenia or even severe sarcopenia, as neither muscle quantity, quality nor function had been measured in addition to strength, as defined by the algorithm for detection of sarcopenia. However, the people that were detected with probable sarcopenia constitute a group with age-related muscle disorder at high risk for further decline.

Moreover, quadriceps strength was shown to be important for independence in daily activities in nursing-home residents. Since no other leg muscles except the quadriceps were evaluated specifically, comprehensive reporting about relevant muscles for independence in ADL cannot be achieved. However, based on the literature, the key muscles important for ADL were selected. Therefore, the research findings contribute important knowledge to the small existing body of literature about strength thresholds in oldest-old nursing-home residents. 
Clinical measures very suitable for clinical research readily available to clinicians were used for evaluation of strength, determinants of strength and intramuscular alterations with age. While measures such as Dual Energy X-Ray Absorptiometry, Magnetic Resonance Imaging and Doubly labelled water measures may provide more accurate estimates of lean body mass, muscle morphology and physical activity, they are not suitable for use in large cohorts and in field-based settings. Measures with good performance characteristics were used in this thesis, and questionnaires have been administered as interviews, to get data as meaningful as possible. This thesis promotes the use of hand-held dynamometry and ultrasound imaging in research of oldest-old people and supports justification for providing these resources in nursing homes. 


\subsection{Future research questions}

While this thesis has demonstrated that handgrip strength assessment in oldest-old people is feasible and meaningful for health-related adverse outcomes, the project has also raised additional questions for future work. Areas for future research are summarized below:

1. What is the intra-tester and inter-tester reliability of the handgrip strength test, the chair stand test, hand-held dynamometry of knee extensors and elbow flexors for detection of isometric muscle strength, and ultrasound measures of muscle thickness and quality reliable (intra-tester and inter-tester reliability) in oldest-old people? (repeated measures study design)

2. Does provision of reference data of handgrip strength to professionals for the classification of health status in older adults increase the use of strength measures in routine geriatric examination? (multicenter prospective cohort study)

3. Is low handgrip strength, as a surrogate measure of probable sarcopenia, sufficiently sensitive to detect longitudinal changes in ADL performance? (prospective cohort study)

4. Does promotion of increased use of strength in daily activities, including demanding household tasks, change the prevalence of probable sarcopenia in the population? (randomized controlled trial)

5. Does low handgrip strength predict adverse outcomes regarding frailty and gait speed in a follow-up of 3 and 6 months? (prospective cohort study)

6. Is the CST from a chair of height $2 / 3$ of leg length a feasible test in nursinghome residents? (cross-sectional study)

7. Do specific exercises aiming at improving strength delay the onset of disability in nursing-home residents with low quadriceps strength? (randomized controlled trial)

8. Which leg and arm muscles are primarily relevant for independence in ADL in nursing-home residents? (prospective cohort study)

9. How do muscle quantity, quality and neural drive determine muscle strength in oldest-old people? (cross-sectional study)

10. What is the temporal relation between changes in muscle strength and muscle composition? (prospective cohort study) 
11. Do exercise programs improve muscle quality in older-old people with reduced muscle strength and altered muscle composition? (randomized controlled trial)

12. What is the cost-effectiveness of exercise interventions to improve muscle strength and functional independence in the older-old and oldest-old? (multicenter randomized controlled trial) 


\subsection{Conclusions}

Despite the methodological considerations discussed above, this research has established reference values for hand grip strength in older-old and oldest-old community-living Swiss adults for health monitoring (Chapter 2). It has for the first time estimated the prevalence of probable sarcopenia of the Swiss population, an important preliminary stage of true sarcopenia, showing that up to $28 \%$ of those aged 75 years and over are at risk of sarcopenia (Chapter 3). This research has also shown that handgrip strength is more feasible than the chair stand test to detect probable sarcopenia in those most at risk, institutionalised elderly and highlighted that low handgrip strength is an estimate of overall strength, meaningful in indicating ADL dependence and frailty (Chapter 4). This research has, for the first time, identified thresholds for thigh strength that can be used to predict ADL dependence in nursinghome residents with $100 \%$ sensitivity and $79 \%$ specificity (Chapter 5). Finally, this research has explored that sonographic measures of muscle quality have the potential to evaluate age-related muscle wasting in institutionalised people and guide interventions aiming to improve strength (Chapter 6). However, further research in larger cohorts is warranted to establish reliability of measures in the oldest-old and verify the present results before clinical implementation of muscle assessment in nursing-home residents can be recommended.

The results provide data to monitor important health aspects in oldest-old communityliving and institutionalized people and give first insights into age-related muscle changes and their relationships with adverse health outcomes. 


\subsection{References}

1. Ludwig C, Cavalli S, Oris M. "Vivre/Leben/Vivere": An interdisciplinary survey addressing progress and inequalities of aging over the past 30 years in Switzerland. Arch Gerontol Geriatr. 2014;59(2):240-8.

2. United Nations DoEaSA. World Population Ageing2017 January 21, 2019:[2-42 pp.].

3. Ethgen O, Beaudart C, Buckinx F, Bruyere O, Reginster JY. The Future Prevalence of Sarcopenia in Europe: A Claim for Public Health Action. Calcif Tissue Int. 2017;100(3):229-34.

4. Cohen-Mansfield J, Shmotkin D, Blumstein Z, Shorek A, Eyal N, Hazan H, et al. The old, old-old, and the oldest old: continuation or distinct categories? An examination of the relationship between age and changes in health, function, and wellbeing. Int J Aging Hum Dev. 2013;77(1):37-57.

5. de Souto Barreto P, Morley JE, Chodzko-Zajko W, K HP, Weening-Djiksterhuis E, Rodriguez-Manas L, et al. Recommendations on Physical Activity and Exercise for Older Adults Living in Long-Term Care Facilities: A Taskforce Report. J Am Med Dir Assoc. 2016;17(5):381-92.

6. Buckinx F, Reginster JY, Gillain S, Petermans J, Brunois T, Bruyere O. Prevalence of Frailty in Nursing Home Residents According to Various Diagnostic Tools. J Frailty Aging. 2017;6(3):122-8.

7. Bohannon RW. Grip Strength: An Indispensable Biomarker For Older Adults. Clin Interv Aging. 2019;14:1681-91.

8. Frederiksen H, Hjelmborg J, Mortensen J, McGue M, Vaupel JW, Christensen $\mathrm{K}$. Age trajectories of grip strength: cross-sectional and longitudinal data among 8,342 Danes aged 46 to 102. Ann Epidemiol. 2006;16(7):554-62.

9. Jeune B, Skytthe A, Cournil A, Greco V, Gampe J, Berardelli M, et al. Handgrip strength among nonagenarians and centenarians in three European regions. $J$ Gerontol A Biol Sci Med Sci. 2006;61(7):707-12.

10. Andersen-Ranberg K, Petersen I, Frederiksen H, Mackenbach JP, Christensen $\mathrm{K}$. Cross-national differences in grip strength among $50+$ year-old Europeans: results from the SHARE study. Eur J Ageing. 2009;6(3):227-36.

11. Rantanen T, Volpato S, Ferrucci L, Heikkinen E, Fried LP, Guralnik JM. Handgrip strength and cause-specific and total mortality in older disabled women: exploring the mechanism. J Am Geriatr Soc. 2003;51(5):636-41.

12. Cheung CL, Nguyen US, Au E, Tan KC, Kung AW. Association of handgrip strength with chronic diseases and multimorbidity: a cross-sectional study. Age. 2013;35(3):929-41.

13. McCormick R, Vasilaki A. Age-related changes in skeletal muscle: changes to life-style as a therapy. Biogerontology. 2018;19(6):519-36.

14. Ling CH, Taekema D, de Craen AJ, Gussekloo J, Westendorp RG, Maier AB. Handgrip strength and mortality in the oldest old population: the Leiden 85-plus study. CMAJ. 2010;182(5):429-35.

15. Werle S, Goldhahn J, Drerup S, Simmen BR, Sprott H, Herren DB. Age- and gender-specific normative data of grip and pinch strength in a healthy adult Swiss population. J Hand Surg Eur Vol. 2009;34(1):76-84. 
16. Betagte Personen in Institutionen [Internet]. bfs. 2011.

17. Cruz-Jentoft AJ, Bahat G, Bauer J, Boirie Y, Bruyere O, Cederholm T, et al. Sarcopenia: revised European consensus on definition and diagnosis. Age Ageing. 2019.

18. Cruz-Jentoft AJ, Baeyens JP, Bauer JM, Boirie Y, Cederholm T, Landi F, et al. Sarcopenia: European consensus on definition and diagnosis: Report of the European Working Group on Sarcopenia in Older People. Age Ageing. 2010;39(4):412-23.

19. lannuzzi-Sucich M, Prestwood KM, Kenny AM. Prevalence of sarcopenia and predictors of skeletal muscle mass in healthy, older men and women. $J$ Gerontol A Biol Sci Med Sci. 2002;57(12):M772-7.

20. Reiss J, Iglseder B, Alzner R, Mayr-Pirker B, Pirich C, Kassmann H, et al. Consequences of applying the new EWGSOP2 guideline instead of the former EWGSOP guideline for sarcopenia case finding in older patients. Age Ageing. 2019.

21. Kim M, Won CW. Prevalence of sarcopenia in community-dwelling older adults using the definition of the European Working Group on Sarcopenia in Older People 2: findings from the Korean Frailty and Aging Cohort Study. Age Ageing. 2019.

22. Su Y, Hirayama K, Han TF, Izutsu M, Yuki M. Sarcopenia Prevalence and Risk Factors among Japanese Community Dwelling Older Adults Living in a SnowCovered City According to EWGSOP2. J Clin Med. 2019;8(3).

23. Franzon K, Zethelius B, Cederholm T, Kilander L. The impact of muscle function, muscle mass and sarcopenia on independent ageing in very old Swedish men. BMC Geriatr. 2019;19(1):153.

24. Alexandre Tda S, Corona LP, Nunes DP, Santos JL, Duarte YA, Lebrao ML. Gender differences in incidence and determinants of disability in activities of daily living among elderly individuals: SABE study. Arch Gerontol Geriatr. 2012;55(2):431-7.

25. Rantanen T, Era P, Heikkinen E. Physical activity and the changes in maximal isometric strength in men and women from the age of 75 to 80 years. J Am Geriatr Soc. 1997;45(12):1439-45.

26. Mijnarends DM, Luiking YC, Halfens RJG, Evers S, Lenaerts ELA, Verlaan S, et al. Muscle, Health and Costs: A Glance at their Relationship. The journal of nutrition, health \& aging. 2018;22(7):766-73.

27. Beaudart C, Rizzoli R, Bruyere O, Reginster JY, Biver E. Sarcopenia: burden and challenges for public health. Arch Public Health. 2014;72(1):45.

28. Beaudart C, Rolland Y, Cruz-Jentoft AJ, Bauer JM, Sieber C, Cooper C, et al. Assessment of Muscle Function and Physical Performance in Daily Clinical Practice : A position paper endorsed by the European Society for Clinical and Economic Aspects of Osteoporosis, Osteoarthritis and Musculoskeletal Diseases (ESCEO). Calcif Tissue Int. 2019;105(1):1-14.

29. Cesari M, Kritchevsky SB, Newman AB, Simonsick EM, Harris TB, Penninx BW, et al. Added value of physical performance measures in predicting adverse 
health-related events: results from the Health, Aging And Body Composition Study. J Am Geriatr Soc. 2009;57(2):251-9.

30. Neumann S, Kwisda S, Krettek C, Gaulke R. Comparison of the Grip Strength Using the Martin-Vigorimeter and the JAMAR-Dynamometer: Establishment of Normal Values. In Vivo. 2017;31(5):917-24.

31. Taekema DG, Gussekloo J, Maier AB, Westendorp RG, de Craen AJ. Handgrip strength as a predictor of functional, psychological and social health. A prospective population-based study among the oldest old. Age Ageing. 2010;39(3):331-7.

32. Wisniowska-Szurlej A, Cwirlej-Sozanska A, Woloszyn N, Sozanski B, Wilmowska-Pietruszynska A. Association between Handgrip Strength, Mobility, Leg Strength, Flexibility, and Postural Balance in Older Adults under Long-Term Care Facilities. Biomed Res Int. 2019;2019:1042834.

33. Roberts HC, Syddall HE, Sparkes J, Ritchie J, Butchart J, Kerr A, et al. Grip strength and its determinants among older people in different healthcare settings. Age Ageing. 2014;43(2):241-6.

34. Shechtman O, Sindhu BS. Grip Strength. In: ASTH, editor. Clinical Assessment Recommendations, 3rd edition2013.

35. McPhee JS, Maden-Wilkinson TM, Narici MV, Jones DA, Degens H. Knee extensor fatigue resistance of young and older men and women performing sustained and brief intermittent isometric contractions. Muscle Nerve. 2014;50(3):393-400.

36. Zech A, Steib S, Sportwiss D, Freiberger E, Pfeifer K. Functional muscle power testing in young, middle-aged, and community-dwelling nonfrail and prefrail older adults. Arch Phys Med Rehabil. 2011;92(6):967-71.

37. Mehmet $\mathrm{H}$, Yang AWH, Robinson SR. What is the optimal chair stand test protocol for older adults? A systematic review. Disabil Rehabil. 2019:1-8.

38. Guralnik JM, Simonsick EM, Ferrucci L, Glynn RJ, Berkman LF, Blazer DG, et al. A short physical performance battery assessing lower extremity function: association with self-reported disability and prediction of mortality and nursing home admission. J Gerontol. 1994;49(2):M85-94.

39. Danilovich MK, Diaz L, Corcos DM, Ciolino JD. Relationship between SHAREFI Frailty Scores and Physical Performance Measures in Older Adult Medicaid Recipients. Geriatrics (Basel). 2018;3(3).

40. Middleton A, Fritz SL, Lusardi M. Walking speed: the functional vital sign. J Aging Phys Act. 2015;23(2):314-22.

41. Onder G, Carpenter I, Finne-Soveri H, Gindin J, Frijters D, Henrard JC, et al. Assessment of nursing home residents in Europe: the Services and Health for Elderly in Long TERm care (SHELTER) study. BMC Health Serv Res. 2012;12:5.

42. Ploutz-Snyder LL, Manini T, Ploutz-Snyder RJ, Wolf DA. Functionally relevant thresholds of quadriceps femoris strength. J Gerontol A Biol Sci Med Sci. 2002;57(4):B144-52.

43. Hairi NN, Cumming RG, Naganathan V, Handelsman DJ, Le Couteur DG, Creasey $\mathrm{H}$, et al. Loss of muscle strength, mass (sarcopenia), and quality 
(specific force) and its relationship with functional limitation and physical disability: the Concord Health and Ageing in Men Project. J Am Geriatr Soc. 2010;58(11):2055-62.

44. Chan OY, van Houwelingen AH, Gussekloo J, Blom JW, den Elzen WP. Comparison of quadriceps strength and handgrip strength in their association with health outcomes in older adults in primary care. Age. 2014;36(5):9714.

45. Casas-Herrero A, Cadore EL, Zambom-Ferraresi F, Idoate F, Millor N, Martinez-Ramirez A, et al. Functional capacity, muscle fat infiltration, power output, and cognitive impairment in institutionalized frail oldest old. Rejuvenation Res. 2013;16(5):396-403.

46. Suzuki $M$, Kirimoto $H$, Inamura A, Yagi M, Omori $Y$, Yamada S. The relationship between knee extension strength and lower extremity functions in nursing home residents with dementia. Disabil Rehabil. 2012;34(3):202-9.

47. de Labra C, Guimaraes-Pinheiro C, Maseda A, Lorenzo T, Millan-Calenti JC. Effects of physical exercise interventions in frail older adults: a systematic review of randomized controlled trials. BMC Geriatr. 2015;15:154.

48. Aguirre LE, Villareal DT. Physical Exercise as Therapy for Frailty. Nestle Nutr Inst Workshop Ser. 2015;83:83-92.

49. Cadore EL, Casas-Herrero A, Zambom-Ferraresi F, Idoate F, Millor N, Gomez $\mathrm{M}$, et al. Multicomponent exercises including muscle power training enhance muscle mass, power output, and functional outcomes in institutionalized frail nonagenarians. Age. 2014;36(2):773-85.

50. Krist L, Dimeo F, Keil T. Can progressive resistance training twice a week improve mobility, muscle strength, and quality of life in very elderly nursinghome residents with impaired mobility? A pilot study. Clin Interv Aging. 2013;8:443-8.

51. Crocker T, Young J, Forster A, Brown L, Ozer S, Greenwood DC. The effect of physical rehabilitation on activities of daily living in older residents of long-term care facilities: systematic review with meta-analysis. Age Ageing. 2013;42(6):682-8.

52. Hunter SK, Pereira HM, Keenan KG. The aging neuromuscular system and motor performance. Journal of applied physiology. 2016;121(4):982-95.

53. Narici MV, Reeves ND, Morse Cl, Maganaris CN. Muscular adaptations to resistance exercise in the elderly. J Musculoskelet Neuronal Interact. 2004;4(2):161-4.

54. Brook MS, Wilkinson DJ, Phillips BE, Perez-Schindler J, Philp A, Smith K, et al. Skeletal muscle homeostasis and plasticity in youth and ageing: impact of nutrition and exercise. Acta Physiol (Oxf). 2016;216(1):15-41.

55. Lamoureux EL, Sparrow WA, Murphy A, Newton RU. Differences in the neuromuscular capacity and lean muscle tissue in old and older communitydwelling adults. J Gerontol A Biol Sci Med Sci. 2001;56(6):M381-5.

56. Delmonico MJ, Harris TB, Visser M, Park SW, Conroy MB, Velasquez-Mieyer P, et al. Longitudinal study of muscle strength, quality, and adipose tissue infiltration. Am J Clin Nutr. 2009;90(6):1579-85. 
57. Simon NG, Noto YI, Zaidman CM. Skeletal muscle imaging in neuromuscular disease. J Clin Neurosci. 2016;33:1-10.

58. Rech A, Radaelli R, Goltz FR, da Rosa LH, Schneider CD, Pinto RS. Echo intensity is negatively associated with functional capacity in older women. Age. 2014;36(5):9708.

59. Fukumoto $\mathrm{Y}$, Ikezoe T, Yamada Y, Tsukagoshi R, Nakamura M, Mori N, et al. Skeletal muscle quality assessed from echo intensity is associated with muscle strength of middle-aged and elderly persons. Eur J Appl Physiol. 2012;112(4):1519-25.

60. Watanabe Y, Yamada Y, Fukumoto Y, Ishihara T, Yokoyama K, Yoshida T, et al. Echo intensity obtained from ultrasonography images reflecting muscle strength in elderly men. Clin Interv Aging. 2013;8:993-8.

61. Laffon de Mazieres C, Morley JE, Levy C, Agenes F, Barbagallo M, Cesari M, et al. Prevention of Functional Decline by Reframing the Role of Nursing Homes? J Am Med Dir Assoc. 2017;18(2):105-10.

62. Akazawa N, Okawa N, Tamura K, Moriyama H. Relationships between intramuscular fat, muscle strength and gait independence in older women: $A$ cross-sectional study. Geriatr Gerontol Int. 2017;17(10):1683-8.

63. Cartwright MS, Kwayisi G, Griffin LP, Sarwal A, Walker FO, Harris JM, et al. Quantitative neuromuscular ultrasound in the intensive care unit. Muscle Nerve. 2013;47(2):255-9.

64. Whittaker JL, Stokes M. Ultrasound imaging and muscle function. The Journal of orthopaedic and sports physical therapy. 2011;41(8):572-80.

65. Arnold CM, Warkentin KD, Chilibeck PD, Magnus CR. The reliability and validity of handheld dynamometry for the measurement of lower-extremity muscle strength in older adults. Journal of strength and conditioning research / National Strength \& Conditioning Association. 2010;24(3):815-24.

66. Agyapong-Badu S, Warner M, Samuel D, Narici M, Cooper C, Stokes M. Anterior thigh composition measured using ultrasound imaging to quantify relative thickness of muscle and non-contractile tissue: a potential biomarker for musculoskeletal health. Physiological measurement. 2014;35(10):2165-76.

67. Harris-Love MO, Seamon BA, Teixeira C, Ismail C. Ultrasound estimates of muscle quality in older adults: reliability and comparison of Photoshop and ImageJ for the grayscale analysis of muscle echogenicity. PeerJ. 2016;4:e1721.

68. Reeves ND, Maganaris CN, Narici MV. Ultrasonographic assessment of human skeletal muscle size. Eur J Appl Physiol. 2004;91(1):116-8.

69. Knechel NA. The challenges of enrolling older adults into intervention studies. Yale J Biol Med. 2013;86(1):41-7.

70. Mody L, Miller DK, McGloin JM, Freeman M, Marcantonio ER, Magaziner J, et al. Recruitment and retention of older adults in aging research. J Am Geriatr Soc. 2008;56(12):2340-8. 


\section{Chapter 8}

\section{Valorisation}

This chapter assesses the relevance and implication of the findings of the thesis for society, as outlined in Chapters 2-6. Potential implementation of the findings for different target groups are discussed in this Chapter, including boundaries that could prevent implementation. Finally, current and future dissemination of research findings are stated.

\subsection{Relevance of the topic}

Sarcopenia is a progressive, generalized muscle disorder characterized by excessive muscle wasting due to age, morbidity and inactivity [1] that can lead to immense health problems and increased health care costs when untreated [2-4], as outlined in Chapter 1. It has been recognized as an independent medical condition since 2016 [5], which highlights its emerging importance in adverse health-related outcomes. It has been estimated that the prevalence of sarcopenia, globally, will increase to $20 \%$ by 2045 , as a consequence of the aging population [6]. However, to date, sarcopenia as a diagnosis has not been mentioned specifically in the Swiss health statistics or the Federal Office for Public Health as an independent medical condition [7, 8]. Understanding sarcopenia, its low muscle strength as a key characteristic and its relationship to health decline is, nonetheless, important for implementing prevention strategies. Furthermore, elderly but particularly adults $>75$ years are at high risk of excessive strength decline. However, strength assessments for the early detection of people at risk of strength decline are rarely part of the routine assessment of community-living older people [9] or nursing-home residents [10]. Reference values for oldest-old age-groups are currently lacking. Moreover, strength assessments and interventions aiming to improve strength in older- old, comorbid people have not been researched extensively and hence recommendations regarding standardized testing tools to guide effective exercise programs have yet to be made [11]. There is a need for information about the overall muscle condition, specific risk of low muscle strength in older-old people (> 75 years) and neuromuscular changes in nursing-home residents (as outlined in Chapter 1 ) to specifically monitor and improve health in the older-old people. This thesis aims to directly address these challenges.

\subsection{Main objectives and findings in brief}

This research has established reference values for hand grip strength in oldest-old Swiss adults aged 85 years and over (Chapter 2). The data can be used by scientists and clinicians to monitor aspects of physical/muscular health in this population. It estimates the specific risk of sarcopenia in the community-living old Swiss population and shows that probable sarcopenia, an important preliminary stage of sarcopenia, was prevalent in about one third of those aged 75 years and over (Chapter 3 ). This research also evaluated the feasibility and relevance of the two recommended tests (handgrip strength and chair rise test) commonly used to detect probable sarcopenia 
in community-living for the evaluation of institutionalized elderly, who are most at risk of sarcopenia (Chapter 4). The results have shown that handgrip strength is superior to the chair stand test in detecting probable sarcopenia in institutionalized elderly as the chair-stand test could only be completed by about $50 \%$ of the participants. The findings highlighted that low handgrip strength is an estimate of overall strength, meaningful indicating ADL dependence and frailty. Moreover, this research reveals, that quadriceps strength is an independent predictor of ADL performance in nursinghome residents (Chapter 5). Finally, this research gave the first insight into the relationship between muscle strength and sonographic measures of muscle quality (on ultrasound images) in nursing-home residents relevant for future evaluation and treatment of age-related muscle wasting in institutionalized elderly people (Chapter 6).

\subsection{Implication, implementation and dissemination plans}

Collectively, the findings of the research undertaken in this thesis would be of interest to clinicians, community service providers, nursing homes and health insurance companies. It is anticipated the research will increase awareness of the importance of strength testing and specific risk assessment of sarcopenia in the oldest age group; and with that, the awareness of individuals for the importance of muscle strength and weakness-related consequences. The implications of each specific project are outlined below.

Reference values for handgrip strength of old-old and oldest-old people were investigated in Chapter 2. These results build upon previously published reference values for young-old people (65-74 years) and for the first time provide data on the oldold (75-84 years) and oldest-old (85+ years) people in Switzerland ensuring a full range of handgrip strength values up to the age of 99 years. These values are of particular importance in light of the recommendations of the World Health Organization (WHO) that handgrip strength is frequently assessed in older people to screen for mobility loss [12]. Currently, handgrip strength is only measured infrequently in routine geriatric assessment [9], as outlined in Chapter 1. Hence, the present findings are of importance to general practitioners and can provide reference values for the evaluation of routine handgrip strength assessment in practices of geriatricians and physiotherapists. This would assist in the timely detection of strength decline and the initiation of specific interventions that counteract muscle wasting, which are critical for health improvement in an age-group most at risk for disability.

To facilitate accessibility of the references values for those interested, apart from publication in this thesis and in BMC geriatrics 2018:8:266, research outcomes are also planned for more popularist dissemination via the journal "Swiss medical forum", a popular national journal commonly read by general practitioners. Participants of the study who expressed interest in seeing their results, received an overview of their individual handgrip strength values and the overall findings of the study. Reference values of this research were implemented for routine handgrip strength assessments at two sites (nursing-home Adullam Basel and Geriatric hospital St Gallen) to screen Swiss residents and patients for sarcopenia. 
The prevalence of probable sarcopenia in older, community-living people $(75+$ years), based on low handgrip strength, was investigated in Chapter 3 . The observation that $26 \%$ of women and $28 \%$ of men were affected by probable sarcopenia could inform the Swiss Federal Statistical Office and Swiss insurance companies to estimate the number of people at risk for developing sarcopenia and consequent health decline.

As the prevalence of sarcopenia is expected to rise up to $20 \%$ in the next 25 years [6], increasing the awareness for sarcopenia and reducing potential negative consequences is necessary. Therefore, a documentary called "Muscle loss in old age" was produced at our study site and broadcast by the local TV channel Tele Basel. The findings of the study investigating probable sarcopenia in the older Swiss population, highlight the need for screening of handgrip strength in routine medical care of community living elderly people. Frequently performed strength assessments could further increase awareness of older people for the importance of overall strength for current and future health. The high prevalence of probable sarcopenia can inform the National health policy about the need for strategies to reduce disease burden and health care costs associated with sarcopenia.

A summary of the findings will be submitted to a local Swiss medical journal together with the reference values for handgrip strength to provide the findings in German language to the general practitioners. Presentation of the results is also planned at physiotherapy practices and in-house at both study sites to inform clinicians, allied health practitioners and the community about the need for frequent strength assessment and the importance of strength for physical health in every age group. The dates will be agreed once the Corona virus situation allows personal meetings of groups. Depending on how long the restrictions last, webinars will be planned and held if necessary.

Feasibility of handgrip strength test and chair stand test in nursing-home residents, and the relevance of detecting probable sarcopenia were investigated in Chapter 4. The handgrip strength test showed to be easy and feasible in nursing-home residents. Based on the findings of this research, it is recommended to be used in institutions and could be implemented in routine assessment of residents at admission and during frequent routine check-ups to inform the medical staff about the need for further evaluation of the person's physical health. The findings show that probable sarcopenia detected by low handgrip strength was indicative of muscle function, ADL performance and frailty. Although these results need to be verified in reliability studies and larger cohort studies before they can be recommended for implementation, clinical examination to specifically address ADL performance and frailty is recommended by leading researchers and clinicians in the field of nursing-home practice [11, 13]. Handgrip strength is an easily applicable instrument to add to a test battery for screening nursing-home residents. 
The relationship between quadriceps strength and independence in daily activities in nursing-home residents was investigated in Chapter 5 . The results highlighted the predictive value of quadriceps strength cut-off values for the detection of independence in daily activities of nursing home residents. Based on the findings of this research, quadriceps strength testing should be used by nursing staff, medical doctors and therapists in nursing-homes to screen residents for ADL performance. Moreover, frequently performed strengthening exercises, targeting a strength of $11 \mathrm{~kg}$ (torque normalized to body mass of $0.52 \mathrm{Nm} / \mathrm{kg}$ ), could potentially be used to help identify and monitor strategies to improve ADL performance and avoid further decline. This approach would be consistent with the recent report of a Task Force of experts in nursing-home care research, who discussed approaches to prevent or slow functional decline and disabilities for nursing-home residents $[11,13]$. They strongly suggest to initiate timely assessments and interventions.

Apart from dissemination of the results in this thesis, in PLoS ONE 2019;14(9): e0223016, and presentation of the results at the 14th International Congress of the European Geriatric Medicine Society 2018 in Berlin (Germany), local nursing-homes will be informed about the importance of quadriceps strength for ADL independence. Additionally, they will be given recommendations for physical activity by an information letter.

Frequent quadriceps strength testing is planned to be implemented at Adullam (a Swiss nursing-home and geriatric hospital) in line with the objective of a project at the local nursing-home (promoting physical activity) at the end of 2020.

The observed relationship between muscle strength and a sonographic index of muscle quality in oldest-old nursing-home residents, investigated in Chapter 6, provided insight into neuromuscular changes of highly disordered muscles. The research builds upon a growing body of scientific literature that collectively indicates that ultrasound imaging may be useful for assessing age-related changes in muscle quality of community-dwelling elderly [14]. Chapter 6 showed that sonographically measured muscle quality was related to muscle strength and gait speed in nursinghome residents. As the results were presented at the 5th International Fascia Research Congress 2018 in Berlin, Germany, and submitted for publication, it is anticipated that these initial findings could stimulate researchers with a specific interest in nursing-home residents to conduct further research in this area. In the longer term, the results may inform ultrasound imaging for the detection of sarcopenia in the oldestold population and be used to monitor advanced interventions for strength improvement in nursing-home residents. 


\subsection{Barriers for implementation of strength assessments and interventions in nursing-homes}

There are likely several barriers to the implementation of strength assessments at the individual and institutional level. These are outlined below:

1. A lack of motivation of oldest-old people to start exercise programs. They often believe that exercising in old age is harmful and cannot be beneficial [15].

2. A lack of motivation to participate in activities aiming at improving health [15]. Those that are admitted to a nursing-home need to give up their accustomed environment, and therewith their own household and to a certain extent social connections. With that, the reason for staying healthy can easily become the reverse.

3. Institutional culture is often orientated towards basic care without additional promotion of an active lifestyle, particularly in the presence of understaffing or financial constraints. In addition, some nursing staff may not feel adequately trained in applying resource-orientated care (encouraging residents to stay as independent in ADL as possible, e.g. helping in household activities, promoting independence in basic ADL, going for a walk under supervision) [11]. Moreover, physical activity interventions are often both time and cost intensive. Although carer are encouraged to reduce the risk of functional decline, health insurance companies do not pay for additional time necessary to offer specific programs. The payment of the health insurance is dependent on the level of care required, with higher payments for higher care levels. People who could benefit the most from physical activity offerings with respect to disability prevention are the ones with minimal care needs [11]. Moreover, long-term physical therapy prescriptions necessary for people with disabilities to instruct and guide specific exercises are often limited by budgetary constraints in Switzerland.

However, the above barriers should not be viewed as an impediment to provide opportunities for an active lifestyle but rather a challenge to advance innovative solutions that evidently improve strength. Regular information sessions for staff and residents could provide knowledge about the benefit of exercise in old age and how to integrate strengthening exercises in daily activities. Activities likely to improve strength without the need of nursing staff could be organized as multi-generational projects e.g. excursions together with children or joint cooking events with the neighborhood of the institution. Moreover, the design of outdoor spaces and equipment for self-use and physical activity groups offered by volunteers could encourage older people to engage in life-long active exercise. 


\subsection{References}

1. Clark BC, Manini TM. Functional consequences of sarcopenia and dynapenia in the elderly. Curr Opin Clin Nutr Metab Care. 2010;13(3):271-6.

2. da Silva Alexandre T, de Oliveira Duarte YA, Ferreira Santos JL, Wong R, Lebrao ML. Sarcopenia according to the european working group on sarcopenia in older people (EWGSOP) versus Dynapenia as a risk factor for disability in the elderly. The journal of nutrition, health \& aging. 2014;18(5):547-53.

3. Rantanen T, Avlund K, Suominen H, Schroll M, Frandin K, Pertti E. Muscle strength as a predictor of onset of ADL dependence in people aged 75 years. Aging Clin Exp Res. 2002;14(3 Suppl):10-5.

4. Brown JC, Harhay MO, Harhay MN. Sarcopenia and mortality among a population-based sample of community-dwelling older adults. J Cachexia Sarcopenia Muscle. 2016;7(3):290-8.

5. Cao L, Morley JE. Sarcopenia Is Recognized as an Independent Condition by an International Classification of Disease, Tenth Revision, Clinical Modification (ICD10-CM) Code. J Am Med Dir Assoc. 2016;17(8):675-7.

6. Ethgen O, Beaudart C, Buckinx F, Bruyere O, Reginster JY. The Future Prevalence of Sarcopenia in Europe: A Claim for Public Health Action. Calcif Tissue Int. 2017;100(3):229-34.

7. Gesundheitsstatistik [Internet]. Bundesamt für Statistik. 2019.

8. Erkrankungen des Bewegungsapparats [Internet]. Bundesamt für Gesundheit. 2018.

9. Keller K. Sarcopenia. Wien Med Wochenschr. 2019;169(7-8):157-72.

10. Onder G, Carpenter I, Finne-Soveri H, Gindin J, Frijters D, Henrard JC, et al. Assessment of nursing home residents in Europe: the Services and Health for Elderly in Long TERm care (SHELTER) study. BMC Health Serv Res. 2012; 12:5.

11. Laffon de Mazieres C, Morley JE, Levy C, Agenes F, Barbagallo M, Cesari M, et al. Prevention of Functional Decline by Reframing the Role of Nursing Homes? J Am Med Dir Assoc. 2017;18(2):105-10.

12. World Health Organisation. Guidelines on Integrated Care for Older People (ICOPE). http://www.who.int/ageing/publications/guidelines-icope/en/; 2017.

13. de Souto Barreto P, Morley JE, Chodzko-Zajko W, K HP, Weening-Djiksterhuis $E$, Rodriguez-Manas L, et al. Recommendations on Physical Activity and Exercise for Older Adults Living in Long-Term Care Facilities: A Taskforce Report. J Am Med Dir Assoc. 2016;17(5):381-92.

14. Correa-de-Araujo R, Harris-Love MO, Miljkovic I, Fragala MS, Anthony BW, Manini TM. The Need for Standardized Assessment of Muscle Quality in Skeletal Muscle Function Deficit and Other Aging-Related Muscle Dysfunctions: A Symposium Report. Frontiers in physiology. 2017; 8:87.

15. Lees FD, Clarkr PG, Nigg CR, Newman P. Barriers to exercise behavior among older adults: a focus-group study. J Aging Phys Act. 2005;13(1):23-33. 


\section{Summary}

Muscle strength is an important indicator of physical function and independence in older people. Research on oldest-old people (>85 years) is limited. This thesis addresses some of the challenges that this population presents for research and clinical management, in relation to assessing muscle strength.

\section{Chapter 1: Background}

Sarcopenia is a progressive, generalized muscle disorder that not only affects the neuromuscular system but also other organ systems and leads to immense health problems when untreated. Characterized by excessive muscle wasting due to age, morbidity and inactivity, sarcopenia is an important geriatric syndrome. It has been recognized as an independent medical condition by the World Health Organization since 2016, which highlights its emerging importance in health-related adverse outcomes. The prevalence of sarcopenia is estimated to increase globally, as a consequence of the aging population. It is anticipated that approximately $20 \%$ of older people will be affected by 2045 . Sarcopenia has been well studied in the so called young-old elderly ( $<75$ years of age) and contributed to the improvement in health condition of this age group by implementation of the research findings into prevention strategies. However, rather little is known about health care needs specifically tailored to older and oldest-old age groups (>75 years), especially those that are institutionalized in nursing-homes.

The diagnosis of sarcopenia is defined by low muscle mass or decreased contraction quality in addition to low strength, and is commonly assessed by thickness and echotexture of ultrasound images in clinical research studies. Information about all three muscle characteristics, strength, thickness and quality, is important not only to diagnose sarcopenia but also to guide interventions aimed at improving strength. Although comprehensive geriatric assessment is necessary to evaluate the severity and potential causes of sarcopenia in detail, handgrip strength has been recommended as a conclusive, stand-alone measurement to screen older people at risk of poor health. According to the updated version of the European Working Group of Sarcopenia (EWGSOP2) the first stage of sarcopenia, called probable sarcopenia, is detected by low handgrip strength ( $<16 \mathrm{~kg}$ for women and $<27 \mathrm{~kg}$ for men) or a slow performance on a repetitive chair-stand test ( $>15$ seconds on 5 sit-to-stands).

\section{Aims of this thesis}

The aims of the thesis were to; (1) complement existing reference values of strength measures of young-old people with those of the older age groups for clinical use, (2) apply recently published guidelines for detection of sarcopenia to update prevalence data of probable sarcopenia for public health monitoring, and (3) provide initial evidence of relationships between low muscle strength and functional performance as 
well as neuromuscular changes in nursing-home residents, which has not been studied before.

\section{Chapter 2}

Since handgrip strength declines with age, is lower in women than men and varies between living environments, country-specific reference values are required for men and women of all age groups to assess strength decline in clinical practice. Chapter 2 describes a cross-sectional study of 244 participants in which handgrip strength was measured in a Swiss community-living and institutionalised population aged 75 years and older. While the results of this study were consistent with previously reported strength values in people aged between 75-84 years, it provided, for the first time, handgrip strength reference values for men and women aged between 85 and 99 years. The oldest-old were found to have significantly (26-32\%) lower handgrip strength than the young and older-old people. The reference values of handgrip strength presented in this thesis, collectively with previously reported normative values of Swiss elderly aged 75-84 years, are of direct clinical use. Handgrip measures are made clinically by physicians, and physical and occupational therapists to screen older people for overall strength and health condition.

\section{Chapter 3}

In 2019, the algorithm to detect sarcopenia changed from a loss of muscle mass as the key characteristic, to a loss of muscle strength. With the application of the new EWGSOP2 guideline, it is important to provide updated prevalence data for probable sarcopenia in the community for health monitoring purposes of this population. In Chapter 3, the point prevalence of probable sarcopenia was investigated in a representative sample $(n=219)$ of community-living Swiss adults according to the new guidelines along with measures of physical activity. The results of this study demonstrated probable sarcopenia in $26 \%$ and $28 \%$ of oldest-old women and men living in the community. Although the prevalence of probable sarcopenia was lower than in previous research in which muscle mass was used for detection of pre-stage sarcopenia, almost one third of the older people still had an increased risk of health decline. Moreover, this research showed that people with low strength had 2.8 times higher risk of dependence in activities of daily living (ADL) than people with normal strength. The relation between strength and functional limitation highlighted the relevance of frequent strength assessments in clinical practice for timely initiation of counteracting interventions.

\section{Chapter 4}

Although Chapter 3 provided new data on the point prevalence of probable sarcopenia and its relation to dependence in ADL in community-living oldest-old, it is not clear whether strength testing for probable sarcopenia is feasible in nursing-home residents and indicative for health-related outcomes in that cohort. Consequently, Chapter 4 evaluated the feasibility and relevance of the handgrip strength test and the chair stand test in a cross-sectional study of institutionalized, older people $(n=30)$. The findings 
showed that although measures of handgrip strength could be obtained from institutionalized older people, the chair-stand test could only be completed by about $50 \%$ of the participants; raising questions of the suitability of the chair-stand test to screen for probable sarcopenia in institutionalized older people. Moreover, the point prevalence of probable sarcopenia was found to be $80 \%$ in this cohort; much higher than that for community living elderly people (26-28\%) as shown in Chapter 3 . It was also shown that probable sarcopenia detected by both tests was associated with diminished gait speed and more advanced frailty status in this cohort, while only low handgrip strength was related to lower overall muscle strength and ADL dependence. Hence, this research raises the possibility that handgrip strength might be suitable to estimate overall strength of old, frail nursing-home residents. Moreover, although further research is required, it also suggests that handgrip strength is a potentially simple clinical test that therapists could use to screen for physical function and ADL performance.

\section{Chapter 5}

Although low handgrip strength was related to ADL dependence in Chapter 4, quadriceps strength has been previously reported as key for specific daily activities, such as transfer activities from sit to stand and stable walking in community-living older people. ADL execution in institutionalized people with very low strength differs from that in community-living older people, as they use their hands and arms as support on standing up and for stabilizing body sway with walking aids. Therefore, assessment of isometric quadriceps muscle strength in this cohort merits special attention, particularly as only $50 \%$ of the institutionalized people were able to perform the chair-stand test, which provides an indirect estimate of quadriceps strength. Chapter 5 evaluated the relationship between quadriceps strength and ADL performance in 30 nursing-home residents. The results indicated that quadriceps strength is also crucial for ADL in nursing-home residents who use their hands for tasks that typically involve the use of the lower limbs. However, the strength required for independent performance was much lower than previously shown in the performance of community-living elderly people not using their hands (peak isometric torque normalized to body mass of 0.6 $\mathrm{Nm} / \mathrm{kg}$ body mass versus 3-3.5 Nm/kg). The findings provide the first evidence that an isometric quadriceps strength of $>11 \mathrm{~kg}$ (normalized peak torque of $0.52 \mathrm{Nm} / \mathrm{kg}$ ) is $100 \%$ sensitive and $79 \%$ specific in predicting ADL-independence in this population. Therefore, isometric quadriceps strength measurement can be recommended as a specific screening test for ADL performance in nursing-home residents. Moreover, exercise programs can be guided by the target quadriceps strength of $11 \mathrm{~kg}(0.52$ $\mathrm{Nm} / \mathrm{kg}$ ) for improvement of ADL independence.

\section{Chapter 6}

To specifically improve strength in older adults, age-related neuromuscular changes that contribute to loss of strength need to be evaluated and addressed by exercise interventions. Intramuscular adipose tissue accumulation has been shown to be one important component in decreasing muscle contraction quality and strength in 
community-living older people. Infiltration of adipose tissue changes the tissue composition within the muscle, which appears as increased echo intensity on ultrasound images. In oldest-old nursing-home residents, muscle changes might differ from young-old community-dwelling people, due to extremely low strength and different percentage contributions of neural and muscular changes leading to low strength. The evaluation of sonographically measured muscle quality of the knee extensors and its relation with strength in institutionalized older adults was addressed in Chapter 6 . The results added proof of concept that a relationship between an ultrasound-derived index of muscle quality and muscle strength also exists in the oldest-old, multi-morbid, frail nursing-home residents. However, the relationship is likely mediated by physical activity level, as the relationship could only be shown in people whose expanded energy per week was above the cut-off value for low physical activity, $383 \mathrm{kcal} / \mathrm{week}$ for men and $270 \mathrm{kcal} / \mathrm{week}$ for women. Changes in muscle quality were detected by a sonographic index of muscle heterogeneity, not previously established in age-related muscle evaluation. The results indicate the usefulness of ultrasound imaging in clinical sarcopenia assessment in nursing-home residents

\section{Conclusions}

Overall, this thesis has produced several novel findings. The studies built upon research findings involving older-old people (75 to 84 years), to provide for the first time, reference values of handgrip strength in the oldest-old (85 to 99 years) for direct clinical use. Further, new specific point prevalence data for probable sarcopenia were established in the oldest-old Swiss population. Cut- off values of handgrip and quadriceps strength have been shown to specifically indicate dependence in ADL in nursing-home residents, potentially useful for screening institutionalized people at risk of functional decline. Furthermore, this thesis has provided the first insight into muscle characteristics of people most at risk of sarcopenia, the comorbid, nursing-home residents, highlighting a potentially new sonographic index of age-related changes in muscle quality. 


\section{Acknowledgement}

The research presented in this thesis was conducted at CAPHRI Care and Public Health Research Institute, Department of Epidemiology of Maastricht University. CAPHRI participates in the Netherlands School of Public Health and Care Research CaRe.

Undertaking this $\mathrm{PhD}$ has been a truly life-changing experience for me and it would have been impossible without the support and help of many people who are gratefully acknowledged here.

First of all, I would like to thank Dr Hansjörg Ledermann and Adullam Foundation Basel for my employment as a research assistant and for access to the research equipment for realization of the research projects. My sincere thanks also go to Elke Heinsohn, who provided me an opportunity to join the physiotherapy team as an intern. Without their precious support, it would not have been possible to conduct this research.

I would like to thank my supervisory team Professor Eling de Bruin, Professor Maria Stokes and Professor Rob de Bie for their assistance with this project.

In particular, I would like to express my sincere gratitude to Eling de Bruin for the continuous support of my PhD study and motivation over the entire time of preparing and undertaking the research, and writing the thesis. I really appreciated his unwavering confidence in positive outcomes of each study, paper submission and final PhD thesis.

I am profoundly indebted to Maria Stokes, for her valuable contribution to study conceptualization, her very insightful comments and suggestions on data interpretation and for polishing my research writing skills. I very much appreciated the quick processing of the research documents.

My special thanks to Rob de Bie and his team Judith Sieben-Wertz and Caroline Bastiaenen for the challenging discussions and advice around the best academic approach of the PhD topic and for important guidance on research conduction.

Thank you very much to the assessment committee of this thesis: Prof. dr. Jos Schols, Prof. dr. Ton Lenssen, Prof. dr. Mirko Petrovic, Dr. Kenneth Meijer and Dr. Timo Hinrichs.

I greatly appreciate the exchange through the collaborative work with Peter Konings, Geriatric Hospital St Gallen.

My deep appreciation goes out to the physiotherapy team members, nursing staff and administration of the three study sites. Their excellent work during participants' recruitment and data collection has made an invaluable contribution towards my PhD. 
Many thanks to the company of redcord ${ }^{\circledR}$ for providing equipment.

Last but not least, I would like to thank my family for moral and financial support, and friends for their indulgence and patience. The most important person and the best support in this special time of doing the PhD was my husband Scott. Always at the right time, he pointed out to me that the next step for completing the research project and the entire thesis is special and particularly attractive. This was the best motivation I can imagine.

Notwithstanding all of the support for this project, any errors and/or omissions are solely my own. 


\section{About the author}

Julia Wearing was born on October $8^{\text {th }} 1971$ in Braunschweig, Germany. She qualified as a physiotherapist in 1996 at the Timmermeister school for Physiotherapy in Münster, Germany and works as such continuously until now. She started further education in 2007 at the Hogeschool Fysiotherapie Thim van der Laan in Nieuwegein, Netherlands, and completed in 2009 with a Bachelor degree of Arts in Physical Therapy. In 2009 Julia moved to Switzerland for partaking in the Master's program of Physical Therapy Sciences at the University College Thim van der Laan in Landquart, where she graduated in 2011. The topic of her Master thesis focused on gait stability in older adults at risk for falls. In 2016, she started her PhD as an external student of Maastricht University. Simultaneously, she became employed as a research assistant and physiotherapist at Adullam geriatric hospital and care center in Basel, Switzerland. Under the supervision of Prof. dr. Eling de Bruin (ETH Zurich), Prof. dr. Maria Stokes (University of Southampton) and Prof. dr. Rob de Bie (Maastricht University) she carried out five research projects which were undertaken at the institution of Adullam, at the Physiotherapy practice Barbara Davies Basel, and the Geriatric Hospital St Gallen, Switzerland. Over the course of her academic education, Julia has undertaken academic courses in methodology, statistics and academic writing, gained experience in teaching undergraduate physiotherapy students, and supervised Bachelor Theses and equivalent certificates of students in Basel, Switzerland.

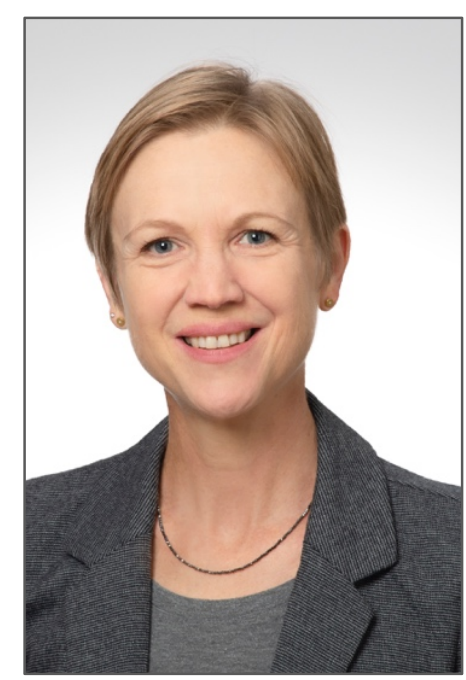

